\title{
Thorium-234 as a tracer of spatial, temporal and vertical variability in particle flux in the North Pacific
}

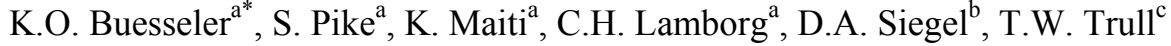 \\ ${ }^{a}$ Department of Marine Chemistry and Geochemistry, Woods Hole Oceanographic Institution, Woods Hole, \\ MA 02543-1541, USA \\ ${ }^{\mathrm{b}}$ Institute for Computational Earth System Science and Department of Geography, University of California, \\ Santa Barbara, CA 93106, USA \\ ${ }^{\mathrm{c}}$ Antarctic Climate and Ecosystems Cooperative Research Centre, University of Tasmania - CSIRO Marine \\ and Atmospheric Research, Hobart, 7001, Australia
}

Revised for DSRI March 27, 2009.

*Corresponding Author

E-mail Address: kbuesseler@whoi.edu (K.O. Buesseler)

Keywords: Thorium-234; particle flux; sediment trap; scavenging; North Pacific

\begin{abstract}
An extensive ${ }^{234} \mathrm{Th}$ data set was collected at two sites in the North Pacific: ALOHA, an oligotrophic site near Hawaii, and K2, a mesotrophic HNLC site in the NW Pacific as part of the VERTIGO (VERtical Transport in the Global Ocean) study. Total ${ }^{234} \mathrm{Th}:{ }^{238} \mathrm{U}$ activity ratios near 1.0 indicated low particle fluxes at ALOHA, while ${ }^{234} \mathrm{Th}^{238} \mathrm{U} \sim 0.6$ in the euphotic zone at $\mathrm{K} 2$ indicated higher particle export. However, spatial variability was large at both sites- even greater than seasonal variability as reported in prior studies. This variability in space and time confounds the use of single profiles of ${ }^{234} \mathrm{Th}$ for sediment trap calibration purposes. At K2, there was a decrease in export flux and increase in ${ }^{234} \mathrm{Th}$ activities over time associated with the declining phase of a summer diatom bloom, which required the use of non-steady state models for flux predictions. This variability in space and time confounds the use of single profiles of ${ }^{234} \mathrm{Th}$ for sediment trap calibration purposes. High vertical resolution profiles show narrow layers $(20-30 \mathrm{~m})$ of excess ${ }^{234} \mathrm{Th}$ below the deep chlorophyll maximum at $\mathrm{K} 2$ associated with particle remineralization resulting in a decrease in flux at depth that may be missed with standard sampling for ${ }^{234} \mathrm{Th}$ and/or with sediment traps. Also, the application of ${ }^{234} \mathrm{Th}$ as POC flux tracer relies on accurate sampling of particulate $\mathrm{POC} /{ }^{234} \mathrm{Th}$ ratios and here the ratio is similar on sinking particles and mid-sized particles collected by in-situ filtration ( $>10-50 \mu \mathrm{m}$ at ALOHA and $>5-350 \mu \mathrm{m}$ at K2). To further address variability in particle fluxes at K2, a simple model of the drawdown of ${ }^{234} \mathrm{Th}$ and nutrients is used to demonstrate that while coupled during export, their ratios in the water column will vary with time and depth after export. Overall these ${ }^{234} \mathrm{Th}$ data provide a detailed view into particle flux and remineralization in the North Pacific over time and space scales that are varying over days to weeks, and 10 's to 100 's $\mathrm{km}$ at a resolution that is difficult to obtain with other methods.
\end{abstract}

\section{INTRODUCTION}

The concept of a flux of sinking particles to the deep sea is not new, and as early as 1888 it was understood that "...deep-sea organisms are nourished by a "rain" of organic detritus from overlying surface waters." Alexander Agassiz (1888). Radionuclides are one way to track the flux of sinking particles. For example the detection of short-lived radionuclides from weapons testing fallout on the deep sea floor was used as early support for a fast connection between surface and deep waters via rapidly sinking particles (Osterberg et al., 1963). Around this time, the term "scavenging" was introduced to describe the broad range of processes that include uptake of particle reactive elements in solution onto suspended and sinking particles and the subsequent transport of a fraction of these particles to depth (Goldberg, 1954). 
In 1967, Bhat et al. (1969) added thorium-234 measurements in the ocean to the arsenal of particle reactive radionuclides that could be used to study scavenging and quantify particle fluxes. Simply, low activities of particle-reactive ${ }^{234} \mathrm{Th}$ in the ocean relative to its conservative parent ${ }^{238} \mathrm{U}$, indicate loss via sinking particles. With a 24.1 day half life, the time scale for application of this tracer is suitable for studies of the biological pump (Volk and Hoffert, 1985), in particular in the surface ocean where scavenging processes occur on a time scale of days to weeks. The application and use of ${ }^{234} \mathrm{Th}$ expanded considerably in the JGOFS era, when the ${ }^{234} \mathrm{Th}{ }^{238} \mathrm{U}$ disequilibrium and the ratio of $\mathrm{POC} /{ }^{234} \mathrm{Th}$ on particles was introduced as a constraint on particulate organic carbon (POC) export in studies of the ocean carbon cycle (Buesseler et al., 1992). By 2006, Waples et al. (2006) counted as many as 237 studies applying ${ }^{234} \mathrm{Th}$ to a range of themes, including a) particle fluxes, b) particle remineralization, c) sediment dynamics and d) horizontal transport and scavenging in coastal systems.

In this work, we present the results of an extensive ${ }^{234} \mathrm{Th}$ data set collected during the VERTIGO (VERtical Transport In the Global Ocean) study. The aim of VERTIGO was to examine the controls and magnitude of particle transport from the surface ocean and flux attenuation below. VERTIGO included analyses of surface food webs that produce particles (Boyd et al., 2008; Elskens et al., 2008; Zhang et al., 2008), as well as heterotrophic processing in the mesopelagic that attenuates flux due to bacterial and zooplankton processing (Kobari et al., 2008; Steinberg et al., 2008; Wilson et al., 2008). Sampling included direct collection of sinking fluxes using a variety of sediment trap designs (Lamborg et al., 2008b; Trull et al., 2008a) and in-situ pumping to collect size-fractionated suspended particles (Bishop and Wood, 2008). Geochemical tracers for particle flux and remineralization were also studied (Casciotti et al., 2008; Dehairs et al., 2008).

Here we use the VERTIGO ${ }^{234}$ Th data set to examine patterns of export and remineralization spatially, within the two contrasting regions of study; temporally, during each of the three week process studies; and with depth, from the surface ocean into the mesopelagic. We also compare the ${ }^{234} \mathrm{Th}$ derived fluxes to the direct measurement of flux in sediment traps and address the variability of $\mathrm{POC}{ }^{234} \mathrm{Th}$ in suspended particles (on filters) and sinking particles (in traps) as used in its application to estimate POC fluxes (Buesseler et al., 2006). The contrasting nature of particle export and remineralization between 150 and $500 \mathrm{~m}$ at two VERTIGO sites, as reported earlier (Buesseler et al., 2007b), is confirmed by the analyses of the ${ }^{234} \mathrm{Th}$ data. More importantly we contend that regional variability in particle flux is greater than can be measured in a single trap deployment, and thus the measurement of ${ }^{234} \mathrm{Th}$ at high spatial resolution may be a better approach for characterizing the magnitude of particle export of any given region in the ocean.

\section{STUDY SITES}

VERTIGO focused on two field sites in the N. Pacific with significant contrast in the magnitude and composition of sinking fluxes due to differences in the associated food webs. The Hawaii Ocean Time-series (HOT) station ALOHA $\left(22.75^{\circ} \mathrm{N}, 158^{\circ} \mathrm{W}\right.$; Karl and Lukas, 1996) was sampled over a 3 week period in June/July 2004. Station ALOHA is an oligotrophic site characterized by warm waters and persistently low macronutrients and correspondingly low surface chlorophyll-a (chl-a). Station K2 in the NW Pacific $\left(47^{\circ} \mathrm{N}\right.$ $160^{\circ} \mathrm{E}$ ) was sampled over a 3 week period in July/August 2005 and is a key time-series mooring station operated by JAMSTEC (Japan Agency for Marine Earth Science Technology; Honda and Watanabe, 2007; Liu et al., 2004). K2 is a colder mesotrophic site in the subarctic gyre, with a summer drawdown of macronutrient concentrations in response to a diatom dominated productivity maximum in June/July.

Conditions during VERTIGO at both sites are described in Buesseler et al., 2008b and the major differences in flux magnitude and composition in Buesseler et al., 2007b and Lamborg et al., 2008b. During VERTIGO, relative to K2, ALOHA was warmer (surface temperature 26 vs. $9.6^{\circ} \mathrm{C}$ ), had lower surface chl-a $\left(0.07\right.$ vs. $\left.0.30 \mathrm{mg} \mathrm{m}^{-3}\right)$, a deeper chl-a maximum $(\mathrm{DCM}=125 \mathrm{vs} .50 \mathrm{~m})$ and lower surface macronutrients (dissolved inorganic $\mathrm{N}=\mathrm{DIN}<0.1 \mathrm{vs.}>10 \mu \mathrm{mol}^{-1}$ ). Phytoplankton assemblages at ALOHA were dominated by smaller picoplankton, with Prochlorococcus spp. being the most abundant phototroph at ALOHA (microscopic analyses, M. Silver, pers. comm.). At K2, larger diatoms dominated the phytoplankton 
community (Chaetoceros spp, Coscinonodiscus marginatus and neodenticula), and fragments of diatoms in fecal pellets and aggregates thereof resulted in a silica-rich particle flux ( $80 \%$ opal by dry weight; Buesseler $e t$ al., 2007b; Boyd et al., 2008). In addition to higher POC fluxes out of the surface mixed layer at K2, the ratio of POC flux at $500 \mathrm{~m} / 150 \mathrm{~m}$ was higher at $\mathrm{K} 2$ than ALOHA (50\% vs. $20 \%$ respectively). Another difference in the flux data and surface biogeochemistry, is that while ALOHA appeared relatively constant in terms of stocks (nutrients, chl-a), rates (net primary production (NPP), new production) and particle fluxes (see below), K2 was sampled during a period of declining diatom biomass (fucoxanthin pigments and microscopy) and decreasing NPP and particle fluxes (Buesseler et al., 2008b).

\section{METHODS}

\subsection{Thorium-234 sampling and analyses}

The primary data set presented here includes $>400$ total ${ }^{234} \mathrm{Th}$ samples (bottle data available on line at http://ocb.whoi.edu/jg/dir/OCB/VERTIGO/ ). We have described our $4 \mathrm{~L}{ }^{234} \mathrm{Th}$ method most recently in Buesseler et al. (2008a), and it uses a $\mathrm{MnO}_{2}$ precipitation concentration step and direct beta counting at sea on a low background, anti-coincidence detector (Risø National Laboratories) to determine ${ }^{234} \mathrm{Th}$ activities decay corrected to the time of collection. ${ }^{230} \mathrm{Th}$ is used as a yield monitor in every sample to trace the precipitation efficiency (Pike et al., 2005) and a final beta count in the lab after complete ${ }^{234} \mathrm{Th}$ decay is used to correct for interfering beta emitters and detector background. The analytical errors for all three of these steps are propagated in our final ${ }^{234} \mathrm{Th}$ activity data which are reported on a dpm $\mathrm{I}^{-1}$ basis with an associated uncertainty $(1 \mathrm{dpm}=1$ disintegration per minute $=1 / 60 \mathrm{~Bq})$. Calibration for ${ }^{234} \mathrm{Th}$ is checked against deep waters and/or stored/aged samples where ${ }^{234} \mathrm{Th}$ and ${ }^{238} \mathrm{U}$ activities are expected to be the same. Uranium-238 can be estimated from salinity, and in the open ocean this relationship is thought to hold within $<1 \%$ (Chen et al., 1986) though differences between groups and some settings may be larger ( $>3 \%$; Pates and Muir, 2007; Rutgers van der Loeff et al., 2006). Unpublished data from this lab at $\mathrm{K} 2$ supports the finding that ${ }^{238} \mathrm{U}$ concentrations can be derived from the U-salinity relationship of Chen et al. (1986) and we also use this relationship at ALOHA, as done in prior ${ }^{234}$ Th studies at this site (Benitez-Nelson et al., 2001a).

We also present VERTIGO sediment trap data (also available on line at same url) collected using neutrally buoyant sediment traps (NBSTs) or more conventional surface tethered traps (so-called "Clap" traps, due to a closing mechanism that shuts at the end of each 3-5 day deployment), as well as for 6.5 day deployments of an Indented Rotating Sphere (IRS) trap operated as an in-situ settling column (Trull et al., 2008a). For both ALOHA and K2 water column sampling for ${ }^{234} \mathrm{Th}$ was conducted before, during, and after two main trap deployments (D1 and D2), with up to 7 NBSTs and 3 Clap traps deployed at 150, 300 and 500 m. Samples from the NBST and Clap traps were immediately wet split and processed on board for ${ }^{234} \mathrm{Th}$ and preserved as appropriate for other analyses (Lamborg et al., 2008b). Up to 6 splits were counted for ${ }^{234} \mathrm{Th}$ from each trap deployment, leading to replication for ${ }^{234} \mathrm{Th}$ from any single device, between devices at the same depth and between 2 deployments (and a shorter single $150 \mathrm{~m}$ Clap trap deployment at the end of the K2 occupation). Comparisons among the NBST and Clap traps and other methods details are provided in Lamborg et al., 2008b. For the IRS in-situ settling column, each sinking rate fraction was processed without splitting (Trull et al., 2008a). For the ${ }^{234} \mathrm{Th}$ analyses, all sinking particles (from the NBST, Clap and IRS devices) were filtered onto $25 \mathrm{~mm}$ diameter, $1 \mu \mathrm{m}$ nominal pore size Ag filters, mounted as for all of the total ${ }^{234} \mathrm{Th}$ samples (under Mylar and 2 layers of Al foil) and beta counted at sea and later in the lab after ${ }^{234} \mathrm{Th}$ decay. For calibration of beta efficiency, some samples were processed within 2-4 weeks of collection in the lab via standard radiochemical purification methods and the purified sample was electroplated and thus counted in an independently calibrated weightless geometry on our beta counters (and later via alpha counting for chemical yields; Rutgers van der Loeff et al., 2006).

We present particulate data from size fractionated filtration, collected via in-situ large volume pumping using MULVFS (Multiple Unit Large Volume Filtration System) as deployed in VERTIGO and most recently described in Bishop and Wood (2008). In this case, filtration steps were sequential, and samples were collected through a sequence of larger to smaller pore-sized screens and filters along two flow paths, one through the standard MULVFS $245 \mathrm{~mm}$ effective diameter filter holder allowing separation into $>51$ and $>1$ - 
$51 \mu \mathrm{m}$ size classes and a parallel flow path through a $138 \mathrm{~mm}$ effective diameter filter holder with up to 5 size classes for K2 (>350, 51-350, 20-51, 5-20 and >1-5 $\mu$ m)and 3 size classes for ALOHA $(>51,10-51$ and 1-10 $\mu \mathrm{m})$. The $1 \mu \mathrm{m}$ filter in each case was a Whatman QMA quartz based filter, while nylon screens were used for the larger size classes. Since our focus was on the $\mathrm{POC}^{234} \mathrm{Th}$ ratio of this material, the screens were rinsed immediately after collection at sea with pre-filtered seawater onto the same $25 \mathrm{~mm}$ diameter $1 \mu \mathrm{m}$ pores size $\mathrm{Ag}$ filters used for the collection of sediment trap particles, as appropriate for ${ }^{234} \mathrm{Th}, \mathrm{CHN}$ and other analyses. Losses of particulate $\mathrm{C}$ or Th to solution, or retention on the screen after gentle rinsing has been documented to be small (Buesseler et al., 1998; Cochran et al., 2008) and is ignored when assessing ratios of the material rinsed off of screens. Counting and calibration of these particulate samples is the same as for the sediment trap material.

\subsection{Other elemental analyses}

Particulate samples were analyzed by $\mathrm{CHN}$ for $\mathrm{C}$ and $\mathrm{N}$, and for other elements as reported in Lamborg et al. (2008b). For particulate organic carbon (POC), we do not acidify/fume filters and trap samples to remove $\mathrm{CaCO}_{3}$, but rather measure total particulate carbon (PC) and subtract out a typically much smaller particulate inorganic carbon (PIC) concentration determined more precisely by coulometric analyses, and thus report POC by difference. While our focus in this manuscript is on C fluxes, VERTIGO trap samples have been analyzed for a wider suite of major and minor elements (Lamborg et al., 2008a; Lamborg et al., 2008b) and thus the fluxes calculated here can be extrapolated to other elemental fluxes, similar to the case shown below for POC flux derived from ${ }^{234} \mathrm{Th}$. Methods for other ancillary data (nutrients, pigments, etc.) can be found in Buesseler et al. (2008a) and references therein.

\subsection{Estimation of particle source funnels}

Particle source funnels for the $150 \mathrm{~m}$ CLAP and NBST trap deployments were estimated following the procedures introduced in Siegel et al. (2008) for the ALOHA deployments. Briefly, observations from each ship's Acoustic Doppler Current Profiler (ADCP) system (R/V Kilo Moana for ALOHA and R/V Revelle for K2) were used to produce a depiction of the time dependent, three-dimensional horizontal current field. This velocity field is used to advect particles backwards in time rising from the trap's instantaneous location at a constant "sinking" speed. Particle sinking speeds explored range from 50 to $200 \mathrm{~m} \mathrm{~d}^{-1}$, which are in the range of direct observations made by Trull et al. (2008a). The ADCP velocity observations are decomposed into an objectively mapped mesoscale current field for each day, tidal (for both ALOHA and K2) and inertial band currents (for ALOHA only) and residual current component every $10 \mathrm{~m}$ of depth in the upper $500 \mathrm{~m}$ of the water column. Particles released from daily trap locations are advected horizontally using the daily objectively analyzed and tidal/inertial band currents in a deterministic manner. The effects of the residual currents are accounted for by creating a stochastic source funnel for each day (see Siegel et al. 2008 for details). The combination of the deterministic (mesoscale and tidal/inertial band currents) and stochastic (residual currents) calculations over the time of the deployment provides determination of source funnels for each trap. This requires the determination of NBST location as a function of time over its deployment period. The correspondence of final NBST location and predicted final NBST location was very good from ALOHA (within $\sim 6 \mathrm{~km}$ for the six NBST deployments at $150 \mathrm{~m}$ over a travel distance of $\sim 55 \mathrm{~km}$ ). However for the K2 deployments, these predictions were less successful $(10 \mathrm{~km}$ offset between observed and predicted final NBST locations over a travel distance of $\sim 45 \mathrm{~km}$ ). This discrepancy can be attributed to issues with the ADCP transducer array on the R/V Revelle, a large degree of data dropouts while the ship was underway and a spacetime pattern of ADCP sampling which was not optimized for estimating the mesoscale horizontal current field. Hence, there is greater uncertainty in the exact location of the NBST source funnels for the K2 deployments. However, the size and extent of the resulting funnels should be largely unaffected by this uncertainty.

\section{4. ${ }^{234}$ Th flux models}


We can calculate the flux of ${ }^{234} \mathrm{Th}$ on sinking particles by comparing the activity balance of total ${ }^{234} \mathrm{Th}$ to known sources and sinks, which is mathematically expressed as:

$$
\partial^{234} \mathrm{Th} / \partial \mathrm{t}=\left({ }^{238} \mathrm{U}-{ }^{234} \mathrm{Th}\right) \cdot \lambda-\mathrm{P}+\mathrm{V}
$$

where $2{ }^{234} \mathrm{Th} / \partial \mathrm{t}$ is the change in ${ }^{234} \mathrm{Th}$ activity with time, ${ }^{238} \mathrm{U}$ is the uranium activity determined from salinity $\left({ }^{238} \mathrm{U}\left(\mathrm{dpm} \mathrm{l}{ }^{-1}\right)=0.0704 \cdot\right.$ Salinity; Chen et al., 1986) ${ }^{234} \mathrm{Th}$ is the measured activity of total ${ }^{234} \mathrm{Th}, \lambda$ is the decay constant for ${ }^{234} \mathrm{Th}\left(=0.0288 \mathrm{day}^{-1}\right), \mathrm{P}$ is the net export flux of ${ }^{234} \mathrm{Th}$ on sinking particles, and $\mathrm{V}$ is the sum of advective and vertical diffusive ${ }^{234} \mathrm{Th}$ fluxes. The ${ }^{234} \mathrm{Th}$ flux, $\mathrm{P}$, can be calculated on a dpm m $\mathrm{d}^{-1}$ basis if the ${ }^{234} \mathrm{Th}$ activity is integrated from the surface to a given depth. Most commonly steady state (SS) is assumed and the contribution due to physical processes are ignored, and that is our starting point here as well.

The assumption that the physical transport term ("V" in eqn. 1) is negligible can often be justified in the open ocean due to minimal advection and diffusion and small gradients in ${ }^{234} \mathrm{Th}$ activities (Savoye et al., 2006). Scaling arguments can also be used to demonstrate that advection will dominate over diffusion in transport of ${ }^{234} \mathrm{Th}$ along horizontal gradients (Buesseler et al., 1994), and this is especially true in regions of low horizontal ${ }^{234} \mathrm{Th}$ gradients. In order to verify the validity of this assumption in our study areas, the measured ${ }^{234} \mathrm{Th}$ activities at different stations were used to calculate the horizontal gradient in ${ }^{234} \mathrm{Th}$ activities. For the upper 0-150 m integrated water column, the average ${ }^{234} \mathrm{Th}$ gradient was estimated to be $0.0006 \mathrm{dpm}^{-1}$ $\mathrm{km}^{-1}$ and $0.0005 \mathrm{dpm} \mathrm{l}^{-1} \mathrm{~km}^{-1}$ around ALOHA and $\mathrm{K} 2$ respectively. However it must be noted here that the spatial heterogeneity associated with this dataset makes this linear relationship between distance and ${ }^{234} \mathrm{Th}$ activity very weak ( $\mathrm{R}^{2}$ values of 0.5 and 0.3 for ALOHA and $\mathrm{K} 2$, respectively).

For horizontal transport at $\mathrm{K} 2$, the west to east gradient in ${ }^{234} \mathrm{Th}$ activity has been considered here, since the surface currents for K2 were found to be predominantly in this direction (Buesseler et al., 2008b). The mean eastward current velocity at station $\mathrm{K} 2$ has been reported to be $0.1 \mathrm{~km} \mathrm{~d}^{-1}$ at a depth of $100 \mathrm{~m}$ (Kawakami and Honda, 2007), or as fast as several $\mathrm{km} \mathrm{d}^{-1}$ based upon the drift trajectories of our traps. The change in ${ }^{234} \mathrm{Th}$ activity as a result of horizontal advection is estimated to be 7.5 to $150 \mathrm{dpm} \mathrm{m} \mathrm{m}^{-1}$ for the upper $150 \mathrm{~m}$ water column in and around station $\mathrm{K} 2$ which is equivalent to $<1-10 \%$ of the average ${ }^{234} \mathrm{Th}$ flux and is thus neglected here. This conclusion is insensitive to the exact choice of velocities and ${ }^{234} \mathrm{Th}$ gradients because this horizontal flux term is much smaller than vertical flux derived from the local Th:U disequilibrium (equation 1).

For the region around station ALOHA where sampling was carried out across a circular eddy field (Buesseler et al., 2008b), ${ }^{234}$ Th advected in one direction will mostly be compensated by water mass flowing in from the opposite direction, especially since the ${ }^{234} \mathrm{Th}$ gradient is so small. However in such a case vertical upwelling may be more important. But the low vertical gradient in ${ }^{234} \mathrm{Th}$ activity in this region (average gradient of $0.0004 \mathrm{dpm} \mathrm{l}^{-1} \mathrm{~m}^{-1}$ between $50 \mathrm{~m}$ and $150 \mathrm{~m}$ ), translates to an underestimation of flux by $60 \mathrm{dpm}$ $\mathrm{m}^{-2} \mathrm{~d}^{-1}$ (in the upper $0-150 \mathrm{~m}$ water column) for an assumed upwelling velocity of $1 \mathrm{~m} \mathrm{~d}^{-1}$. Based on these results we can assume that the effect of physical processes on ${ }^{234} \mathrm{Th}$ fluxes are reasonably small and are probably lower than the uncertainty term associated with the above flux estimates. Prior studies came to the same conclusions regarding the assumption of negligible physical transport for ${ }^{234} \mathrm{Th}$ at ALOHA (BenitezNelson et al., 2001a) and K2 (Kawakami and Honda, 2007).

\section{RESULTS}

\subsection{Total ${ }^{234} \mathrm{Th}$ and chlorophyll profiles}

We have chosen to summarize the total ${ }^{234} \mathrm{Th}$ data in one Figure for each of the two sites, comparing 147 samples from ALOHA collected on 19 CTD casts (Figure 1a) and 285 samples from K2 collected on 26 CTD casts (Figure 1b). By plotting versus density, the impacts of internal waves are removed although the vertical scaling vs. density stretches out the upper layers when considered vs. depth, as shown on right hand Y axis. Error bars are shown if larger than the symbol size, but on this scale, they are insignificant. The considerably higher total ${ }^{234} \mathrm{Th}$ activities at ALOHA vs. K2 are evident in these figures. While the average 
${ }^{234} \mathrm{Th} /{ }^{238} \mathrm{U}$ activity ratio is only slightly lower than 1.0 within the euphotic zone at ALOHA (avg. $=0.97$ above the $24.5 \mathrm{~kg} \mathrm{~m}^{-3}$ potential density 24.5 surface), it is 0.58 at $\mathrm{K} 2$ (above the $26.3 \mathrm{~kg} \mathrm{~m}^{-3}$ potential density 26.4 surface). At both sites, we have also shown chl-a to indicate the depth of algal production in the euphotic zone which is the main source of new particle surfaces in these open waters. Within this layer the ${ }^{234} \mathrm{Th}$ deficit is largest, particularly at K2. Below the DCM at least at K2, there are some samples with an excess of ${ }^{234} \mathrm{Th}$ that we will use later to examine remineralization below the depth of the euphotic zone.

To a first order, the much higher rates of ${ }^{234} \mathrm{Th}$ removal and particle fluxes at K2 than at ALOHA, associated with higher phytoplankton biomass at K2clearly delinieate the major differences between the two sites (e.g. Buesseler et al., 2007b). We will attempt to resolve more nuanced features in these data below, by comparing spatial and temporal variability, but start first with the 1-D steady state prediction of flux vs. depth.

\subsection{Thorium-234 and sediment trap fluxes}

The calculated ${ }^{234} \mathrm{Th}$ flux from individual ${ }^{234} \mathrm{Th}$ profiles are compared to all of the ${ }^{234} \mathrm{Th}$ analyses on the $150 \mathrm{~m}$ traps (Figure 2). The data are arranged in time, and during ALOHA (Figure 2a), the average trap ${ }^{234} \mathrm{Th}$ flux did not change significantly between D1 and D2 $\left(310 \pm 85 \mathrm{dpm} \mathrm{m}^{-2} \mathrm{~d}^{-1}\right.$; average trap flux indicated by horizontal gray bar). As reported in Lamborg et al., 2008b, the particle flux did not vary significantly between replicates of all elements measured from any given trap or between NBST and Clap trap designs. Calculated SS fluxes from the total ${ }^{234} \mathrm{Th}$ profiles vary from essentially zero to $1290 \mathrm{dpm} \mathrm{m}^{-2} \mathrm{~d}^{-1}$ (Table 1). The average error on any individual ${ }^{234} \mathrm{Th}$ flux calculation propagated from the uncertainty on the total ${ }^{234} \mathrm{Th}$ activity $\left( \pm 125 \mathrm{dpm} \mathrm{m}^{-2} \mathrm{~d}^{-1}\right)$ is shown for the last sample on the right side of each panel, and thus the calculated fluxes just below zero at 4 of the stations overlap with zero within errors. The average calculated ${ }^{234} \mathrm{Th}$ flux from all the stations is $377 \pm 395 \mathrm{dpm} \mathrm{m}^{-2} \mathrm{~d}^{-1}$ (calculated from data in Table 1). During VERTIGO, we sampled a much larger area than the potential source region for particles in these shallow traps to more fully characterize the regional export patterns. Therefore a better matching between trap fluxes and individual profiles was attempted using a particle "source funnel" analysis (Figure 3, see source funnel insert). The 2-D field in Figure 3 thus represents likely source regions for both trap types and a wide range of particle sinking speeds. The average flux of ${ }^{234} \mathrm{Th}$ for these 5 stations (assuming zero flux if negative) within the source area for both ALOHA D1 and D2 is $200 \pm 213 \mathrm{dpm} \mathrm{m}^{-2} \mathrm{~d}^{-1}$, which overlaps with the trap fluxes.

At K2, the shallowest sediment traps at $150 \mathrm{~m}$ were much deeper than the euphotic zone $(0.1 \%$ light at $50 \mathrm{~m}$ ), hence we calculated ${ }^{234} \mathrm{Th}$ fluxes at two depths- $60 \mathrm{~m}$, or just below the euphotic zone (Figure $2 \mathrm{~b}$ ), and at $150 \mathrm{~m}$ which corresponds to the depth of the traps (Figure $2 \mathrm{c}$ ). The calculated ${ }^{234} \mathrm{Th}$ fluxes at $60 \mathrm{~m}$ range from 1040-2130 dpm m $\mathrm{d}^{-1}$, while the range is much larger, from $470-2400 \mathrm{dpm} \mathrm{m}^{-2} \mathrm{~d}^{-1}$ at $150 \mathrm{~m}$ (Table 1). This is because some stations include profiles where the ${ }^{234} \mathrm{Th}:{ }^{238} \mathrm{U}$ disequilibrium continues to increase below $60 \mathrm{~m}$ (fluxes increase with depth), as well as those with ${ }^{234} \mathrm{Th}$ excess below $60 \mathrm{~m}$ (fluxes decrease with depth). To first order, the processes of particle loss in the euphotic zone at K2 (i.e. fluxes at $60 \mathrm{~m}$ )are more uniform than the processes that control remineralization below the layer of net particle production (i.e. fluxes at $150 \mathrm{~m}$; see Section 5.5.).

The traps at K2 show higher fluxes than at ALOHA with a decrease in flux between D1 and D2. For $\mathrm{D} 1$, the average $150 \mathrm{~m}$ trap flux is $1260 \pm 195 \mathrm{dpm} \mathrm{m}^{-2} \mathrm{~d}^{-1}$ which is similar to the flux calculated using all the $\mathrm{D} 1{ }^{234} \mathrm{Th}$ data and a SS model $\left(1625 \pm 640 \mathrm{dpm} \mathrm{m}^{-2} \mathrm{~d}^{-1}\right.$; Table 1). We also found lower flux during D1 for the Clap traps relative to NBSTs at both $150 \mathrm{~m}$ and $300 \mathrm{~m}$ (Lamborg et al., 2008b). The flux difference here at $150 \mathrm{~m}$ for ${ }^{234}$ Th during D1 is $1340 \pm 160$ for NBSTs and $1040 \pm 85 \mathrm{dpm} \mathrm{m}^{-2} \mathrm{~d}^{-1}$ for Clap traps (see Lamborg et al., 2008a and 2008b, for further discussion of trap comparisons for other elements). For D2, the ${ }^{234} \mathrm{Th}$ trap flux is considerably lower $\left(460 \pm 85 \mathrm{dpm} \mathrm{m}^{-2} \mathrm{~d}^{-1}\right)$, similar to all other elemental fluxes that decreased from D1 to D2 (Lamborg et al., 2008b). The SS flux calculated from ${ }^{234}$ Th profiles collected during D2 (average $=1455$ $\pm 380 \mathrm{dpm} \mathrm{m} \mathrm{d}^{-1}$ ) is similar to D1, and is higher than the traps (Table 1). A final single drifting Clap trap deployment collected a ${ }^{234} \mathrm{Th}$ flux at $150 \mathrm{~m}$ of $780 \pm 70 \mathrm{dpm} \mathrm{m}^{-2} \mathrm{~d}^{-1}$ (Figure 2c). As with the ALOHA data, we sampled a much larger area for ${ }^{234} \mathrm{Th}$ than the particle source region for our $150 \mathrm{~m}$ traps. If we selected only those water column profiles from within the predicted particle source funnel (Figure 3 ) and closest in temporal 
match to the traps (Figure 2c- gray squares) the data suggest average fluxes of $1100 \pm 365$ and $1350 \pm 105 \mathrm{dpm}$ $\mathrm{m}^{-2} \mathrm{~d}^{-1}$ for D1 and D2, respectively, i.e. overlapping with traps during D1 and still higher than traps during D2.

\subsection{Spatial variability in ${ }^{234}$ Th fluxes}

Figure 3 shows the spatial distribution of ${ }^{234} \mathrm{Th}$ fluxes at $150 \mathrm{~m}$ for ALOHA and K2, on map coordinates with the flux proportional to the area of the circle at each sampling point and the locations of the traps and trap particle source funnels as indicated. Sampling a larger area in survey mode allows for the assessment of spatial patterns in surface export. If spatial variability in export and remineralization is significant on the scales that a trap samples, one should not expect a trap collecting flux from a smaller particle source funnel to be characteristic of a broader region many times larger than a particle source funnel.

At ALOHA, we have a confounding issue, in that the ${ }^{234} \mathrm{Th}$ deficit is quite small, resulting in relatively higher errors in the flux estimates. The error as propagated from uncertainties in the ${ }^{234} \mathrm{Th}$ activities alone averaged $\pm 125 \mathrm{dpm} \mathrm{m}^{-2} \mathrm{~d}^{-1}$ (Table 1), or $\sim 40 \%$ for the average ALOHA ${ }^{234}$ Th flux of $375 \mathrm{dpm} \mathrm{m}^{-2} \mathrm{~d}^{-1}$. However considering that we neglected physical processes and non-steady state changes in ${ }^{234} \mathrm{Th}$ activities, the true uncertainty may be larger. At ALOHA, the standard deviation in flux among all the sites is $\pm 395 \mathrm{dpm} \mathrm{m}^{-2}$ $\mathrm{d}^{-1}$ or \pm 215 if just the 5 stations within the source funnel are considered. Also the prediction of the ${ }^{234} \mathrm{Th}$ flux is limited by the relatively low vertical resolution of sampling at some stations which may miss features (4 to 10 depths per ${ }^{234} \mathrm{Th}$ profile at ALOHA). When integrating ${ }^{234} \mathrm{Th}$ activities to $150 \mathrm{~m}$, there is a larger uncertainty in those stations with lower sampling resolution, since we have seen, even at low flux sites (Buesseler et al., 2008a) and here at K2 (see below), that there is considerable fine scale structure in the profile of ${ }^{234} \mathrm{Th}$ vs. depth. For this reason, the flux predicted at station 27 ( $\mathrm{n}=10$ depths) and 67 ( $\mathrm{n}=8$ depths) for ALOHA-D1 and D2, respectively, are the best choice for more detailed comparison since they have both the best depth resolution and lie within the particle source funnels. These two stations have an estimated ${ }^{234} \mathrm{Th}$ flux of 337 and $487 \mathrm{dpm} \mathrm{m}^{-2} \mathrm{~d}^{-1}$ for station 27 and 67 respectively (Table 1), so again, the predicted fluxes are within the range of the trap derived fluxes of $288 \pm 91$ and $340 \pm 65 \mathrm{dpm} \mathrm{m}^{-2} \mathrm{~d}^{-1}$ for D1 and D2, respectively. A few stations, 33, 40, 61, 72 and 99, have predicted ${ }^{234}$ Th fluxes $>500 \mathrm{dpm} \mathrm{m}^{-2} \mathrm{~d}^{-1}$ (Table 1) but there is no obvious biogeochemical difference in these stations that might be used to explain these differences (looking at chl-a, nutrients, or HPLC pigments- see Section 5.4.).

For K2, the spatial variability in flux also shows no clear north-south or east-west gradients (Figure 3). While the absolute value and range of predicted ${ }^{234} \mathrm{Th}$ fluxes is higher than at ALOHA, the variability between stations is slightly smaller on a percentage basis $\left(1540 \pm 525 \mathrm{dpm} \mathrm{m}^{-2} \mathrm{~d}^{-1} ; \pm 35 \%\right)$. The trap flux decrease from D1 to D2 can not be explained by a change in particle source funnel, as the stations that match the trap source funnel most closely, have similar predicted fluxes between D1 and D2 (Figure 3, Table 1). Also note that as with ALOHA, there is significant variability in the depth resolution for ${ }^{234} \mathrm{Th}$ profiles $(\mathrm{n}=8$ to 24 depths per ${ }^{234} \mathrm{Th}$ profile at K2). Fortunately, there are two key stations with high vertical resolution within the source funnel corresponding to D1 and D2 that we can further examine for potential non-steady state effects and the extent of remineralization below the euphotic zone (see below).

\subsection{Non-steady state ${ }^{234} \mathrm{Th}$ flux modeling at $\mathrm{K} 2$}

High resolution ${ }^{234}$ Th profiles are available from VERTIGO K2 stations 24 and 67 within the particle source funnel during deployments D1 and D2 ( $\mathrm{n}=20$ depths for ${ }^{234} \mathrm{Th}$; Figure $\left.4 \mathrm{a}\right)$. Both profiles show a similar pattern with the lowest ${ }^{234} \mathrm{Th}$ activities in the upper 30-40 m, below which activities increase and then exceed ${ }^{238} \mathrm{U}$ between 70 and $110 \mathrm{~m}$. Using the steady state model at both stations you would expect ${ }^{234} \mathrm{Th}$ flux to increase vs. depth until about $80 \mathrm{~m}$, at which point the source of ${ }^{234} \mathrm{Th}$ exceeds its removal, as ${ }^{234} \mathrm{Th}>{ }^{238} \mathrm{U}$ (Figure $4 \mathrm{a}$ ). In this layer, particles carrying ${ }^{234} \mathrm{Th}$ from the surface are remineralized or at least stop sinking with any appreciable velocity, so that they contribute excess ${ }^{234} \mathrm{Th}$ to the total ${ }^{234} \mathrm{Th}$ inventory in that layer. Calculated SS fluxes thus decrease below that depth, and as discussed above are predicted to be around 1500 and $1200 \mathrm{dpm} \mathrm{m} \mathrm{d}^{-1}$ for D1 and D2, respectively, at $150 \mathrm{~m}$ (Figure $4 \mathrm{~b}$ ).

However, as discussed in many prior ${ }^{234} \mathrm{Th}$ papers (see Savoye et al., 2006 for review), if the total activity of ${ }^{234} \mathrm{Th}$ is changing over the time scale of its decay, we may need to consider non-steady state (NSS) 
changes to the ${ }^{234} \mathrm{Th}$ activity balance in the ${ }^{234} \mathrm{Th}$ flux model $\left(\partial^{234} \mathrm{Th} / \partial \mathrm{t}\right.$ in equation 1$)$. Ideally, that would be done by Lagrangian sampling of a single water mass to look at changes in ${ }^{234} \mathrm{Th}$ activities over the course of its characteristic decay time scale (e.g. sampling several times over 3-4 weeks). When total water column ${ }^{234} \mathrm{Th}$ activities are decreasing with time, the predicted NSS fluxes increase, and when the activities are increasing, the fluxes decrease.

In this K2 data set, we make this time-series comparison at stations 24 and 67, which were sampled 11 days apart within the particle source funnel. The waters showed similar physical structure and $\mathrm{T} / \mathrm{S}$ properties during this time (i.e. we have no evidence of a shift in water masses; data not shown). As derived in Buesseler et al. (1992), we use a linear interpolation for the ${ }^{234} \mathrm{Th}$ activity change for each depth interval, and then apply this single NSS term $\left(\partial^{234} \mathrm{Th} / \partial \mathrm{t}\right.$ in equation 1$)$ to the activity balance at the time of sampling at station 24 or 67. More correctly, this activity change applies for the period between station 24 and 67, but this calculation sets a wider bound on the NSS flux estimates by assuming $\partial^{234} \mathrm{Th} / \partial \mathrm{t}$ is constant and can be applied to the Th:U disequilibrium at both time points (the between time point flux would be the average).

Figure $4 \mathrm{~b}$ shows the NSS estimates of the ${ }^{234} \mathrm{Th}$ flux profile, which are considerably lower at all depths including the $150 \mathrm{~m}$ trap depth (NSS average $=425 \pm 280$ ). It is evident from this calculation that the ${ }^{234}$ Th flux is quite sensitive to the inclusion of the NSS term. One interpretation that is consistent with both traps and water column ${ }^{234} \mathrm{Th}$ data, is that the decrease in trap flux between D1 and D2 is real and that conditions prior to our arrival were relatively constant (3-4 weeks prior). Thus a SS derived flux at station 24 and NSS model at station 67 provide our most accurate assessment of fluxes in this region. A wide variety of ancillary data support this conclusion (satellite chl-a, moored time-series nutrient samplers; Buesseler et al., 2008b).

\subsection{High resolution vertical ${ }^{234} \mathrm{Th}$ profiles at $\mathrm{K} 2$}

The ${ }^{234} \mathrm{Th}$ activity data in Figure $4 \mathrm{a}$ are replotted in Figure $5 \mathrm{a}$ vs. potential density to look more closely at remineralization and temporal changes in surface and subsurface chlorophyll and nutrient fields at K2. In both profiles there is a DCM, but between stations there is a loss of the shallow chl-a peak (Figure 5b), and an increase in shallow dissolved inorganic nitrogen and silicate ratios (DIN:dSi; Figure 5c). We attributed this change to a loss of large diatoms from the surface layer, and confirmed this with microscopic analyses, changes in pigment concentration, and a more rapid decrease in dSi than DIN during this period of diatom growth and export from the euphotic zone (Buesseler et al., 2008b). Below the DCM, we see in both profiles (and at other stations, Figure 1) a clear ${ }^{234}$ Th excess peak that coincides with an increase in the DIN:dSi ratio (Figures 5a and 5c). We have previously attributed this change in DIN:dSi below the DCM to preferential $\mathrm{N}$ remineralization over biogenic $\mathrm{Si}(\mathrm{bSi})$, because bSi has longer length scales for remineralization on sinking particles (Buesseler et al., 2008b). Other VERTIGO studies also suggest rapid sub-euphotic zone remineralization of $\mathrm{N}$ from sinking particles (Elskens et al., 2008). Below the ${ }^{234} \mathrm{Th}$ excess peak and in deeper waters (below potential densities greater than $26.8 \mathrm{~kg} \mathrm{~m}^{-3}$ ), the DIN:dSi ratio continues to decrease.

To broaden this analysis to the entire K2 study region, we compare all of the ${ }^{234} \mathrm{Th}$ activity data relative to the DIN:dSi ratio (Figure 6). We have divided the data by the 3 potential density layers shown in Figure 5 and within these layers, we see a regional pattern emerging. Those sites with the lowest ${ }^{234} \mathrm{Th}$ activities have the highest DIN:dSi ratios, though there are sites with low ${ }^{234} \mathrm{Th}$ and a wide range of DIN:dSi values. We interpret the high DIN:dSi as being an indicator of prior diatom growth and export, given the observed inverse relationship between DIN:dSi and fucoxanthin, a diatom algal biomarker (see Section 5.4. below and Figure 10 in Buesseler et al., 2008b).

In the ${ }^{234} \mathrm{Th}$ profiles (Figure 5a), excess ${ }^{234} \mathrm{Th}$ is found most frequently in the layer between potential densities of 26.4 and $26.8 \mathrm{~kg} \mathrm{~m}^{-3}$ below the DCM (depths between about 60 and $120 \mathrm{~m}$; open circles, Figure 6). As suggested in the vertical profiles, we attribute this excess to ${ }^{234} \mathrm{Th}$ release from sinking particles, which we see as a common feature in this larger regional data set. The DIN:dSi ratio of these waters is slightly enhanced relative to waters below, which we attribute to more rapid DIN remineralization from sinking particles as discussed above. There are some ${ }^{234} \mathrm{Th}$ excess data in deeper waters (Figure 1b), so remineralization certainly 
can continue at depth on short time scales. Though the concept of a ${ }^{234} \mathrm{Th}$ excess is not new, in early studies with less vertical resolution, there are usually very few data points to resolve such features (e.g. Usbeck et al., 2002). Since the euphotic zone is a source of net particle production, this layer immediately below the DCM is the first depth in the twilight zone where net particle production due to phytoplankton has ceased, and remineralization of the most labile materials may be expected.

\subsection{Thorium-234 and suspended particles}

Thorium is known to strongly adsorb to particle surfaces, however the exact organic and inorganic controls on this partitioning are not well known on the molecular level (Santschi et al., 2006). We compare the total and particulate ${ }^{234} \mathrm{Th}$ activities in Figure 7 vs. depth (Figures $7 \mathrm{a}$ and 7b- ALOHA; 7e and 7f- K2) and see that about $10 \%$ of the total ${ }^{234} \mathrm{Th}$ activity is associated with the $1-51 \mu \mathrm{m}$ "small" particles, a distribution typical of many open ocean sites (e.g. Bacon et al., 1996). For ALOHA, there is only a small decrease in $1-51 \mu \mathrm{m}$ particulate ${ }^{234} \mathrm{Th}$ vs. depth, and $<1 \%$ of total ${ }^{234} \mathrm{Th}$ is in the $>51 \mu \mathrm{m}$ "large" particle fraction (depths $<150 \mathrm{~m}$; Figure $7 \mathrm{~b}$ ). At K2 there is a significantly higher surface ${ }^{234} \mathrm{Th}$ deficit in total ${ }^{234} \mathrm{Th}$ (Figure $7 \mathrm{e}$ ), and the average particulate ${ }^{234} \mathrm{Th}$ in the $1-51 \mu \mathrm{m}$ fraction is $12 \%$ and for the $>51 \mu \mathrm{m}$ fraction $6 \%$ relative to total ${ }^{234} \mathrm{Th}$ (depths $<60 \mathrm{~m}$; Figure 7f) Large and small PC concentrations decrease with depth at both sites due to heterotrophic consumption of POC (Figures $7 \mathrm{c}$ and $7 \mathrm{~g}$ ).

In addition to higher particulate ${ }^{234} \mathrm{Th}$ at $\mathrm{K} 2$, the $>1-51 \mu \mathrm{m}$ PC fraction is considerably higher and there is a large and essentially equal concentration of PC in both large and small size classes at K2, in at least the upper $50 \mathrm{~m}$ (Figure $7 \mathrm{~g}$ ). While the profile of particulate ${ }^{234} \mathrm{Th}$ does not track the other ancillary data well at ALOHA, at K2 the small particulate ${ }^{234} \mathrm{Th}$ profile has two peaks, one associated with the DCM or within the ML and another closer to $200 \mathrm{~m}$. Barium excess is thought to be an indicator of the strength of local remineralization on seasonal time scales, and during VERTIGO, Dehairs et al. (2008) attribute the higher $\mathrm{Ba}^{\mathrm{ex}}$ at K2 to higher surface export and subsurface remineralization at depth (Figure $7 \mathrm{~b}$ ). The increase in particulate

${ }^{234} \mathrm{Th}$ at depths $>200 \mathrm{~m}$ may be affiliated with that deeper $\mathrm{Ba}^{\mathrm{ex}}$ feature, where particles are being broken down and these suspended surfaces could act as new sorptive sites for the uptake of ${ }^{234} \mathrm{Th}$. There is also evidence from the profiles of beam attenuation at K2 for a secondary suspended particle maximum between 100 and 300 $\mathrm{m}$ (Lam and Bishop, 2008) that matches shape of the deep particulate ${ }^{234}$ Th profile. Lam and Bishop (2008) attribute this feature to the lateral input of suspended $\mathrm{Mn}$ and Fe oxides from the Kuril/Kamchatka margin (Lam and Bishop, 2008). If the transport of these particles requires several months or more to reach K2 (based upon horizontal velocities derived from our trap trajectories- several $\mathrm{km} \mathrm{d}^{-1}$ ), then the suspended particle plume would be too small to induce large activity gradients in total ${ }^{234} \mathrm{Th}$, but would result in a higher fraction of particulate ${ }^{234} \mathrm{Th}$ in equilibrium with these margin derived suspended particulates.

\subsection{Ratios of $\mathrm{POC} /{ }^{234} \mathrm{Th}$ on suspended and sinking particles}

One common application of ${ }^{234} \mathrm{Th}$ is as flux proxy, most often for POC, to derive site and depth specific export fluxes and this is based on the ${ }^{234} \mathrm{Th}$ flux (derived from eqn. 1) multiplied by a particulate component to particulate ${ }^{234} \mathrm{Th}$ ratio (Buesseler et al., 2006). The main assumption is that the POC/ $/{ }^{234} \mathrm{Th}$ ratio sampled is representative of the entire sinking flux, though it is more often derived from some type of filtration process of suspended material rather than from a direct measurement on sinking particles (see Section 5.2.).

The VERTIGO C/Th bulk trap ratios at 150, 300 and $500 \mathrm{~m}$ decrease with depth, from about 5-6 to 1$2 \mu \mathrm{mol} \mathrm{dpm}{ }^{-1}$ at ALOHA (Figure 8a and 8b), and from 3-5 to $1-2 \mu \mathrm{mol} \mathrm{dpm}^{-1}$ at K2 (Figure $8 \mathrm{c}$ and $8 \mathrm{~d}$ and data in Table 2a; note we use $\mathrm{C} / \mathrm{Th}$ as shorthand for $\mathrm{POC} /{ }^{234} \mathrm{Th}$ and always report this ratio in units of $\mu \mathrm{mol} \mathrm{dpm}^{-1}$ ). This decrease vs. depth is common to most prior $\mathrm{C} / \mathrm{Th}$ data sets (e.g. Buesseler et al., 2006). Similar bulk values were obtained from the IRS in-situ settling column deployed at $300 \mathrm{~m}$, although individual sinking rate fractions ranged from 0.9 to 6.6 at ALOHA and 1.3 to 15 at K2 (Table 2b). On average, the particles caught using a QMA filter, thus greater than $1 \mu \mathrm{m}$ and smaller than the next size screen (1-10 or 1-51 $\mu \mathrm{m}$ at ALOHA; $1-5$ or $1-51 \mu \mathrm{m}$ at $\mathrm{K} 2$ ), had a lower $\mathrm{C} / \mathrm{Th}$ ratio (Table $2 \mathrm{~b}$ ). At ALOHA the average $\mathrm{C} / \mathrm{Th}$ ratio of particles caught on QMA filters at $150 \mathrm{~m}$ was 1.9 for $1-10 \mu \mathrm{m}$ and 2.1 for $1-51 \mu \mathrm{m}$ particles vs. 5.1 in the traps. The average at $150 \mathrm{~m}$ at $\mathrm{K} 2$ was 1.4 for $1-5 \mu \mathrm{m}$ and 2.5 for $1-51 \mu \mathrm{m}$ vs. 3.9 in the traps. 
For the mid-sized particle classes at ALOHA, the C/Th of the 10-51 $\mu$ m material was 3.1, 2.1 and 1.8 for 150,300 and $500 \mathrm{~m}$ respectively, while the traps had an average C/Th of 5.0, 2.0 and 1.4 for the same depths (Figure 8a and 8b). For K2, we had C/Th ratios for 10 to $20 \mu \mathrm{m}$ material of 3.2, 2.1 and 2.6 for $150 \mathrm{~m}$, $300 \mathrm{~m}$ and $500 \mathrm{~m}$, respectively, and for the same depths and 20 to $51 \mu \mathrm{m}$ material, 2.8, 1.4 and 2.0 (Figure $8 \mathrm{c}$ and 8d). The largest particles were collected by the first screen, with a nominal 51 or $350 \mu \mathrm{m}$ mesh size, as used at ALOHA and K2, respectively. These $>51 \mu \mathrm{m}$ and $>350 \mu \mathrm{m} \mathrm{C} / \mathrm{Th}$ data (Figure 8- red stars), at least below the surface layer, have significantly higher $\mathrm{C} / \mathrm{Th}$ ratios than any of the other size classes or traps. We discuss below possible causes for these data, in particular as it relates to the application of ${ }^{234} \mathrm{Th}$ as an elemental flux proxy (see Section 5.2.).

\section{DISCUSSION}

We can use this extensive ${ }^{234} \mathrm{Th}$ data set to address a variety of issues. In this section we will first look at the use of ${ }^{234} \mathrm{Th}$ as a method for the assessment of upper ocean sediment trap collection efficiency. Secondly, we can take advantage of the wider spatial and temporal sampling for ${ }^{234} \mathrm{Th}$ to derive regional estimates of POC flux using ${ }^{234} \mathrm{Th}$ fluxes multiplied by the ratio of $\mathrm{POC} /{ }^{234} \mathrm{Th}$ on particles. We have sampled both sinking and size fractionated material on filters to examine how best to apply this method. We can also compare VERTIGO estimates of POC flux to prior studies at ALOHA and K2, to address spatial and seasonal variability in export and its relationship to production in surface waters. The spatial variability in ${ }^{234} \mathrm{Th}$ activities and flux is then compared to the variability in nutrients, plankton pigments and other biogeochemical indicators to assess controls on local particle fluxes and discuss how the variability in fluxes and stocks can be decoupled. Finally, ${ }^{234} \mathrm{Th}$ excess at K2 indicates remineralization of sinking particles below the DCM, and we evaluate the magnitude of the flux changes vs. depth to see how the extent of remineralization varies between sites.

\subsection{Flux of thorium-234 derived from sediment traps and water column activities}

Early on in the application of sediment traps for measuring sinking particle fluxes, radionuclides were proposed to "calibrate" traps by comparing measured trap fluxes to those predicted from water column radionuclide distributions and simple scavenging models (Bacon et al., 1985; Coale and Bruland, 1985; Knauer et al., 1979; Tsunogai et al., 1986). While some early syntheses of these data suggested a "reasonable" agreement between predicted and measured sediment trap fluxes (GOFS, 1989), others suggested that differences of up to a factor of 3-10 were common, at least in the upper ocean (Buesseler, 1991). This led to further studies to examine the different time and space scales measured by traps and radionuclide budgets, which was addressed in part by conducting time-series Lagrangian sampling around traps (Buesseler et al., 1994). Also considered were advective terms and their impact on ${ }^{234} \mathrm{Th}$ budgets and the calibration of traps (e.g. Dunne and Murray, 1999). One limitation of most calibration studies, is that they include relatively few coupled observations (Buesseler et al., 1994; Coppola et al., 2002; Hung et al., 2004; Murray et al., 1996; Schmidt et al., 1990). More recent trap vs. water column ${ }^{234} \mathrm{Th}$ comparisons have supported the finding that single profiles are inadequate to constrain fluxes, at least during post bloom conditions (Lampitt et al., 2008). By consideration of time-series ${ }^{234} \mathrm{Th}$ trap data and back-calculating water column ${ }^{234} \mathrm{Th}$ activities, Cochran et al. (2008) concluded that advective influences may have a significant effect on water column derived fluxes, with predicted fluxes at a fixed trap site influenced by ${ }^{234} \mathrm{Th}$ scavenging processes which are tens to hundreds of kilometers away.

Our data can be used to address some of the same issues, as variability in water column predicted ${ }^{234} \mathrm{Th}$ fluxes in time (Figure 2) and space (Figure 3) are larger than the variability in trap ${ }^{234} \mathrm{Th}$ fluxes. At ALOHA, where ${ }^{234} \mathrm{Th}$ trap fluxes and biogeochemical conditions are relatively constant, the average trap flux in both D1 and D2 overlaps with predicted fluxes using a simple 1-D SS model for ${ }^{234}$ Th (Figure 2a). Using all ALOHA data, trap/calculated ${ }^{234} \mathrm{Th}$ flux $=0.83 \pm 0.90$. However, the variability around this average ratio is large and any individual profile does not necessarily capture the source funnel for the sinking particles collected in the traps. When considering only those stations within the space and time scale of the predicted particle source funnel of the $150 \mathrm{~m}$ traps, the trap and water column fluxes also overlap, but variability even on this smaller scale is large. Within the particle source funnel, individual trap/calculated ${ }^{234} \mathrm{Th}$ flux ratios range 
from 0.9 to 1.9 for stations with a positive flux, but two of the stations have a calculated flux that overlaps with zero (average trap/calculated ${ }^{234} \mathrm{Th}$ flux $=1.80$ for all source funnel stations, including zero flux stations in Table 1). Thus in a low flux setting, even with relatively stable conditions, the use of single profiles does not allow for an accurate calibration of upper ocean traps and the variability is too large to constrain the trap fluxes better than a factor of about two.

At K2, we found a larger Th:U disequilibrium (Figure 1b), hence higher surface fluxes and lower relative flux errors (Figure 2c). Calculated SS fluxes overlapped on average with the traps for D1 (using all K2-D1 data, trap/calculated ${ }^{234} \mathrm{Th}$ flux $=0.78 \pm 0.33$ ), but exceeded the trap flux on D2 (using all K2-D2 data, trap/calculated ${ }^{234} \mathrm{Th}=0.32 \pm 0.10$ ). Using only water column stations within the particle source funnel (Figure 3), the results are similar (trap/calculated $=1.14 \pm 0.42$ for D1 and $0.34 \pm 0.07$ for D2). We can explain this apparent difference in the trap and SS flux during D2 by the fact that flux changes can occur much faster than changes to the inventory of ${ }^{234} \mathrm{Th}$ in the water column. To account for this changing flux, we focused on two stations within the particle source region with non-changing $\mathrm{T} / \mathrm{S}$ properties and high enough vertical resolution to better capture different layers of Th:U deficit and excess (stations 24 \& 67). Using these two stations, the calculated NSS flux overlaps with the measured K2-D2 sediment traps (Figure 4b; trap/calculated ${ }^{234} \mathrm{Th}=1.08 \pm 0.74$ ).

While other K2 profiles did not have the same vertical resolution to define these rather narrow layers of ${ }^{234} \mathrm{Th}$ scavenging and remineralization, the composite data from the entire study area do show a similar temporal trend of increasing shallow ${ }^{234} \mathrm{Th}$ activities, from $1.30 \pm 0.33 \mathrm{dpm}^{-1}$ for D1 to $1.53 \pm 0.29$ for D2 (average for shallow water with potential densities $<26.4$, i.e. depths where $\mathrm{Th}<\mathrm{U}$ ). Given the 11 days between the mid-point of D1 and D2 ${ }^{234} \mathrm{Th}$ profiles, this regional average change in $\partial^{234} \mathrm{Th} / \partial \mathrm{t}$ would be equivalent to a decrease in ${ }^{234} \mathrm{Th}$ flux of about $1000 \mathrm{dpm} \mathrm{m}^{-2} \mathrm{~d}^{-1}$, reducing the predicted flux to around 300 $\mathrm{dpm} \mathrm{m} \mathrm{m}^{-2} \mathrm{~d}^{-1}$ and thus overlapping with the observed D2 trap measurements. Unless the temporal changes are large relative to measurement uncertainties and intrinsic spatial variations, non-steady state calculations cannot be rigorously applied to estimate trap ${ }^{234} \mathrm{Th}$ fluxes. Also, while horizontal and vertical physical processes introduce small uncertainties in the ${ }^{234}$ Th derived fluxes during VERTIGO $(<\mathrm{few} \%$, see Section 4.2.), at other sites and times, these physical transport terms may be significant and difficult to constrain (Savoye et al., 2006).

In conclusion, without time-series Lagrangian sampling around a sediment trap over several weeks and with high enough vertical resolution to capture layering of particle scavenging and remineralization, it becomes difficult to calibrate any single trap deployment. However, there may be more general rules or understanding that can be obtained from larger compilations of water column Th-derived and trap fluxes. In a comparison of time-series data collected over at least one annual cycle, ${ }^{234} \mathrm{Th}$ trap calibration results from the Baltic Sea (Gustafsson et al., 2004), Dabob Bay (Wei and Murray, 1992), BATS (Buesseler et al., 2000) and HOT (Benitez-Nelson et al., 2001a), all suggested on average a flux-weighted under-trapping bias of approximately a factor of two (data compiled in Buesseler et al., 2007a). For deeper moored traps calibrated by annual balances in the longer-lived radionuclides ${ }^{230} \mathrm{Th}$ and ${ }^{231} \mathrm{~Pa}$, an under-trapping bias for shallow moored conical traps $(<1000 \mathrm{~m})$ is also evident in larger data sets (Scholten et al., 2001; Yu et al., 2001). These general findings cannot be applied to any single trap deployment as there are multiple factors that can influence trap collection efficiency and radionuclide budgets, but they provide some indication of the scale and differences in the two sets of particle flux estimates.

Finally, even if a trap is calibrated using thorium, this does not necessarily imply the other elemental fluxes will have the same flux bias, as the major carrier phases of sinking ${ }^{234} \mathrm{Th}, \mathrm{POC}, \mathrm{bSi}$, PIC etc. may differ. A SCOR working group suggested reporting any calibration factors along with the flux model, water column data and the uncorrected flux data (Buesseler et al., 2007a). We thus agree with the conclusion of Cochran et al. (2008) that "sediment trap and water column estimates of ${ }^{234} \mathrm{Th}$ flux provide complementary views of the removal of ${ }^{234} \mathrm{Th}$ from the water column" and urge caution in using single ${ }^{234} \mathrm{Th}$ profiles to calibrate traps. We continue to use here the ${ }^{234} \mathrm{Th}$ data to provide one view on the variability in the regional flux and attenuation patterns within and between the different VERTIGO sites. 


\section{2. $\mathrm{POC} /{ }^{234}$ Th ratios and $P O C$ fluxes}

In the application of ${ }^{234} \mathrm{Th}$ to determine other fluxes, the ${ }^{234} \mathrm{Th}$ flux is multiplied by its ratio to other components on sinking particles, i.e. for organic carbon, Flux $\mathrm{POC}=\left(\right.$ flux $\left.{ }^{234} \mathrm{Th}\right) \times\left(\mathrm{POC} /{ }^{234} \mathrm{Th}\right)$ on sinking particles. The reliability of this approach depends both upon the ability to quantify the ${ }^{234} \mathrm{Th}$ export flux, as well as how accurately one can characterize the $\mathrm{C} / \mathrm{Th}$ ratio of sinking particles. As discussed in a review article (Buesseler et al., 2006), there are a variety of processes that can alter the $\mathrm{C} / \mathrm{Th}$ ratio, such as particle surface:volume ratios, solution chemistry and particle properties, POC assimilation by foodwebs, and particle aggregation/disaggregation. Observations suggest that the $\mathrm{C} / \mathrm{Th}$ ratio generally decreases with depth and there is less variability in $\mathrm{C} / \mathrm{Th}$ ratios below the mixed layer. In part, this empirical method was derived to avoid the use of sediment traps (which have their own potential biases), so when sampling particles using filtration, the important assumption is that the elemental ratio on filtered particles is similar to that in an ideal flux collector, i.e. a flux weighted average. If some class of particles differs in its $\mathrm{C} / \mathrm{Th}$ ratio and dominates the sinking flux, yet is missed by filtration (or masked by other particle types), then the method would be inaccurate (Burd et al., 2000; Waite and Hill, 2006; Smith et al., 2006). For this approach to work, ${ }^{234} \mathrm{Th}$ and POC do not have to be carried by the same particle types, but rather only sampled at the same relative ratio on filters as found in sinking particles (and this is only an issue if the $\mathrm{C} / \mathrm{Th}$ ratios differ between particle types). Most studies use filtration cut-offs for separating particles into a small, nominal $>1-51 \mu \mathrm{m}$ fraction and a large, $>51 \mu \mathrm{m}$ fraction (c.f., Bishop, 1989). They often assume that the larger size classes are more representative of this sinking flux and/or report both $\mathrm{C} / \mathrm{Th}$ ratios to set some bounds on the predicted POC export flux. One goal of VERTIGO was to examine variability in the $\mathrm{C} / \mathrm{Th}$ ratio of suspended particles of different sizes to compare to replicate samples at different depths and during multiple deployments of both NBST and Clap traps.

Our $\mathrm{C} / \mathrm{Th}$ data suggest that at least by depths of $150 \mathrm{~m}$ and below, where there are direct measurements of sinking particles in traps, that the sinking and suspended $\mathrm{C} / \mathrm{Th}$ ratios overlap at both VERTIGO sites, with two notable exceptions (Figure 8). First, the C/Th on the QMA fractions are lower than the traps (Table 2a), such that a POC flux at $150 \mathrm{~m}$ derived from ${ }^{234} \mathrm{Th}$ and a QMA filter to represent sinking particles would be a factor of two lower than observed. A lower relative $\mathrm{C} / \mathrm{Th}$ ratio on the small particle fraction collected by QMA filters has been noted in many (Benitez-Nelson et al., 2001a; Buesseler et al., 1998; Charette et al., 1999; Cochran et al., 2000) but not all prior studies (Table 1 in Buesseler et al., 2006). In VERTIGO, particles were all collected with in-situ pumps and both elements analyzed on the exact same sample, so this ratio is not impacted by collecting POC with bottles vs. pumps, which generally show higher POC in bottle samples (Gardner et al., 2003; Liu et al., 2005; Moran et al., 1999). There is evidence of preferential sorption of dissolved ${ }^{234} \mathrm{Th}$ on to quartz based filters (Benitez-Nelson et al., 2001b; Rutgers van der Loeff et al., 2006), and this may be one reason that on average C/Th ratios are lower on QMAs, though there are other possibilities, such as greater Th uptake onto the higher surface:volume ratio of small particles, or greater removal of organic carbon by respiration during the generation of suspended small particles from larger sinking particles.

The second exception is that for all samples below $150 \mathrm{~m}$ (especially at K2), the first screen $(>51 \mu \mathrm{m}$ at ALOHA; $>350 \mu \mathrm{m}$ at $\mathrm{K} 2$ ) had $\mathrm{C} / \mathrm{Th}$ ratios that were up to an order of magnitude higher than the sinking material (Figure 8). This finding of $\mathrm{C} / \mathrm{Th}>50-200$ in VERTIGO for the largest size class is unusual compared to most ${ }^{234}$ Th studies, but not unique. Savoye et al. (2008) find C/Th ratios up to 1100 during the Southern Ocean KEOPS experiment for a $>330 \mu \mathrm{m}$ fraction at $130 \mathrm{~m}$, and similarly, ratios $>25-100$ for another Southern Ocean transect using the same methods (shown in Fig. 3 in Buesseler et al., 2006).

Live zooplankton are the only source we know for material with a $\mathrm{C} / \mathrm{Th}$ ratio $>100$ below the mixed layer. For example, $\mathrm{C} / \mathrm{Th}$ ratios between 120 and 12,000 were found in fresh zooplankton from the Mediterranean, while ratios in the fecal material from these same zooplankton had $\mathrm{C} / \mathrm{Th}$ ratios one to three orders of magnitude lower (Rodriguez y Baena et al., 2007). This distribution fits with earlier studies of POC and ${ }^{234} \mathrm{Th}$ in swimmers and trap materials (Buesseler et al., 1994; Coale, 1990) and can be explained by a low

surface:volume ratio for zooplankton (enriches POC over ${ }^{234} \mathrm{Th}$ ) and decreases in $\mathrm{C} / \mathrm{Th}$ with POC assimilation by heterotrophic activity and fecal pellet production. 
While most in-situ pumps do not capture zooplankton as efficiently as nets, they can capture some zooplankton with variable efficiency depending upon the hydrodynamics of the pump (determined to first order by flow rate and inlet type). Savoye et al. (2008) inspected their screens under a microscope and found that their $>335 \mu \mathrm{m}$ fraction was largely dominated by zooplankton. These samples also had elevated $\delta^{15} \mathrm{~N}$ and lower C:N ratios (Trull et al., 2008b). Our own particulate $\delta^{15} \mathrm{~N}$ data (T. Trull, unpublished) also show elevated $\delta^{15} \mathrm{~N}$ and lower $\mathrm{C}: \mathrm{N}$ values on the $>350 \mu \mathrm{m}$ screen samples at $\mathrm{K} 2$ indicative of a zooplankton origin.

Why do these two studies differ from others that also used in-situ pumps but found on average much lower $\mathrm{C} / \mathrm{Th}$ ratios for the largest size classes? Savoye et al. (2008) used a sampling hose with a high flow rate (50 $1 \mathrm{~min}^{-1}$; Trull and Armand, 2001), and it is apparently fast enough to catch zooplankton with some efficiency, at least in these Southern Ocean waters. VERTIGO used a $138 \mathrm{~mm}$ effective diameter filter holder on the MULVS system, and pumped at lower flow rates (5-10 $\left.1 \mathrm{~min}^{-1}\right)$. However, the opening for the filter holder was a narrow inlet (1 cm diameter), in contrast to the wide mouth inlet on baffled filter holders (12-13 $\mathrm{cm}$ diameter opening) as supplied on most battery-powered in-situ pumps (McLane or Challenger Oceanics) and used in the majority of ${ }^{234} \mathrm{Th}$ studies. Liu et al. (2008) in a study of bottle vs. pump POC differences showed that the filter head inlet design has a significant impact on the ability of an in-situ pump to capture live zooplankton, because of their natural ability to escape collection as they swim away from flow disturbances. A pump with an inlet design and narrow opening similar to that used in VERTIGO, had up to 10 times higher zooplankton POC than the standard wide baffle openings on the other filter heads tested. While Liu et al. found that in-situ pumps collected less zooplankton POC than bottles, this factor of 10 higher contribution of zooplankton POC could contribute to a higher than average collection efficiency for the VERTIGO screens for zooplankton vs. passively sinking particles. Given orders of magnitude higher $\mathrm{C} / \mathrm{Th}$ in live zooplankton vs. pellets (Rodriguez y Baena et al., 2007), even a small number of swimmers can increase the C/Th ratio of the particulate sample.

Our conclusion for this set of VERTIGO samples is similar to Savoye et al. (2008), in that we do not think that the highest $\mathrm{C} / \mathrm{Th}$ ratios represent sinking material, but rather living zooplankton "swimmers" that are caught by this particular filtration and narrow inlet design. Future studies that employ pumps to collect large particles should avoid such designs, and are also advised to inspect the material collected to confirm a lack of zooplankton swimmers if screens are to be used for $\mathrm{C} / \mathrm{Th}$ ratios. One can potentially remove zooplankton swimmers similar to sediment trap "picking". In addition, VERTIGO data suggest that the mid-sized classes of particulate material, i.e. $>10-20 \mu \mathrm{m}$ but less than the largest cut-off screen, do resemble the sinking particles in terms of $\mathrm{C} / \mathrm{Th}$ ratios (Table 2a). Taken together, these data suggest that some caution is needed in applying the ${ }^{234} \mathrm{Th}$ approach using $\mathrm{C} / \mathrm{Th}$ ratios from filters. The assumption that one can use a priori large size particles defined by filtration as representative of sinking particles, will depend upon multiple factors, including the type of filtration system used to collect these particles.

An alternative or complementary method to determine the flux weighted $\mathrm{C} / \mathrm{Th}$ ratio is to separate particles based upon sinking rate using the IRS trap modified for in-situ settling column experiments (Peterson et al., 2005). Interestingly, when particles were collected and binned into sinking rates ranging from a few $\mathrm{m} \mathrm{d}^{-}$ ${ }^{1}$ to nearly $1000 \mathrm{~m} \mathrm{~d}^{-1}$, there was no clear relationship between sinking rate and C/Th ratio at either ALOHA or $\mathrm{K} 2$ (Table 2b), and individual sinking rate fractions generally had $\mathrm{C} / \mathrm{Th}$ ratios within a factor of 2-3 of the bulk trap values. This lack of a relationship between sinking rate and $\mathrm{C} / \mathrm{Th}$, such as might be expected from simple surface:volume considerations or ballast arguments has been observed before in the Mediterranean (Stewart $e t$ al., 2007). In the Mediterranean, Szlosek et al. (2008) using 3 modified IRS traps found a general decrease in $\mathrm{C} / \mathrm{Th}$ vs. depth for all sinking classes (from 300 to $1900 \mathrm{~m}$ ), and consistently low and relatively invariant ratios vs. settling velocity.

In the application of ${ }^{234} \mathrm{Th}$ as a POC flux proxy, it is arguably easier to determine ${ }^{234} \mathrm{Th}$ activities in the water column than sampling flux directly with traps. Fortunately, if the $\mathrm{C} / \mathrm{Th}$ ratio below the euphotic zone is found to be relatively constant, as seen here, than the higher spatial and depth resolved ${ }^{234} \mathrm{Th}$ activity data can be used to better resolve regional and vertical changes in POC flux. 


\subsection{POC fluxes and comparison to other studies at ALOHA and K2}

The POC flux for all of the VERTIGO ${ }^{234} \mathrm{Th}$ stations can be estimated using the site specific estimate of ${ }^{234} \mathrm{Th}$ flux and a representative $\mathrm{C} / \mathrm{Th}$ ratio for each cruise and depth (Table 1). This is done first using a SS ${ }^{234} \mathrm{Th}$ model, which for ALOHA and K2-D1 we consider reasonable, but by the second deployment at K2, the SS model would overestimate POC fluxes considerably, and hence a NSS model is needed for K2-D2 (see Section 5.1.).

Looking first at ALOHA, POC fluxes at $150 \mathrm{~m}$ range from zero to almost $7 \mathrm{mmol} \mathrm{m} \mathrm{d}^{-1}$, with a mean and standard deviation of $2.1 \pm 2.0 \mathrm{mmol} \mathrm{m}^{-2} \mathrm{~d}^{-1}$ (Table 3). The $150 \mathrm{~m}$ trap fluxes from both deployments recorded a POC flux of $1.4 \pm 0.3 \mathrm{mmol} \mathrm{m} \mathrm{d}^{-1}$ (mean \pm st. dev. for all traps and types; $\mathrm{n}=7$ for ALOHA 150 $\mathrm{m})$. Both estimates differ in part by the nature of what each measures. The traps were deployed for 3 days over two deployments, so over this 6 day period within a 11 day window, they captured sinking material from a small particle source region with scales of $\sim 10-20 \mathrm{~km}$ as depicted in Figure $3 .{ }^{234} \mathrm{Th}$ on the other hand, is an in-situ tracer with a 35 day mean life $(1 / \lambda)$, so its activity reflects scavenging that took place up to several weeks prior to sampling, and in this case assuming no significant flux changes if using a SS model. Therefore it has a larger/wider window both because of its longer mean life and because it was sampled at 19 locations in space/time over the broader ALOHA region (scales $\sim 100-200 \mathrm{~km}$ ). It is not surprising perhaps that the variability in the water column derived ${ }^{234}$ Th fluxes is larger (see Section 5.4.).

The only other ${ }^{234} \mathrm{Th}$ based studies of POC export at ALOHA, were conducted as part of the HOT program (Benitez-Nelson et al., 2001a). Single thorium-234 profiles on the monthly HOT cruises and standard drifting trap fluxes at $150 \mathrm{~m}$ were compared, and an annual average POC flux of $4.0 \mathrm{mmol} \mathrm{m} \mathrm{d}^{-1}$ was determined using ${ }^{234} \mathrm{Th}$ (Table 3). This was higher than trap based POC fluxes during the same period, but if two high flux months in October and December 1999 are ignored (though they are real features in the ${ }^{234} \mathrm{Th}$ data), the annual average is only $2.9 \mathrm{mmol} \mathrm{m}^{-2} \mathrm{~d}^{-1}$, closer to the HOT traps and the average POC flux we observed during VERTIGO. The ${ }^{234} \mathrm{Th}$ derived POC flux compared to measured NPP is similar between the HOT annual average and VERTIGO $\left(\mathrm{ThE}\right.$ ratio $=$ POC flux from ${ }^{234} \mathrm{Th} / \mathrm{NPP}=10-12 \%$; Table 3 ). However, the range in POC flux within this single 3 week VERTIGO study of the ALOHA region (0 to $7 \mathrm{mmol} \mathrm{m}^{-2} \mathrm{~d}^{-1}$; Table 1) is as great as the seasonal variability seen over 9 months by Benitez-Nelson et al. (2001). This points to the difficulty in quantifying seasonal changes in flux when spatial variability in the processes that produce and attenuate flux are large (and currently unpredictable). Also, when the Th: $U$ disequilibrium $\sim 1$, the errors on POC flux derived from the water column ${ }^{234} \mathrm{Th}$ data are large, at least $\pm 40 \%$, especially when the vertical sampling resolution for ${ }^{234} \mathrm{Th}$ is poor, and this may introduce added variability.

At K2, the average $60 \mathrm{~m}$ POC fluxes derived from ${ }^{234} \mathrm{Th}$ decrease from $13.1 \pm 2.8 \mathrm{mmol} \mathrm{m}^{-2} \mathrm{~d}^{-1}$ for D1 (using SS model) to $2.6 \pm 0.4$ for D2 (using NSS model; Table 3). The euphotic zone was approximately $50 \mathrm{~m}$ deep, so the $60 \mathrm{~m}$ POC flux (vs. $150 \mathrm{~m}$ ) should be compared to NPP which decreases from 44 to $30 \mathrm{mmol} \mathrm{m}^{-2}$ $\mathrm{d}^{-1}$ from D1 to D2 (Boyd et al., 2008), and new production (NP), which decreases from 11 to $6 \mathrm{mmol} \mathrm{m}^{-2} \mathrm{~d}^{-1}$ (Elskens et al., 2008). New and export production need not match over short time scales (e.g. Eppley, 1989), and not all export needs to be as sinking POC, however, we find that new and export production are similar during these K2-D1 and a factor of 2 higher during K2-D2 (Table 3). The decrease in ThE ratio at $60 \mathrm{~m}$ from $30 \%$ to $9 \%$ between K2-D1 and K2-D2 tracks a shift in size fractionated NPP, with a lower fraction of NPP associated with the $>20 \mu \mathrm{m}$ algal fraction in D2, consistent with the microscopic observations and pigment data indicating preferential loss of large diatoms from the euphotic zone (Boyd et al., 2008).

POC fluxes generally decrease with depth, and the average extent of POC remineralization can be calculated from the gradient in $\mathrm{C} / \mathrm{Th}$ vs. depth. This ratio decreases by about a factor of two between the euphotic zone and $150 \mathrm{~m}$ in the two trap deployments and the 4 in-situ pump casts where size fractionated particles were collected at $\mathrm{K} 2$ (Figure $8 \mathrm{c}$ and $8 \mathrm{~d}$ ). Using the $>53-350 \mu \mathrm{m}$ particle data for estimating $\mathrm{C} / \mathrm{Th}$ at $60 \mathrm{~m}$, essentially half of the C/Th is lost by $150 \mathrm{~m}$, and POC fluxes decrease from 12.8 to $6.3 \mathrm{mmol} \mathrm{m}^{-2} \mathrm{~d}^{-1}$ in D1 and from 2.6 to $1.5 \mathrm{mmol} \mathrm{m}^{-2} \mathrm{~d}^{-1}$ in D2 between 60 and $150 \mathrm{~m}$. Similar decreases are obtained if the $>20$ $51 \mu \mathrm{m}$ particle $\mathrm{C} / \mathrm{Th}$ ratios are used. It is obvious from this calculation that the depth of integration for POC 
flux is critical when comparing surface export to other properties, such as NPP, since the export ratio will generally decrease with depth (ThE $=14 \%$ vs. $30 \%$ at 150 vs. $60 \mathrm{~m}$ for K2-D1; $5 \%$ vs. $9 \%$ for K2-D2). For this reason, standardization of fluxes to a depth near the base of the euphotic zone (here 50-60 m) is recommended for comparison in export efficiencies between different regions and even between seasonally varying euphotic zone depths at one site (Buesseler and Boyd, 2009).

One other group has used similar ${ }^{234} \mathrm{Th}$ methods at K2 but combined single profiles of ${ }^{234} \mathrm{Th}$ from individual cruises over different years to yield a composite annual estimate of POC flux at $100 \mathrm{~m}$ (Kawakami and Honda, 2007). Their individual estimate of POC flux for August 2004 lie between the D1 and D2 values for 60 and $150 \mathrm{~m}$ (Table 3), and they found a composite annual average POC flux of $7 \mathrm{mmol} \mathrm{m}^{-2} \mathrm{~d}^{-1}$ and a peak in early July of $15 \mathrm{mmol} \mathrm{m}^{-2} \mathrm{~d}^{-1}$. Data from moored traps and a time-series nutrient sampler in 2005 (Figure 4 in Buesseler et al., 2008b), show higher nutrient levels and POC fluxes prior to our arrival at K2 during VERTIGO, consistent with an earlier July peak in the diatom bloom and higher ${ }^{234} \mathrm{Th}$ and POC fluxes as proposed by Kawakami and Honda (2007) and evident in other studies of this region (Honda, 2003). The same can be said about POC flux variability at K2 as with ALOHA, namely the variability in flux within the 100$200 \mathrm{~km}$ study area, is as large as the range in seasonal variability seen in prior studies.

\subsection{Variability in particle flux and attenuation}

While early studies suggested a simple relationship between deep ocean particle flux and NPP (Berger et al., 1988; Pace et al., 1987; Suess, 1980), this has not been born out by more recent studies in the upper ocean, such as at ALOHA, where the time-series sediment trap fluxes and NPP show no correlation (Karl and Lukas, 1996). Certainly the build up of phytoplankton biomass does not necessarily lead to a fixed ratio of POC export, because of differences in the community structure of primary producers and heterotrophic community and local changes in physical and geochemical properties. This lack of correspondence between export flux and NPP may also be caused by spatial variability in export that operates on smaller spatial scales than that for phytoplankton pigment concentrations or NPP. Evidence of this can be found in the literature (e.g., Mackas and Boyd, 1979; Abraham, 1998) assuming that ${ }^{234} \mathrm{Th}$ scavenging and particle export flux varies on the same spatial scales as zooplankton abundance in the euphotic zone. This is conceivable as zooplankton create export through their production of fecal pellets and as the packagers of marine snow (e.g., Alldredge and Silver, 1988). Observations and numerical experiments generally show power spectra for phytoplankton abundance that have redder (steeper) wavenumber spectra than do zooplankton distributions (e.g., Mackas and Boyd, 1979; Tsuda et al., 1993; Abraham, 1998 - though counter examples have been discussed by Martin and Srokosz, 2002). This means that more of the variance in phytoplankton concentrations is contained on larger scales than for zooplankton abundances and presumably for export and ${ }^{234} \mathrm{Th}$ flux. Hence a decoupling between particle formation processes (particle abundance and NPP) and export (here using zooplankton as an index) is expected.

At ALOHA, there was only NPP data at the central trap locations, so one cannot compare the regional variability in ${ }^{234} \mathrm{Th}$ flux to NPP at all sites, but it is possible to compare the ${ }^{234} \mathrm{Th}$ fluxes to average concentrations in the mixed layer of chl-a, HPLC pigments and other hydrographic properties and optical sensor data from the CTD (transmissivity, turbidity). Similar to the time-series data at ALOHA, there is no simple correlation between these properties and ${ }^{234} \mathrm{Th}$ fluxes (or ${ }^{234} \mathrm{Th}$ activities), and it can be concluded that the processes that determine export in this low flux setting are more complicated than for example the level of biomass or particle abundances. In addition, uncertainties in the flux model, especially when ${ }^{234} \mathrm{Th}$ is close to secular equilibrium, and the different time and space scales represented in the ${ }^{234} \mathrm{Th}$ data and other properties will confound these relationships (see below for K2 nutrients and ${ }^{234} \mathrm{Th}$ ).

In other settings, positive correlations have been noted between biomass, specifically diatom abundances, and total ${ }^{234}$ Th flux (Arabian Sea- Ducklow et al., 2001; Baffin Bay- Amiel et al., 2002). Similarly, the drawdown of macronutrients and total ${ }^{234} \mathrm{Th}$ have been shown to co-vary, such as at the start of a diatom bloom in the North Atlantic (Buesseler et al., 1992). At K2, we sampled several weeks after the peak in diatom abundances and flux and found no correlation between the ${ }^{234} \mathrm{Th}$ flux below the euphotic zone $(60 \mathrm{~m})$ and the average mixed layer concentrations of diatom pigments (Figure 9a) or nutrients when compared on a station by station 
basis (Figure 9b). We also looked at other pigments, CTD properties, transmissivity and turbidity and found no correlation with these properties and the observed ${ }^{234} \mathrm{Th}$ flux variability at each station (data not shown).

There are a number of confounding issues when one seeks a relationship between properties that integrate over different time scales, have different sources and sinks, and when compared during different stages of a bloom. Consider phytoplankton biomass (i.e. pigments), nutrients and ${ }^{234} \mathrm{Th}$ activities. Phytoplankton growth at K2, in particular diatoms, results in a seasonal decrease in macronutrients and an increase in silica-rich particle flux. However during VERTIGO, stations with the lowest surface dSi, indicating higher diatom uptake, have the lowest diatom marker pigment levels (Figure 10). This is interpreted as reflecting a late bloom condition, when locations that have seen higher diatom growth and export in the past, now show the lowest residual fucoxanthin signal (shown also in Buesseler et al., 2008b Figure 10, as an inverse relationship between DIN:dSi ratios and fucoxanthin pigments).

During VERTIGO, the entire K2 study area can thus be characterized by decreasing macronutrients, a reduction in the abundance of large diatoms and a declining export flux; however, each station or water parcel may reflect a slightly different state in the seasonal progression of that bloom. Thus the nutrient levels within the euphotic zone can vary considerably between stations depending upon the history of export from each depth and station, however the relationship between DIN and dSi drawdown remains more constant (Figure 11). While average diatom uptake ratios for dSi:DIN are closer to 1:1 (Brzezinski, 1985; Sarthou et al., 2005), ratios higher than this such as seen here $(\mathrm{dSi}: \mathrm{DIN}=3.6 \mathrm{~mol}: \mathrm{mol})$ are characteristic of more heavily silicified diatoms, particularly in iron stressed systems (Hutchins and Bruland, 1998). Sub-optimal values of Fv/Fm found throughout the $\mathrm{K} 2$ region during VERTIGO are consistent with iron stress (Boyd et al., 2008), and iron depletion may limit macronutrient uptake and trigger the end of production by large diatoms that leads to enhanced export.

Why then is total ${ }^{234} \mathrm{Th}$ not more closely correlated to DIN and dSi if both are removed on sinking particles? One can explain this variability by considering the difference between their removal rates and resupply terms. In Figure 12, bottle ${ }^{234} \mathrm{Th}$, DIN and dSi data for the euphotic zone are shown to illustrate a range of possible removal and resupply scenarios. A potential density of 26.4 (depth approximately $55 \mathrm{~m}$ ) is used for the base of the euphotic zone and the concentrations at that depth as the end member is used here for the seasonal drawdown of both nutrients and ${ }^{234} \mathrm{Th}$ (Figure 12a and $12 \mathrm{~b}$ - white square at ${ }^{234} \mathrm{Th}=2.07 \pm 0.08 \mathrm{dpm} \mathrm{l}^{-}$ ${ }^{1}$; DIN $\left.=25.3 \pm 1.8 \mu \mathrm{mol} \mathrm{l}^{-1} ; \mathrm{dSi}=49 \pm 5 \mu \mathrm{mol} \mathrm{l}^{-1}\right)$. A concentration lower than this end member, indicates nutrient removal at a ratio relative to ${ }^{234} \mathrm{Th}$ that varies between the bounds of the data- in the case of DIN, at drawdown ratios of 4 to $30\left(\mu \mathrm{mol} \mathrm{dpm}{ }^{-1}\right.$; Figure $12 \mathrm{a}$. From a budget of mixed layer nutrients and ${ }^{234} \mathrm{Th}$ fluxes,

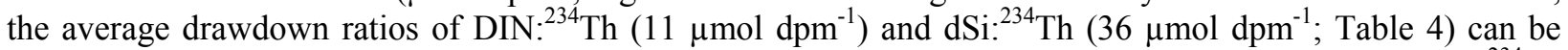
calculated, and these lie in the middle of the data ranges for DIN and $\mathrm{dSi}$ in Figure $12 \mathrm{a}$ and $12 \mathrm{~b}\left(\mathrm{dSi}{ }^{234} \mathrm{Th}\right.$ bounds are drawn based upon the DIN range and a DIN:dSi ratio of 3.2 ; Table 4).

Shallow data in general (data are color coded vs. depth) show higher rates of nutrient drawdown, presumably due to higher light levels and rates of NPP, but there is considerable variability with depth when all of the data are compared. Also note that ${ }^{234} \mathrm{Th}$ activities are variable, for example at the lower nutrient concentrations ${ }^{234} \mathrm{Th}$ activities range from 1 to $1.5 \mathrm{dpm} \mathrm{l}^{-1}$ at DIN $\sim 12 \mu \mathrm{mol}{ }^{-1}$ (Figure 12a) and dSi $\sim 10 \mu \mathrm{mol}$ $1^{-1}$ (Figure $12 \mathrm{~b}$ ). There are two ways to end up with such a variable nutrient ${ }^{234} \mathrm{Th}$ ratio. Either uptake rates have to change over time/depth or re-supply terms differ. On seasonal timescales, winter mixing essentially will reset all concentrations back to our end member concentrations. On shorter time scales, one needs to consider ${ }^{234} \mathrm{Th}$ ingrowth and remineralization within the euphotic layer as causes for this variability. Looking first at ingrowth of ${ }^{234} \mathrm{Th}$ from ${ }^{238} \mathrm{U}$, if DIN and ${ }^{234} \mathrm{Th}$ were removed from surface waters at a constant ratio of 11 and the flux ceased, surface water DIN would remain constant and low, yet ${ }^{234} \mathrm{Th}$ would increase. For example, with a DIN $=12 \mu \mathrm{mol} \mathrm{l}^{-1}$, a ${ }^{234} \mathrm{Th}$ activity of $1.0 \mathrm{dpm} \mathrm{l}^{-1}$ would increase by $0.44 \mathrm{dpm} \mathrm{l^{-1 }}$ to $1.44 \mathrm{dpm}$ $\mathrm{I}^{-1}$ after a 2 week period with no additional flux (horizontal black arrow in Figure $12 \mathrm{a}$ starting at ${ }^{234} \mathrm{Th}=1.0$ $\mathrm{dpm} \mathrm{l}^{-1}$ ). Since this term varies with the Th: $\mathrm{U}$ ratio (faster relative ingrowth for lower ${ }^{234} \mathrm{Th}^{238} \mathrm{U}$ ratios), a similar 2 week period of no flux will increase a ${ }^{234} \mathrm{Th}$ activity of $1.5 \mathrm{dpm} \mathrm{l}^{-1}$, by only $0.28 \mathrm{dpm}{ }^{-1}$, to $1.78 \mathrm{dpm}$ $1^{-1}$ (horizontal black arrow in Figure 12a starting at ${ }^{234} \mathrm{Th}=1.5 \mathrm{dpm}^{-1}$ ). With a decrease in flux, the direction 
for change would not be horizontal, but somewhere between the initial flux ratio and the no flux rate of change (see red arrows in Figure 12a). Similarly, nutrient ${ }^{234} \mathrm{Th}$ ratios can change vs. depth if nutrients are remineralized faster on sinking particles and the observation that in general, the deeper observations lie above the average drawdown curve, supports that concept.

The point of this exercise was to see if we could explain the variable nutrient ${ }^{234} \mathrm{Th}$ ratios in the water column with a common removal process. The ratios we found set at least some bounds on the maximum/minimum drawdown ratios, but are also consistent with a single average surface drawdown ratio of $11 \mathrm{DIN}:{ }^{234} \mathrm{Th}$ and $36 \mu \mathrm{mol} \mathrm{dpm}{ }^{-1} \mathrm{dSi}^{234} \mathrm{Th}$, followed by ingrowth at all depths and preferential remineralization of DIN and $\mathrm{dSi}$ relative to ${ }^{234} \mathrm{Th}$ on sinking particles. Ingrowth must be occurring, and the rate of ${ }^{234} \mathrm{Th}$ increase will be greatest for sites/depths with the lowest ${ }^{234} \mathrm{Th}$ activities due to the balance between production and decay terms for ${ }^{234} \mathrm{Th}$. Preferential remineralization of nutrients is also likely, as from traps between 150 and $500 \mathrm{~m}$ one finds that the relative flux attenuation order is DIN $>\mathrm{dSi}>{ }^{234} \mathrm{Th}$ (Lamborg et al., 2008b). Also, DIN: ${ }^{.234}$ Th flux ratios decrease from 11 in the water column budgets, to $0.5 \mu \mathrm{mol} \mathrm{dpm}^{-1}$ in the $150 \mathrm{~m}$ sediment traps, and for $\mathrm{dSi}^{234} \mathrm{Th}$, from 36 to $7 \mu \mathrm{mol} \mathrm{dpm}^{-1}$ (Table 4) indicating a greater extent of $\mathrm{N}$ remineralization. Incubation experiments with ${ }^{15} \mathrm{~N}$ suggest up to $95 \% \mathrm{PON}$ remineralization in the upper 150 $\mathrm{m}$ at K2 (Elskens et al., 2008) with most of this taking place just above the depth of the DCM.

\subsection{Flux variability vs. depth at $\mathrm{K} 2$}

While earlier studies have detected ${ }^{234} \mathrm{Th}$ excess at depth and interpreted this signal as remineralization (Bacon et al., 1996; Morris et al., 2007; Savoye et al., 2004; Usbeck et al., 2000), the feature is often confined to single depths and few profiles in any given study. The application of small volume ${ }^{234} \mathrm{Th}$ methods is allowing us to capture what might be a more common feature that indicates an extensive remineralization layer immediately below the DCM (Buesseler et al., 2008a). It is interesting to speculate though why this feature is seen in some, but not all of the K2 stations, and how this is reflected in the greater variability in our deeper predicted ${ }^{234} \mathrm{Th}$ fluxes. As noted previously, at $\mathrm{K} 2$ the range in ${ }^{234} \mathrm{Th}$ fluxes is higher at $150 \mathrm{~m}$ (st. dev. $\pm 35 \%$ ) than immediately below the euphotic zone at $60 \mathrm{~m}$ (st. dev. $\pm 20 \%$; Table 1). At some stations, the ${ }^{234}$ Th flux below $60 \mathrm{~m}$ continues to increase (Th:U $\left.<1\right)$, while at others, there is excess ${ }^{234} \mathrm{Th}$ (Th:U >1), indicating net particle remineralization, resulting in lower fluxes below that depth. There is up to $60 \%$ less flux at $150 \mathrm{~m}$ vs. $60 \mathrm{~m}$, or as much as a $40 \%$ increase (calculated from data in Table 1; (flux $150 \mathrm{~m}$ flux $60 \mathrm{~m}) /($ flux $60 \mathrm{~m})$ ). When this flux ratio is compared to the other station to station properties, there is a weak, but potentially intriguing relationship with diatom pigments $\left(\mathrm{R}^{2}=0.43\right.$ or 0.67 if station 52 is excluded; Figure 13). The 3 stations with the higher rates of remineralization (stations 10,18, 54), were sites where there is less evidence of diatom activity (from pigments and higher average surface $\mathrm{dSi}=25 \mu \mathrm{mol} \mathrm{l}^{-1}$ vs. $10.5 \mu \mathrm{mol}$ $1^{-1}$ for other stations- dSi data not shown). In contrast, the stations with increasing ${ }^{234} \mathrm{Th}$ flux vs. depth are sites where there had been a higher rate of diatom growth and export (evidenced by lower fucoxanthin and $\mathrm{dSi}$ ), with the exception of station 52 .

It is curious why those sites where there had been higher diatom growth, experience less net particle remineralization below the DCM. If real, the cause for this relationship could be related to either the properties of the Si rich particles (higher sinking rates, organic matter preservation, etc.) or changes in the

heterotrophic response in the upper twilight zone. A similar decrease in ${ }^{234}$ Th excess below a DCM was seen after the stimulation of a diatom bloom by iron in a Southern Ocean iron experiment (SOFeX; Buesseler et al., 2005). More work is needed, but these higher ${ }^{234} \mathrm{Th}$ resolution data allow us to see these rather interesting shifts in shallow remineralization that would be difficult to catch in traps or by other methods.

\section{CONCLUSIONS}

To first order, comparisons of even a single profile of ${ }^{234} \mathrm{Th}$ from K2 and ALOHA would define rather different particle flux conditions, with higher fluxes in the mesotrophic HNLC waters of the NW Pacific, and lower fluxes in the oligotrophic waters off Hawaii. However the higher resolution ${ }^{234} \mathrm{Th}$ data vs. time, space and depth have opened a wider window to examine flux variability for the two sites. Increasingly, high resolution ${ }^{234} \mathrm{Th}$ data sets in coastal settings (Cai et al., 2008; Giuliani et al., 2007), across mesoscale eddies 
(Buesseler et al., 2008a; Maiti et al., 2008) and here in the North Pacific suggest that the spatial scales of export are more variable than the concentration of phytoplankton or NPP. Such variability on small spatial scales make it difficult to "calibrate" upper ocean sediment traps using ${ }^{234}$ Th better than a factor of about two, as the traps collect particles from a source region that varies with sinking rate and captures only part of this spatially variable flux field. At K2, we also had to consider the decreasing particle fluxes and their impact on the ${ }^{234} \mathrm{Th}$ activity balance. Changes to stocks are much slower than changes to fluxes, whether for nutrients, $\mathrm{C}$ or ${ }^{234} \mathrm{Th}$. In the application of ${ }^{234} \mathrm{Th}$, a NSS model was needed to match the decreasing flux rates during K2D2.

In the application of ${ }^{234} \mathrm{Th}$ to POC and other fluxes, the ratio of Th to POC on sinking particles is critical. These data demonstrate that variability in the ${ }^{234} \mathrm{Th}$ flux is greater than that found for $\mathrm{C} / \mathrm{Th}$ on filtered or trapped particles, at least at depths below the euphotic zone. The $\mathrm{C} / \mathrm{Th}$ ratio of sinking particles was similar to larger filtered particles caught on screens, with the exception that on some in-situ filtration systems, the first screen can be "contaminated" by zooplankton swimmers, resulting in a ratio much higher $\mathrm{C} / \mathrm{Th}$ ratio than is characteristic of sinking particles. The average POC flux predicted from the VERTIGO ${ }^{234} \mathrm{Th}$ data matches prior estimates, although the range in POC flux spatially at ALOHA and K2 was as large as that found in prior studies for the entire annual cycle. Some of this variability at K2 is caused by variability in subsurface remineralization, as the flux between 60 and $150 \mathrm{~m}$ can increase by as much as $44 \%$ or decrease by $>60 \%$ depending upon the extent of ${ }^{234} \mathrm{Th}$ remineralization, as seen here by excess ${ }^{234} \mathrm{Th}$ in a rather narrow depth layer immediately below the DCM. We suggest that the control on the extent of remineralization may be driven by diatom export, with sites of higher diatom fluxes associated with lower remineralization. Overall, the higher vertical resolution ${ }^{234} \mathrm{Th}$ data used here allows us to explore these relationships and suggest targeted sampling of these layers in future programs.

At $\mathrm{K} 2$, some of the variability in particle flux could be attributed to capturing different states of a declining diatom bloom, with waters that had seen the most diatom production and dSi uptake having the lowest remaining diatom pigments (e.g. fucoxanthin). The relationship between diatom export, nutrient drawdown and ${ }^{234} \mathrm{Th}$ removal is confounded however by their different sources and sinks. We show how one can expect a wide range of nutrient: ${ }^{234} \mathrm{Th}$ ratios in the euphotic zone of $\mathrm{K} 2$, even if exported at a single removal ratio due to the impact of ${ }^{234} \mathrm{Th}$ resupply via its ingrowth from ${ }^{238} \mathrm{U}$, and the more rapid remineralization of DIN and dSi than ${ }^{234} \mathrm{Th}$.

Overall, this VERTIGO ${ }^{234}$ Th data set allows us to better characterize the local particle flux fields at two sites in the North Pacific and provides a robust set of constraints on POC flux and remineralization in the euphotic zone and waters immediately below. Regional variability in particle flux within each study area seen with ${ }^{234} \mathrm{Th}$ is greater than can be measured in a single trap deployment and the changes vs. depth are sharper than caught with trap profiles as well. This higher resolution view is one of the advantages of using ${ }^{234} \mathrm{Th}$ as a tracer of upper ocean export and remineralization. However this added resolution also points to complicating issues related to the differences in response times, sources and sinks of ${ }^{234} \mathrm{Th}$ and POC and the ecological processes that drive flux changes. We contend that this added resolution with more extensive ${ }^{234} \mathrm{Th}$ data will help to improve our understanding of the ecological and physical processes that control the biological pump. 


\section{ACKNOWLEDGEMENTS}

We thank the officers, crew and shore based support teams for the R/V Kilo Moana (2004) and R/V Roger Revelle (2005). We also thank our many VERTIGO collaborators, in particular S. Manganini and S. Bray for on-deck leadership in many successful sediment trap deployments, J. Valdes for NBST design and engineering, J. Andrews and C. Bertrand for NBST and Clap trap analytical programs, J. Bishop for collection of size-fractionated particle samples, E. Fields and J. Hummon for assistance in estimating particle source funnels, R. Bidigare for HPLC pigments, and the W.H.O.I. Plasma Mass Spectrometry Facility and W.H.O.I. Nutrient Analytical Facility. Constructive comments by three anonymous reviewers and S. Owens are greatly appreciated. Funding for VERTIGO in the US was provided primarily by research grants from the US National Science Foundation Programs in Chemical and Biological Oceanography with additional support by the US Department of Energy (DAS). For TWT, support came from the Australian Cooperative Research Centres program. 
REFERENCES

Abraham, E. R. (1998). The generation of plankton patchiness by turbulent stirring. Nature 391, 577-580.

Agassiz, A., 1888. Three cruises of the United States Coast and Geodetic Survey steamer Blake in the Gulf of Mexico, in the Caribbean Sea, and along the Atlantic coast of the United States from 1877 to 1880. Bull. Museum Comparative Zoology Harvard 1 (14), 1-314.

Alldredge, A.L., Silver, M.W. 1988. Characteristics, dynamics and significance of marine snow. Progress in Oceanography 20, 41- 82.

Amiel, D., Cochran, J.K., Hirschberg, D.J., 2002. ${ }^{234} \mathrm{Th} /{ }^{238} \mathrm{U}$ disequilibrium as an indicator of the seasonal export flux of particulate organic carbon in the North Water. Deep-Sea Research II 49, 5191-5209.

Bacon, M.P., Cochran, J.K., Hirschberg, D., Hammar, T.R., Fleer, A.P., 1996. Export flux of carbon at the equator during the EqPac time-series cruises estimated from ${ }^{234} \mathrm{Th}$ measurements. Deep-Sea Research II 43, 1133-1154.

Bacon, M.P., Huh, C.A., Fleer, A.P., Deuser, W.G., 1985. Seasonality in the flux of natural radionuclides and plutonium in the deep Sargasso Sea. Deep-Sea Research 32, 273-286.

Benitez-Nelson, C., Buesseler, K.O., Karl, D., Andrews, J., 2001a. A time-series study of particular matter export in the North Pacific Subtropical Gyre based upon ${ }^{234} \mathrm{Th}:{ }^{238} \mathrm{U}$ disequilibrium. Deep-Sea Research I 48(12), 2595-2611.

Benitez-Nelson, C., Buesseler, K.O., Rutgers van der Loeff, M., Andrews, J., Ball, L., Crossin, G., Charette, M., 2001b. Testing a new small-volume technique for determining thorium-234 in seawater. Journal of Radioanalytical and Nuclear Chemistry 248(3), 795-799.

Berger, W.H., Fischer, K., Lai, C., Wu, G., 1988. Ocean carbon flux: global maps of primary production and export production. In: Agegian, C.R. (Ed.), Biogeochemical cycling and fluxes between the deep euphotic zone and other oceanic realms, pp. 131-176.

Bhat, S.G., Krishnaswamy, S.K., Lal, D., Rama, D., Moore, W.S., 1969. ${ }^{234} \mathrm{Th} /{ }^{238} \mathrm{U}$ ratios in the ocean. Earth and Planetary Science Letters 5, 483-491.

Bishop, J., 1989. Regional extremes in particulate matter composition and flux: Effects on the chemistry of the ocean interior. In: Berger, W.H., Smetacek, V.S., Wefer, G. (Eds.), Productivity of the Ocean: Present and Past. John Wiley and Sons, New York, pp. 117- 138.

Bishop, J.K.B., Wood, T.J., 2008. Particulate matter chemistry and dynamics in the twilight zone at VERTIGO ALOHA and K2 sites. Deep Sea Research Part I: Oceanographic Research Papers 55 (12), 1684-1706.

Boyd, P.W., Gall, M.P., Silver, M.W., J.L.K.B., B., 2008. Quantifying the surface-subsurface biogeochemical coupling during the VERTIGO ALOHA and K2 studies. Deep-Sea Research II 55 (14-15), 15771593.

Brzezinski, M.A., 1985. The Si:C:N ratio of marine diatoms: Interspecific variability and the effect of some environmental variables. Journal of Phycology 21 (3), 347-357.

Buesseler, K., Michaels, A.F., Siegel, D.A., Knap, A.H., 1994. A three dimensional time-dependent approach to calibrating sediment trap fluxes. Global Biogeochemical Cycles 8 (2), 179-193.

Buesseler, K.O., 1991. Do upper-ocean sediment traps provide an accurate record of particle flux? Nature 353, 420-423.

Buesseler, K.O., Andrews, J.E., Pike, S., Charette, M.A., Goldson, L.E., Brzezinski, M.A., Lance, V.P., 2005. Particle export during the Southern Ocean Iron Experiment (SOFeX). Limnology and Oceanography 50, 311-327.

Buesseler, K.O., Antia, A.N., Chen, M., Fowler, S.W., Gardner, W.D., Gustafsson, O., Harada, K., Michaels, A.F., Rutgers van der Loeff, M., Sarin, M., Steinberg, D.K., Trull, T.W., 2007a. An assessment of the use of sediment traps for estimating upper ocean particle fluxes. Journal of Marine Research 65 (3), 345-416.

Buesseler, K.O., Bacon, M.P., Cochran, J.K., Livingston, H.D., 1992. Carbon and nitrogen export during the JGOFS North Atlantic Bloom Experiment estimated from ${ }^{234} \mathrm{Th}:{ }^{238} \mathrm{U}$ disequilibria. Deep-Sea Research 39 (7-8), 1115-1137.

Buesseler, K.O., Ball, L., Andrews, J., Benitez-Nelson, C., Belastock, R., Chai, F., Chao, Y., 1998. Upper ocean export of particulate organic carbon in the Arabian Sea derived from thorium-234. Deep-Sea Research II 45(10-11), 2461-2487.

Buesseler, K.O., Benitez-Nelson, C.R., Moran, S.B., Burd, A., Charette, M., Cochran, J.K., Coppola, L., Fisher, N.S., Fowler, S.W., Gardner, W.D., Guo, L.D., Gustafsson, O., Lamborg, C., Masque, P., Miquel, J.C., Passow, U., Santschi, P.H., Savoye, N., Stewart, G., Trull, T., 2006. An assessment of particulate organic carbon to thorium-234 ratios in the ocean and their impact on the application of 234Th as a POC flux proxy. Marine Chemistry 100, 213-233. 
Buesseler, K.O., Boyd, P.W., 2009. Shedding light on processes that control particle export and flux attenuation in the twilight zone. Limnology and Oceanography in press.

Buesseler, K.O., Lamborg, C., Cai, P., Escoube, R., Johnson, R., Pike, S., Masque, P., McGillicuddy, D., Verdeny, E., 2008a. Particle fluxes associated with mesoscale eddies in the Sargasso Sea. Deep-Sea Research II 55, 1426-1444.

Buesseler, K.O., Lamborg, C.H., Boyd, P.W., Lam, P.J., Trull, T.W., Bidigare, R.R., Bishop, J.K.B., Casciotti, K.L., Dehairs, F., Elskens, M., Honda, M., Karl, D.M., Siegel, D.A., Silver, M.W., Steinberg, D.K., Valdes, J., Van Mooy, B., Wilson, S., 2007b. Revisiting carbon flux through the ocean's twilight zone. Science 316, 567-570.

Buesseler, K.O., Steinberg, D.K., Michaels, A.F., Johnson, R.J., Andrews, J.E., Valdes, J.R., Price, J.F., 2000. A comparison of the quantity and quality of material caught in a neutrally buoyant versus surfacetethered sediment trap. Deep-Sea Research I 47, 277-294.

Buesseler, K.O., Trull, T.W., Steinberg, D.K., Silver, M.W., Siegel, D.A., Saitoh, S.-I., Lamborg, C.H., Lam, P.J., Karl, D.M., Jiao, N.Z., Honda, M.C., Elskens, M., Dehairs, F., Brown, S.L., Boyd, P.W., Bishop, J.K.B., Bidigare, R.R., 2008b. VERTIGO (VERtical Transport In the Global Ocean): a study of particle sources and flux attenuation in the North Pacific. Deep-Sea Research II 55 (14-15), 15221539.

Burd, A.B., Moran, S.B., Jackson, G.A., 2000. A coupled adsorption-aggregation model of the POC/ ${ }^{234}$ Th ratio of marine particles. Deep-Sea Research I 47, 103-120.

Cai, P., Chen, W., Dai, M., Wan, Z., Wang, D., Li, Q., Tang, T., Lv, D., 2008. A high-resolution study of particle export in the southern South China Sea based on 234Th:238U disequilibrium. J. Geophys. Res. 113 (C04019).

Casciotti, K.L., Glover, D., Trull, T., Davies, D., 2008. Constraints on Nitrogen Cycling at the Subtropical North Pacific Station ALOHA from Isotopic Measurements of Nitrate and Particulate Nitrogen. DeepSea Research II 55 (14-15) 1661-1672.

Charette, M.A., Moran, S.B., Bishop, J.K.B., 1999. ${ }^{234}$ Th as a tracer of particulate organic carbon export in the subarctic Northeast Pacific Ocean. Deep-Sea Research II 46(11-12), 2833-2861.

Chen, J.H., Edwards, R.L., Wasserburg, G.J., $1986 .{ }^{238} \mathrm{U},{ }^{234} \mathrm{U}$ and ${ }^{232} \mathrm{Th}$ in seawater. Earth and Planetary Science Letters 80, 241-251.

Coale, K.H., 1990. Labyrinth of doom: A device to minimize the "swimmer" component in sediment trap collections. Limnology and Oceanography 35(6), 1376-1381.

Coale, K.H., Bruland, K.W., 1985. ${ }^{234}$ Th: ${ }^{238} \mathrm{U}$ disequilibria within the California Current. Limnology and Oceanography 30 (1), 22-33.

Cochran, J.K., Buesseler, K., Bacon, M.P., Wang, H.W., Hirschberg, D.J., Ball, L., Andrews, J., Crossin, G., Fleer, A., 2000. Short-lived thorium isotopes (234Th, 228Th) as indicators of POC export and particle cycling in the Ross Sea, Southern Ocean. . Deep-Sea Research II 47 (15-16), 3451-3490.

Cochran, J.K., Miquel, J.C., Armstrong, R., Fowler, S.W., Masque, P., Gasser, B., Hirschberg, D., Szlosek, J., Rodriguez y Baena, A., Verdeny, E., Stewart, G., 2008. Time-series measurements of 234Th in water column and sediment trap samples from the northwestern Mediterranean Sea. Deep sea Research II submitted.

Coppola, L., Roy-Barman, M., Wassmann, P., Mulsow, S., Jeandel, C., 2002. Calibration of sediment traps and particulate organic carbon export using ${ }^{234} \mathrm{Th}$ in the Barents Sea. Marine Chemistry 80, 11-26.

Dehairs, F., Jacquet, S., Savoye, N., Van Mooy, B.A.S., Buesseler, K., Bishop, J.K., Lamborg, C., Elskens, M., Baeyens, W., Boyd, P., Casciotti, K.L., Monnin, C., 2008. Barium in Twilight Zone suspended matter as a proxy for particulate organic carbon remineralization: Results for the North Pacific. Deep-Sea Research II 55 (14-15), 1673-1683.

Ducklow, H.W., Steinberg, D.K., Buesseler, K.O., 2001. Upper ocean carbon export and the biological pump. Oceanography 14 (4), 50-58.

Dunne, J.P., Murray, J.W., 1999. Sensitivity of ${ }^{234}$ Th export to physical processes in the central equatorial Pacific. Deep-Sea Research I 46, 831-854.

Elskens, M., Baeyens, W., Boyd, P., Buesseler, K., Dehairs, F., Savoye, N., Van Mooy, B., 2008. Primary, new and export production in the NW Pacific Subarctic Gyre during the VERTIGO K2 experiments. Deep-Sea Research II 55 (14-15), 1594-1604.

Eppley, R.W., 1989. New Production: History, Methods, Problems. In: Berger, W.H., Smetacek, V.S., Wefer, G. (Eds.), Productivity of the Ocean: Present and Past. Wiley, New York, pp. 85-97.

Gardner, W.D., Richardson, M.J., Carlson, C.A., Hansell, D.A., Mishonov, A.V., 2003. Determining true particulate organic carbon: bottles, pumps and methodologies. Deep sea Research II 50 (3-4), 655692. 
Goldberg, E.D., 1954. Marine Chemistry 1. Chemical scavengers of the sea. Journal of Geology 62, 249-265.

Gustafsson, Ö., Andersson, P., Roos, P., Kukulska, Z., Broman, D., Larsson, U., Hajdu, S., Ingri, J., 2004. Evaluation of the collection efficiency of upper ocean sub-photic-layer sediment traps: A 24-month in situ calibration in the open Baltic Sea using ${ }^{234} \mathrm{Th}$. Limnology and Oceanography: Methods 2, 62-74.

Honda, M.C., 2003. Biological pump in the Northwestern North Pacific. Journal of Oceanography 59, 671684.

Honda, M.C., Watanabe, S., 2007. Utility of an automatic water sampler to observe seasonal variability in nutrients and DIC in the Northwestern North Pacific. Journal of Oceanography 63, 349-362.

Hung, C.-C., Guo, L.D., Roberts, K.A., Santschi, P.H., 2004. Upper ocean carbon flux determined by sizefractionated 234Th data and sediment traps in the Gulf of Mexico. Geochemical Journal 38 (6), 601611.

Hutchins, D.A., Bruland, K.W., 1998. Iron-limited diatom growth and Si:N uptake ratios in a coastal upwelling regime. Nature 393, 561-564.

Giuliani, S., Radakovitch, O., Frignani, M., Bellucci, L.G., 2007. Short time scale variations of 234Th/238U disequilibrium related to mesoscale variability on the continental slope of the Gulf of Lions (France). Marine Chemistry 106 (3-4), 403-418.

GOFS, U.S., 1989. U.S. Global Ocean Flux Study - Sediment Trap Technology and Sampling, Report of the U.S. GOFS Working Group on Sediment Trap Tehcnology and Sampling. U.S. GOFS Planning Report No. 10.

Karl, D.M., Lukas, R., 1996. The Hawaii Ocean Time-series (HOT) Program: Background, rationale and field implementation. Deep-Sea Research II 43 (2-3), 129-156.

Kawakami, H., Honda, M.C., 2007. Time-series observation of POC fluxes estimated from 234Th in the northwestern North Pacific. Deep-Sea Research Part I 54 (7), 1070-1090.

Knauer, G.A., Martin, J.H., Bruland, K.W., 1979. Fluxes of particulate carbon, nitrogen, and phosphorous in the upper water column of the northeast Pacific. Deep-Sea Research A 26, 97-108.

Kobari, T., Steinberg, D.K., Ueda, A., Tsuda, A., Silver, M.W., Kitamura, M., 2008. Impacts of ontogenetically migrating copepods on downward carbon flux in the western subarctic Pacific Ocean. Deep-Sea Research II 55 (14-15), 1648-1660.

Lam, P.J., Bishop, J.K.B., 2008. The continental margin is a key source of iron to the HNLC North Pacific Ocean. Geophysical Research Letters (35), L07608, doi:07610.01029/02008GL033294.

Lamborg, C.H., Buesseler, K.O., Lam, P.J., 2008a. Sinking fluxes of minor and trace elements in the North Pacific Ocean measured during the VERTIGO program. Deep-Sea Research II 55 (14-15), 1564-1577.

Lamborg, C.H., Buesseler, K.O., Valdes, J., Bertrand, C.H., Bidigare, R., Manganini, S., Pike, S., Steinberg, D., Trull, T., Wilson, S., 2008b. The Flux of Bio- and Lithogenic Material Associated with Sinking Particles in the Mesopelagic "Twilight Zone" of the Northwest and North Central Pacific Ocean. Deep-Sea Research II 55 (14-15), 1540-1563.

Lampitt, R.S., Boorman, B., Brown, L., Lucas, M., Salter, I., Sanders, R., Saw, K., Seeyave, S., Thomalla, S.J., Turnewitsch, R., 2008. Particle export from the euphotic zone: Estimates using a novel drifting sediment trap, 234Th and new production. Deep-Sea Research Part I 55, 1484-1502.

Liu, H., Suzuki, K., Saito, H., 2004. Community Structure and Dynamics of Phytoplankton in the Western Subarctic Pacific Ocean: A Synthesis Journal of Oceanography 60 (1), 119-137.

Liu, Z., Cochran, J.K., Lee, C., Gasser, B., Miquel, J.C., Wakeham, S.G., 2008. Further investigations on why POC concentrations differ in samples collected by Niskin bottle and in-situ pumps. Deep sea Research II submitted.

Liu, Z., Stewart, G., Cochran, J.K., Lee, C., Armstrong, R.A., Hirschberg, D.J., Gasser, B., Miquel, J.-C., 2005. Why do POC concentrations measured using Niskin bottle collections sometimes differ from those using in-situ pumps? . Deep-Sea Research I 52, 1324-1344.

Mackas, D.L., Boyd, C.M. 1979. Spectral analysis of zooplankton spatial heterogeneity. Science 204, 62-64.

Maiti, K., Benitez-Nelson, C.R., Rii, Y., Bidigare, R., 2008. The influence of a mature cyclonic eddy on particle export in the lee of Hawaii. Deep Sea Research Part II: Topical Studies in Oceanography 55 (10-13), 1445-1460.

Martin A.P., Srokosz, M.A. 2002. Plankton distribution spectra: inter-size class variability and the relative slopes for phytoplankton and zooplankton, Geophys. Res. Lett. 29 (24), 2213.

Moran, S.B., Charette, M.A., Pike, S.M., Wicklund, C.A., 1999. Differences in seawater particulate organic carbon concentration in samples collected using small-volume and large-volume methods: the importance of DOC adsorption to the filter blank. Marine Chemistry 67, 33-42. 
Morris, P.J., Sanders, R., Turnewitsch, R., Thomalla, S.J., 2008. 234Th-derived particulate organic carbon export from an island-induced phytoplankton bloom in the Southern Ocean. Deep sea Research II 54 (18-20), 2208-2232.

Murray, J.W., Young, J., Newton, J., Dunne, J., Chapin, T., Paul, B., 1996. Export flux of particulate organic carbon from the central equatorial Pacific determined using a combined drifting trap ${ }^{234} \mathrm{Th}$ approach. Deep-Sea Research II 43, 1095-1132.

Osterberg, C.A., Carey, G.J., Curl, H., 1963. Acceleration of sinking rates of radionuclides in the ocean. Nature 200, 1276-1277.

Pace, M.L., Knauer, G.A., Karl, D.M., Martin, J.H., 1987. Primary production, new production and vertical flux in the eastern Pacific Ocean. Nature 325, 803-804.

Pates, J.M., Muir, G.K.P., 2007. U-salinity relationships in the Mediterranean: Implications for 234Th:238U particle flux studies. Marine Chemistry 106, 530-545.

Peterson, M.L., Wakeham, S.G., Lee, C., Askea, M.A., Miquel, J.-C., 2005. Novel techniques for collection of sinking particles in the ocean and determining their settling rates. Limnology and Oceanography: Methods 3, 520-532.

Pike, S., Buesseler, K.O., Andrews, J.A., Savoye, N., 2005. Quantification of ${ }^{234}$ Th recovery in small volume sea water samples by inductively coupled plasma mass spectrometry. Journal of Radioanalytical and Nuclear Chemistry 263 (2), 355-360.

Rodriguez y Baena, A.M., Fowler, S.W., Miquel, J.C., 2007. Particulate organic carbon: natural radionuclide ratios in zooplankton and their freshly produced fecal pellets from the NW Mediterranean (MedFlux 2005) Limnol. Oceanogr. 52 (3), 966-974.

Rutgers van der Loeff, M., Sarin, M.M., Baskaran, M., Benitez-Nelson, C., Buesseler, K.O., Charette, M., Dai, M., Gustafsson, Ö., Masque, P., Morris, P.J., Orlandini, K., Rodriguez y Baena, A., Savoye, N., Schmidt, S., Turnewitsch, R., Vöge, I., Waples, J.T., 2006. A review of present techniques and methodological advances in analyzing 234Th in aquatic systems. . Marine Chemistry 100, 190-212.

Santschi, P.H., Murray, J.W., Baskaran, M., Benitez-Nelson, C.R., Guo, L.D., Hung, C.-C., Lamborg, C., Moran, S.B., Passow, U., Roy-Barman, M., 2006. Thorium speciation in seawater. Marine Chemistry $100(3-4), 250-268$.

Sarthou G., Timmermans K. R., Blain S., Treguer P., 2005. Growth physiology and fate of diatoms in the ocean: a review. Journal of Sea Research 53, 25-42

Savoye, N., Benitez-Nelson, C., Burd, A.B., Cochran, J.K., Charette, M., Buesseler, K.O., Jackson, G., RoyBarman, M., Schmidt, S., Elskens, M., 2006. ${ }^{234}$ Th sorption and export models in the water column: a review. Marine Chemistry 100, 234-249.

Savoye, N., Buesseler, K.O., Cardinal, D., Dehairs, F., 2004. ${ }^{234}$ Th deficit and excess in the Southern Ocean during spring 2001: particle export and mineralization. Geophysical Research Letters 31, L12301, doi: 10.1029/2004GL019744.

Savoye, N., Trull, T.W., Jacquet, S.H.M., Navez, J., Dehairs, F., 2008. 234Th-based export fluxes during a natural iron fertilization experiment in the Southern Ocean (KEOPS). Deep-Sea Research Part II.

Schmidt, S., Reyss, J.L., Nguyen, H.V., Buat-Ménard, P., 1990. ${ }^{234}$ Th cycling in the upper water column of the northwestern Mediterranean Sea. Palaeoceanography, Palaeoclimatology, Palaeoecology 89, 25-33.

Scholten, J.C., Fietzke, J., Vogler, S., Rutgers van der Loeff, M., Mangini, A., Koeve, W., Stoffers, P., Antia, A.N., Neuer, S., Waniek, J., 2001. Trapping efficiencies of sediment traps from the deep eastern North Atlantic: The 230Th calibration. Deep-Sea Research II 48(10), 2383-2578.

Siegel, D.A., Fields, E., Buesseler, K.O., 2008. A bottom-up view of the biological pump: Modeling source funnels above ocean sediment traps. Deep Sea Research I 55 (1), 108-127.

Smith, J.N., Moran, S.B., Speicher, E.A., 2006. On the accuracy of upper ocean particulate organic carbon export fluxes estimated from 234Th/238U disequilibrium. Deep-Sea Research Part I 53 (5), 860-868.

Steinberg, D.K., Cope, J.S., Wilson, S.E., Kobari, T., 2008. A comparison of mesozooplankton community structure in the subtropical and subarctic Pacific Ocean. Deep-Sea Research II 55, 1615-1635.

Stewart, G., Cochran, J.K., Miquel, J.C., Masqué, P., Szlosek, J., Rodriguez y Baena, A.M., Fowler, S.W., Gasser, B., Hirschberg, D.J., 2007. Comparing POC export from $234 \mathrm{Th} / 238 \mathrm{U}$ and $210 \mathrm{Po} / 210 \mathrm{~Pb}$ disequilibria with estimates from sediment traps in the northwest Mediterranean. Deep-Sea Research I 54 (9), 1549-1570.

Suess, E., 1980. Particulate organic carbon flux in the oceans-surface productivity and oxygen utilization. Nature 288, 260-263.

Szlosek, J., Cochran, J.K., Miquel, J.C., Masque, P., Armstrong, R., Fowler, S.W., Gasser, B., Hirschberg, D., 2008. Particulate organic carbon-234Th relationships in particles separated by settling velocity in the northwest Mediterranean Sea. Deep sea Research II submitted. 
Trull, T., Buesseler, K., Bray, S., Moy, C., Ebersbach, F., Lamborg, C., Pike, S., Manganini, S., 2008a. In-situ measurement of mesopelagic particle sinking rates and the control of carbon transfer to the ocean interior during the Vertical Flux in the Global Ocean (VERTIGO) voyages in the North Pacific. DeepSea Research II 55 (14-15), 1684-1695.

Trull T. W., Davies D., Casciotti K. 2008b. Insights into nutrient assimilation and export in naturally ironfertilized waters of the Southern Ocean from nitrogen, carbon, and oxygen isotopes. Deep Sea Research II 55(5-7), 820-840.

Trull, T.W., Armand, L., 2001. Insights into Southern Ocean carbon export from the $\delta 13 \mathrm{C}$ of particles and dissolved inorganic carbon during the SOIREE iron fertilisation experiment. Deep-Sea Research II 48(11-12), 2655-2680.

Tsuda, A., Sugisaki, H., Ishimaru, T., Saino, T., Sato, T. 1993. White-noise-like distribution of the oceanic copepod Neocalanus cristatus in the subarctic North Pacific. Marine Ecology Progress Series 97, 39 46.

Tsunogai, S., Taguchi, K., Harada, K., 1986. Seasonal variation in the difference between observed and calculated particulate fluxes of Th-234 in Funka Bay, Japan. J. Oceanogr. Soc. Japan 42, 91-98.

Usbeck, R., Rutgers van der Loeff, M., Hoppema, M., Schlitzer, R., 2002. Shallow remineralization in the Weddell Gyre Geochemistry, Geophysics, Geosystems 3 (1), doi: 10.1029/2001GC000182.

Volk, T., Hoffert, M.I., 1985. Ocean carbon pumps: Analysis of relative strengths and efficiencies in oceandrive atmospheric $\mathrm{CO} 2$ changes. Geophysical Monographs 32, 99-110.

Waite, A.M., Hill, P.S., 2006. Flocculation and phytoplankton cell size can alter 234Th-based estimates of the vertical flux of particulate organic carbon in the sea Marine Chemistry 100 (3-4), 366-375.

Waples, J.T., Benitez-Nelson, C., Savoye, N., Rutgers van der Loeff, M., Baskaran, M., Gustafsson, Ö., 2006. An introduction to the application and future use of $234 \mathrm{Th}$ in aquatic systems. Marine Chemistry 100 (3-4), 166-189.

Wei, C.-L., Murray, J.W., 1992. Temporal variations of ${ }^{234}$ Th activity in the water column of Dabob Bay: Particle scavenging. Limnology and Oceanography 37 (2), 296-314.

Wilson, S.E., Steinberg, D.K., Buesseler, K.O., 2008. Changes in fecal pellet characteristics with depth as indicators of zooplankton repackaging of particles in the mesopelagic zone. Deep-Sea Research II 55 (14-15), 1636-1647.

Yu, E.-F., Francois, R., Bacon, M.P., Honjo, S., Fleer, A.P., Manganini, S.J., Rutgers van der Loeff, M.M., Ittekot, V., 2001. Trapping efficiency of bottom-tethered sediment traps estimated from the intercepted fluxes of ${ }^{230} \mathrm{Th}$ and ${ }^{231} \mathrm{~Pa}$. Deep-Sea Research I 48 (3), 865-889.

Zhang, Y., Jiao, N.Z., Hong, N., 2008. Comparative studies on picoplankton biomass and community structure in different provinces from subarctic to subtropical oceans. Deep-Sea Research II 55 (14-15), 1605 1614. 
Table 1. VERTIGO ${ }^{234}$ Th derived 1D steady state fluxes

\begin{tabular}{|c|c|c|c|c|c|c|c|c|c|}
\hline CTD\# & $n^{(1)}$ & $\begin{array}{l}\text { Day of } \\
\text { Year }\end{array}$ & $\begin{array}{l}\text { Lat } \\
\mathbf{N}\end{array}$ & $\begin{array}{l}\text { Long } \\
\text { W }\end{array}$ & 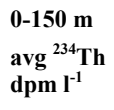 & $\begin{array}{l}150 \text { m } \\
\text { Th flux } \\
\text { dpm m } \text { m }^{-2} d^{-1}\end{array}$ & $\begin{array}{l}150 \mathrm{~m} \\
\operatorname{POC~flux}^{(4)} \\
\text { mmol m}^{-2} d^{-1}\end{array}$ & $\begin{array}{l}60 \mathrm{~m} \\
\text { Th flux } \\
\text { dpm m }{ }^{-2} d^{-1}\end{array}$ & $\begin{array}{l}60 \mathrm{~m} \\
\text { POC flux } \\
\text { mmol m}^{-2} d^{-1}\end{array}$ \\
\hline \multicolumn{10}{|l|}{ ALOHA } \\
\hline $17 \star^{(2)}$ & 4 & 175.8 & 22.767 & 158.001 & 2.48 & $-19 \pm 133$ & $0^{(7)} \pm 0.72$ & & \\
\hline $20 \star$ & 6 & 176.7 & 22.791 & 157.959 & 2.44 & $177 \pm 129$ & $0.96 \pm 0.72$ & & \\
\hline $27 \star$ & 10 & 178.6 & 22.760 & 158.000 & 2.41 & $337 \pm 119$ & $1.82 \pm 0.74$ & & \\
\hline 33 & 10 & 180.7 & 22.671 & 157.977 & 2.32 & $730 \pm 126$ & $3.94 \pm 1.05$ & & \\
\hline 40 & 4 & 182.1 & 22.976 & 157.756 & 2.18 & $1287 \pm 130$ & $6.95 \pm 1.58$ & & \\
\hline 42 & 5 & 182.2 & 22.973 & 158.001 & 2.34 & $585 \pm 140$ & $3.16 \pm 0.99$ & & \\
\hline 44 & 5 & 182.4 & 22.980 & 158.244 & 2.46 & $76 \pm 155$ & $0.41 \pm 0.84$ & & \\
\hline 49 & 5 & 183.0 & 22.525 & 158.244 & 2.51 & $-103 \pm 149$ & $0 \pm 0.81$ & & \\
\hline 53 & 5 & 183.2 & 22.525 & 157.756 & 2.41 & $315 \pm 150$ & $1.70 \pm 0.88$ & & \\
\hline $57 \star$ & 5 & 183.6 & 22.750 & 158.001 & 2.51 & $-116 \pm 122$ & $0 \pm 0.67$ & & \\
\hline 61 & 7 & 184.1 & 23.752 & 158.002 & 2.29 & $850 \pm 140$ & $4.59 \pm 1.20$ & & \\
\hline 64 & 8 & 184.5 & 22.749 & 159.081 & 2.46 & $113 \pm 130$ & $0.61 \pm 0.71$ & & \\
\hline $67 \star$ & 8 & 185.0 & 22.750 & 157.997 & 2.37 & $487 \pm 164$ & $2.63 \pm 1.04$ & & \\
\hline 70 & 8 & 185.3 & 22.750 & 156.917 & 2.38 & $472 \pm 121$ & $2.55 \pm 0.83$ & & \\
\hline 72 & 8 & 185.7 & 22.084 & 158.001 & 2.27 & $1008 \pm 103$ & $5.44 \pm 1.24$ & & \\
\hline 79 & 10 & 186.6 & 22.750 & 158.001 & 2.51 & $-85 \pm 157$ & $0 \pm 0.85$ & & \\
\hline 83 & 9 & 188.6 & 22.750 & 157.989 & 2.46 & $124 \pm 83$ & $0.67 \pm 0.47$ & & \\
\hline 95 & 10 & 190.6 & 22.751 & 158.250 & 2.41 & $285 \pm 91$ & $1.54 \pm 0.58$ & & \\
\hline 99 & 10 & 192.6 & 22.751 & 158.250 & 2.34 & $586 \pm 72$ & $3.17 \pm 0.75$ & & \\
\hline ALOHA Trap D1 & 4 & $174.8-177.5$ & & & & $288 \pm 91$ & & & \\
\hline ALOHA Trap D2 & 4 & $184.0-187.2$ & & & & $340 \pm 65$ & & & \\
\hline \multicolumn{10}{|l|}{$K 2$} \\
\hline 4 & 10 & 207.5 & 46.099 & 201.321 & 1.76 & $2518 \pm 140$ & $10.1 \pm 1.4$ & $1865 \pm 64$ & $15.9 \pm 1.6$ \\
\hline 5 & 11 & 207.7 & 46.550 & 200.661 & 1.98 & $1548 \pm 165$ & $6.2 \pm 1.0$ & $1369 \pm 59$ & $11.6 \pm 1.2$ \\
\hline 6 & 10 & 207.9 & 46.936 & 200.094 & 2.00 & $1434 \pm 157$ & $5.7 \pm 1.0$ & $1630 \pm 63$ & $13.9 \pm 1.4$ \\
\hline 7 & 10 & 208.1 & 47.451 & 199.340 & 1.78 & $2396 \pm 153$ & $9.6 \pm 1.3$ & $2060 \pm 67$ & $17.5 \pm 1.7$ \\
\hline 8 & 10 & 208.4 & 47.901 & 198.681 & 1.80 & $2303 \pm 198$ & $9.2 \pm 1.4$ & $2131 \pm 64$ & $18.1 \pm 1.8$ \\
\hline 10 & 10 & 208.7 & 47.000 & 198.680 & 2.23 & $471 \pm 172$ & $1.9 \pm 0.7$ & $1261 \pm 74$ & $10.7 \pm 1.2$ \\
\hline $12^{(8)}$ & 10 & 209.0 & 46.099 & 198.679 & 2.07 & $1230 \pm 188$ & $4.9 \pm 1.0$ & $1483 \pm 90$ & $12.6 \pm 1.4$ \\
\hline 14 & 8 & 209.5 & 47.074 & 200.108 & 1.90 & $1890 \pm 217$ & $7.6 \pm 1.3$ & $1759 \pm 92$ & $15.0 \pm 1.6$ \\
\hline 15 & 10 & 209.8 & 47.901 & 201.320 & 1.93 & $1768 \pm 176$ & $7.1 \pm 1.1$ & $1226 \pm 75$ & $10.4 \pm 1.2$ \\
\hline 16 & 10 & 210.1 & 47.901 & 200.000 & 1.82 & $2251 \pm 177$ & $9.0 \pm 1.3$ & $1900 \pm 68$ & $16.2 \pm 1.6$ \\
\hline $18 \star$ & 8 & 211.7 & 47.001 & 198.990 & 2.14 & $864 \pm 159$ & $3.5 \pm 0.8$ & $1401 \pm 106$ & $11.9 \pm 1.4$ \\
\hline $24 \star$ & 20 & 213.8 & 46.999 & 199.000 & 1.99 & $1521 \pm 102$ & $6.1 \pm 0.9$ & $1605 \pm 63$ & $13.6 \pm 1.4$ \\
\hline $31 \star$ & 9 & 215.7 & 47.034 & 198.749 & 2.12 & $921 \pm 158$ & $3.7 \pm 0.8$ & $1040 \pm 80$ & $8.8 \pm 1.1$ \\
\hline 39 & 8 & 217.7 & 47.000 & 198.763 & 1.91 & $1827 \pm 172$ & $7.3 \pm 1.1$ & $1748 \pm 77$ & $14.9 \pm 1.5$ \\
\hline 42 & 10 & 218.6 & 47.721 & 199.000 & 1.89 & $1944 \pm 187$ & $7.8 \pm 1.2$ & $1395 \pm 81$ & $11.9 \pm 1.3$ \\
\hline 44 & 10 & 218.8 & 47.721 & 200.057 & 2.01 & $1394 \pm 150$ & $5.6 \pm 0.9$ & $1519 \pm 64$ & $12.9 \pm 1.3$ \\
\hline 47 & 10 & 219.2 & 46.639 & 200.057 & 2.03 & $1296 \pm 186$ & $5.2 \pm 1.0$ & $1317 \pm 78$ & $11.2 \pm 1.2$ \\
\hline 48 & 10 & 219.4 & 46.279 & 200.057 & 1.89 & $1897 \pm 188$ & $7.6 \pm 1.2$ & $1782 \pm 84$ & $15.2 \pm 1.6$ \\
\hline 50 & 10 & 219.7 & 46.279 & 199.000 & 2.05 & $1226 \pm 173$ & $4.9 \pm 0.9$ & $1259 \pm 74$ & $10.7 \pm 1.2$ \\
\hline 52 & 10 & 220.0 & 46.279 & 197.943 & 1.90 & $1862 \pm 166$ & $7.4 \pm 1.1$ & $1445 \pm 64$ & $12.3 \pm 1.3$ \\
\hline 54 & 10 & 220.4 & 47.000 & 197.943 & 2.21 & $530 \pm 171$ & $2.1 \pm 0.7$ & $1142 \pm 66$ & $9.7 \pm 1.1$ \\
\hline $58 \star$ & 9 & 221.0 & 47.000 & 199.000 & 2.02 & $1357 \pm 164$ & $5.4 \pm 0.9$ & $1407 \pm 75$ & $12.0 \pm 1.3$ \\
\hline $62 \star$ & 9 & 222.7 & 47.050 & 199.000 & 2.00 & $1449 \pm 163$ & $5.8 \pm 1.0$ & $1097 \pm 68$ & $9.3 \pm 1.0$ \\
\hline $67 \star$ & 20 & 224.8 & 47.050 & 199.000 & 2.05 & $1240 \pm 102$ & $5.0 \pm 0.7$ & $1435 \pm 59$ & $12.2 \pm 1.2$ \\
\hline 76 & 9 & 226.7 & 47.000 & 198.701 & 2.00 & $1432 \pm 155$ & $5.7 \pm 0.9$ & $1215 \pm 71$ & $10.3 \pm 1.1$ \\
\hline 85 & 24 & 228.8 & 47.118 & 198.642 & 2.00 & $1460 \pm 99$ & $5.8 \pm 0.8$ & $1467 \pm 60$ & $12.5 \pm 1.3$ \\
\hline K2 Trap D1 & 4 & $211.0-214.3$ & & & & $1260 \pm 195$ & & & \\
\hline K2 Trap D2 & 4 & $221.9-223.6$ & & & & $460 \pm 85$ & & & \\
\hline
\end{tabular}

(1) $\mathrm{n}=$ number of ${ }^{234} \mathrm{Th}$ data points in the profile at each station.

(2) Stations in Bold and with a $\star$ were sampled within 1 day of trap deployment and within the estimated particle source region.

(3) Steady state model used to derive ${ }^{234} \mathrm{Th}$ fluxes at $150 \mathrm{~m}$ for ALOHA and K2.

(4) ALOHA POC/Th $=5.4 \pm 1.1 \mu \mathrm{mol} \mathrm{dpm}{ }^{-1}, \mathrm{~K} 2 \mathrm{POC} / \mathrm{Th}=4.0 \pm 0.5 \mu \mathrm{mol} \mathrm{dpm}{ }^{-1}$, for $150 \mathrm{~m}$ NBSTs used to derive POC flux.

(5) Steady state model used to derive ${ }^{234} \mathrm{Th}$ fluxes at $60 \mathrm{~m}$ at K2.

(6) $\mathrm{K} 2 \mathrm{POC} / \mathrm{Th}=8.2 \pm 0.76 \mu \mathrm{mol} \mathrm{dpm}{ }^{-1}$ from $>55-350 \mu \mathrm{m}$ particles @ $35 \mathrm{~m}$ used for $60 \mathrm{~m}$ POC flux.

(7) ${ }^{234} \mathrm{Th}$ fluxes $<0$ are set to zero for POC flux calculations and averages.

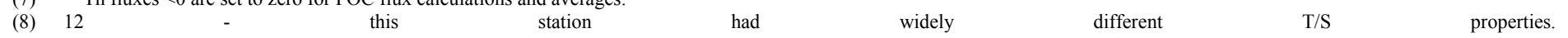




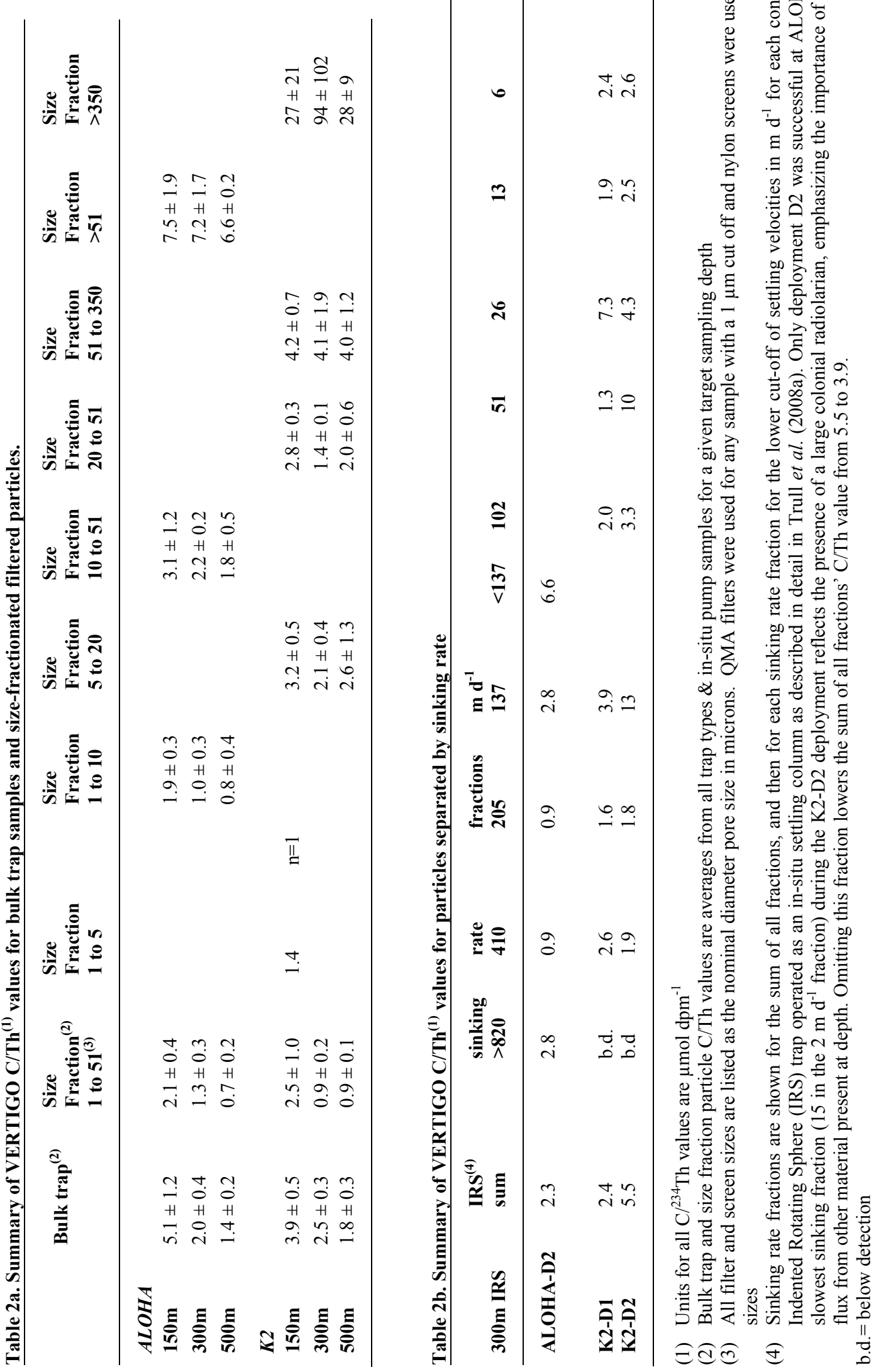




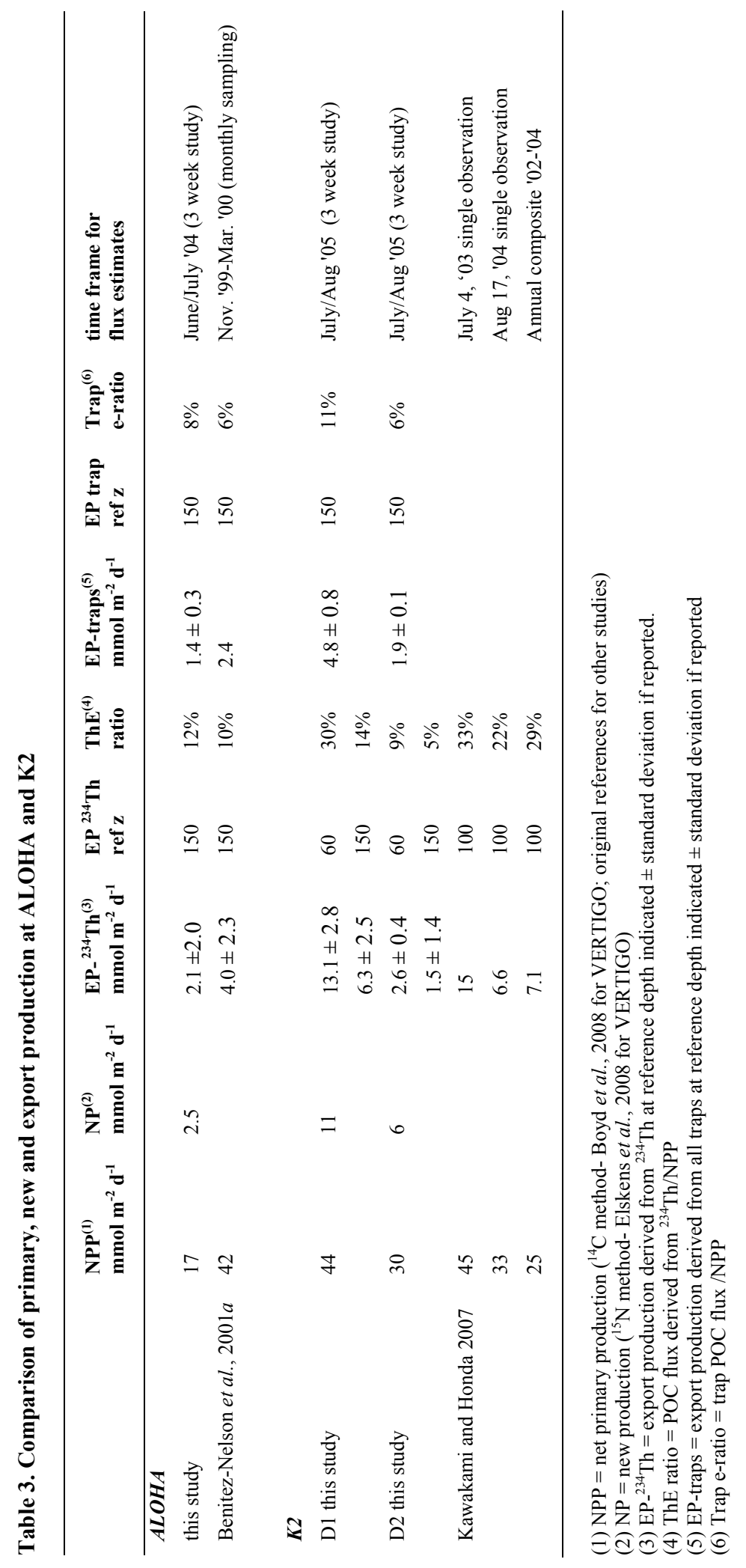


Table 4. Relative export ratios for DIN, dSi and ${ }^{234} \mathrm{Th}$

\begin{tabular}{lll}
\hline & Upper $^{25 m^{(1)}}$ & $\mathbf{1 5 0 m}$ traps $^{(2)}$ \\
\hline $\mathbf{d S i} / \mathbf{D I N}$ & 3.2 & 14.4 \\
$\mathbf{D I N} \mathbf{2}^{234} \mathbf{T h}$ & 11.2 & 0.5 \\
$\mathbf{d S i}{ }^{234} \mathbf{T h}$ & 36.3 & 7.2 \\
\hline
\end{tabular}

(1) dSi/DIN based upon nutrient profiles in VERTIGO and moored nutrient sampler data between June 28 and Aug. 7 (Buesseler $e t$ al., $2008 b$ ). ${ }^{234} \mathrm{Th}$ flux ratios derived from ${ }^{234} \mathrm{Th}$ flux at $25 \mathrm{~m}$ calculated for D1 and D2 using SS and NSS models, and average used here for comparison to nutrient budgets.

(2) VERTIGO $150 \mathrm{~m}$ sediment trap average for D1 and D2 from fluxes reported in Lamborg et al., $2008 \mathrm{~b}$. 
Figure Captions. Buesseler et al. Thorium-234 as a local and regional tracer

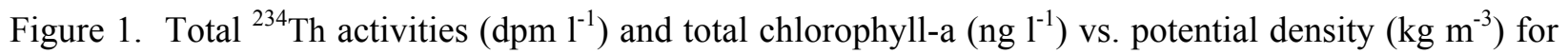
a)ALOHA and b)K2. Thorium-234 data are plotted as gray circles with error bars shown if greater than the symbol size, using the upper $\mathrm{X}$-axis and plotted relative to ${ }^{238} \mathrm{U}$ (black line) near $2.3 \mathrm{dpm} \mathrm{I}^{-1}$. Total Chl-a data are offset to run from 0 to $1000 \mathrm{ng}^{-1}$ starting at the point along the lower $\mathrm{X}$-axis where ${ }^{234} \mathrm{Th}={ }^{238} \mathrm{U}$, to emphasize ${ }^{234} \mathrm{Th}$ removal associated with the euphotic zone. Density scales (Y axis- left) differ at the two sites, and for convenience, approximate water depths are shown along the right $\mathrm{Y}$ axis specific to each site.

Figure 2. Thorium-234 fluxes $\left(\mathrm{dpm} \mathrm{m} \mathrm{m}^{-2} \mathrm{~d}^{-1}\right)$ vs. Day of Year for ALOHA at $150 \mathrm{~m}$ (2a upper panel), K2 at $60 \mathrm{~m}$ (2b middle) and $\mathrm{K} 2$ at $150 \mathrm{~m}$ (2c lower). Sediment trap fluxes at $150 \mathrm{~m}$ are shown as open symbols with the average as a horizontal gray bar corresponding to the duration of the trap deployment. Replicate trap data are shown for up to 4 different traps and 6 replicates per trap as analyzed for ${ }^{234} \mathrm{Th}$. Clap trap data are always shown by an open circle, whereas triangles and diamonds are used for the NBSTs. Fluxes derived from total ${ }^{234} \mathrm{Th}$ and a steady state model are shown as squares, with gray squares corresponding to those stations most closely associated with the particle source funnel and time of the trap deployment.

Figure 3. Map view of ${ }^{234} \mathrm{Th}$ fluxes derived from water column data broken down by the first and second half of each cruise, or deployments D1 and D2 for the sediment traps. Station \#'s are indicated and the area of each circle corresponds to the $150 \mathrm{~m}$ flux (see key for scaling and note expanded view of particle source area). Also shown are the trajectories of the surface drifter for the Clap traps (solid line), start and end locations of the NBSTs (triangles), and shaded regions for the particle source funnel for the traps in each deployment.

Figure 4. Plot of high resolution vertical profiles of total ${ }^{234} \mathrm{Th}$ for $\mathrm{K} 2$ station 24 (D1- filled circles) and 67 (D2- open triangles). In panel $4 \mathrm{a}$ the ${ }^{234} \mathrm{Th}$ activity data are plotted with associated errors and relative to ${ }^{238} \mathrm{U}$ (solid line). These data are used in the lower panel (4b) to calculate the ${ }^{234} \mathrm{Th}$ flux $\left(\mathrm{dpm} \mathrm{m}^{-2} \mathrm{~d}^{-1}\right)$ vs. depth using a steady-state (SS) model as described in the text for stations 24 (D1-SS; filled circles) and 67 (D2-SS; open triangles). Calculated non-steady state (NSS) fluxes are also shown for D1 (solid line) and D2 (dashed line). Overlain on the lower panel fluxes are the average and standard deviation of the trap fluxes at $150 \mathrm{~m}$ (staggered on Y axis to separate) for D1 (filled symbols) and D2 (open symbols), with NBST fluxes as triangles and the Clap traps as circles.

Figure 5. Profiles of total ${ }^{234} \mathrm{Th}\left(\mathrm{dpm} \mathrm{l}^{-1}\right.$; including ${ }^{238} \mathrm{U}$ as solid line, 5a), total chlorophyll-a (ng $\left.\mathrm{l}^{-1} ; 5 \mathrm{~b}\right)$ and DIN:dSi ratios (molar; 5c) for station 24 (filled circles) and 67 (open triangles). Data are plotted vs. potential density $\left(\mathrm{kg} \mathrm{m}^{-3}\right.$; Y-axis) with horizontal dashed lines at potential densities of 26.4 and $26.8 \mathrm{~kg} \mathrm{~m}^{-}$ ${ }^{3}$ used to separate layers of net particle production and remineralization, as described in the text and used in Figure 6.

Figure 6. Plot of all total ${ }^{234} \mathrm{Th}$ activities from K2 relative to the DIN:dSi ratio. The data in the surface layer (potential density $<26.4 \mathrm{~kg} \mathrm{~m}^{-3}$ ) are shown as gray squares, from the remineralization layer as open circles (potential density bounded by 26.4 and $26.8 \mathrm{~kg} \mathrm{~m}^{-3}$ ) and for the deeper layer, as black triangles (potential density $>26.8 \mathrm{~kg} \mathrm{~m}^{-3}$ ). ${ }^{238} \mathrm{U}$ data are shown as a solid line around $2.3 \mathrm{dpm} \mathrm{l}^{-1}$.

Figure 7. Depth profiles from ALOHA (7a-7d, upper 4 panels) and K2 (7e-7h, lower 4 panels) of total ${ }^{234} \mathrm{Th}(7 \mathrm{a}$ and $7 \mathrm{e}$ ) for stations closest in space/time to the MULVFS in situ particle sampling. Particle data include particulate ${ }^{234} \mathrm{Th}\left(7 \mathrm{~b}\right.$ and $7 \mathrm{f}$ ), particulate carbon (PC; 7c and $7 \mathrm{~g}$ ) and excess $\mathrm{Ba}\left(\mathrm{Ba}^{\mathrm{ex}}\right)$, and Chl-a (7d and $7 \mathrm{~h}$ ). For particulate ${ }^{234} \mathrm{Th}$, discrete data from 4 MULVFS casts are shown for the $>1-51 \mu \mathrm{m}$ fraction, with the average of these as a solid line (same station key as in total ${ }^{234} \mathrm{Th}$ panel). For the $>51$ 
$\mu \mathrm{m}{ }^{234} \mathrm{Th}$ fraction, the average is shown from 4 or 5 depths (stars). PC is shown as the average for both $>1-51 \mu \mathrm{m}$ fraction (solid circles \& line) and $>51 \mathrm{um}$ fraction (stars). Excess-Ba (in excess of lithogenic fraction; see Dehairs et al., 2008), is plotted as the average of all casts (right panels), and a representative profile of Chl-a (derived from CTD fluorometer and calibrated against HPLC total Chl-a concentrations; Buesseler et al., 2008) is also shown for each site (station 27 for ALOHA, station 18 for K2).

Figure 8. Ratios of C/Th for traps and MULVFS filtered particles for ALOHA-D1 and -D2 (8a and 8b) and K2-D1 and -D2 (8c and 8d) as identified. Trap data are shown at 150, 300 and $500 \mathrm{~m}$ (points staggered in vertical to assist visualization) for NBSTs (dark blue triangles- up) and Clap traps (light blue triangles- down). For ALOHA, particulate samples size classes included $>1-10,10-51$ and $>51 \mu \mathrm{m}$ on one flow path and 1-51 $\mu \mathrm{m}$ on a separate MULVFS flow path. For K2, these included $>1-5,5-20,20-51$, $51-350,>350 \mu \mathrm{m}$ on one flow path and $>1-53 \mu \mathrm{m}$ on a separate flow path. The largest size class for ALOHA and K2 is shown as a red star. Other size classes as indicated in key. Trap samples are reported as POC/Th, i.e. corrected for a minor contribution to total PC from PIC (PIC is increasing from 13-30\% by weight for traps at ALOHA, $<4 \%$ at all trap depths at K2), while the filtered particles are reported here as total PC only.

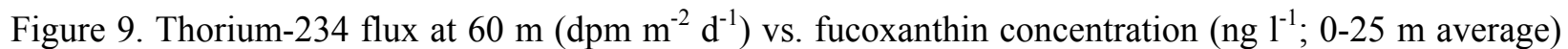
in upper panel a, and vs. DIN (filled triangles; $\mu \mathrm{mol} \mathrm{l}^{-1} ; 0-25 \mathrm{~m}$ average) and dSi (open triangles; $\mu \mathrm{mol} 1^{-1}$; $0-25 \mathrm{~m}$ average) in lower panel $\mathrm{b}$ at K2. Line is best fit to the data $\left(\mathrm{R}^{2}=0.09\right.$ for Fucoxanthin, 0.09 for DIN and 0.14 for $\mathrm{dSi}$ ).

Figure 10. Station to station variability in average fucoxanthin concentration ( $\mathrm{ng}^{-1} ; 0-25 \mathrm{~m}$ average) and surface dSi ( $\mu \mathrm{mol} \mathrm{l}^{-1}$; surface samples $<15 \mathrm{~m}$ only) at K2. Line is best fit to the data $\left(\mathrm{R}^{2}=0.68\right)$.

Figure 11. DIN vs. dSi (both in $\mu \mathrm{mol}{ }^{-1}$ ) for all $\mathrm{K} 2$ data from potential density $<26.4 \mathrm{~kg} \mathrm{~m}^{-3}$. White square is the average immediately below euphotic zone at a potential density of $26.4 \mathrm{~kg} \mathrm{~m}^{-3}$ (see Figure 12). Reference lines are shown for $1: 1$ and 1:4 drawdown ratio for DIN:dSi relative to that end member as discussed in text (best fit slope to all data would be 1:3.6 with $\mathrm{R}^{2}=0.90$ ).

Figure 12. Thorium-234 (dpm 1 ${ }^{-1}$ ) vs. DIN ( $\mu \mathrm{mol} \mathrm{l}^{-1}$, upper panel a) or dSi ( $\mu$ mol $1^{-1}$, lower panel b) at K2. The depth of each sample is indicated by the color of the circles as follows: white $=1-10 \mathrm{~m}$; red $=10-20$ $\mathrm{m}$; green $=20-30 \mathrm{~m}$; yellow $=30-40 \mathrm{~m}$; blue $=40-50 \mathrm{~m}$; gray $=50-60 \mathrm{~m}$. All $\mathrm{K} 2$ data from potential densities $<26.4 \mathrm{~kg} \mathrm{~m}^{-3}$ are plotted if concentrations are lower than the average end member concentrations at $26.4 \pm 0.1$ (open square with error bars denotes end member concentrations). Lines are drawn for the average drawdown ratio of $\mathrm{DIN}:{ }^{234} \mathrm{Th}=11$, and range lines at 4 to $30 \mu \mathrm{mol} \mathrm{dpm}{ }^{-1}$ (Figure 12a) and $\mathrm{dSi}^{234} \mathrm{Th}=36$ and range lines at 13 to $96 \mu \mathrm{mol} \mathrm{dpm}{ }^{-1}$ (Figure $12 \mathrm{~b}$ ) as discussed in the text. The length of the horizontal black arrows at ${ }^{234} \mathrm{Th}=1$ and $1.5 \mathrm{dpm} \mathrm{1}{ }^{-1}$, corresponds to the increase in ${ }^{234} \mathrm{Th}$ calculated from a period of 14 days ingrowth and decay for ${ }^{234} \mathrm{Th}$, but no additional removal from the euphotic zone. As shown by the red arrows in 12a, the relative direction of change for a period of no flux, would be horizontal along the X-axis or a slightly negative slope after a decrease in flux of both nutrient and ${ }^{234} \mathrm{Th}$. Preferential remineralization of DIN (or $\mathrm{dSi}$ ) would cause the observed concentration of nutrient to increase without a corresponding change in ${ }^{234} \mathrm{Th}$ activity (vertical red arrow).

Figure 13. Station to station variability in average fucoxanthin concentration (ng $\mathrm{l}^{-1} ; 0-25 \mathrm{~m}$ average) and the percent change in ${ }^{234} \mathrm{Th}$ flux at 60 vs. $150 \mathrm{~m}$ (flux $(150-60) /$ flux 60$)$ at K2. Points above zero on xaxis are stations where ${ }^{234} \mathrm{Th}$ flux increases between 60 and $150 \mathrm{~m}$, and below zero, where there is a decrease in flux, i.e. remineralization. Line is best fit to the data $\left(\mathrm{R}^{2}=0.43\right.$, or 0.67 if outlier at station 52 is excluded). Station ID's included for selected sites as discussed in text. 
Figure 1a. Buesseler et al. DSRI 08-00230

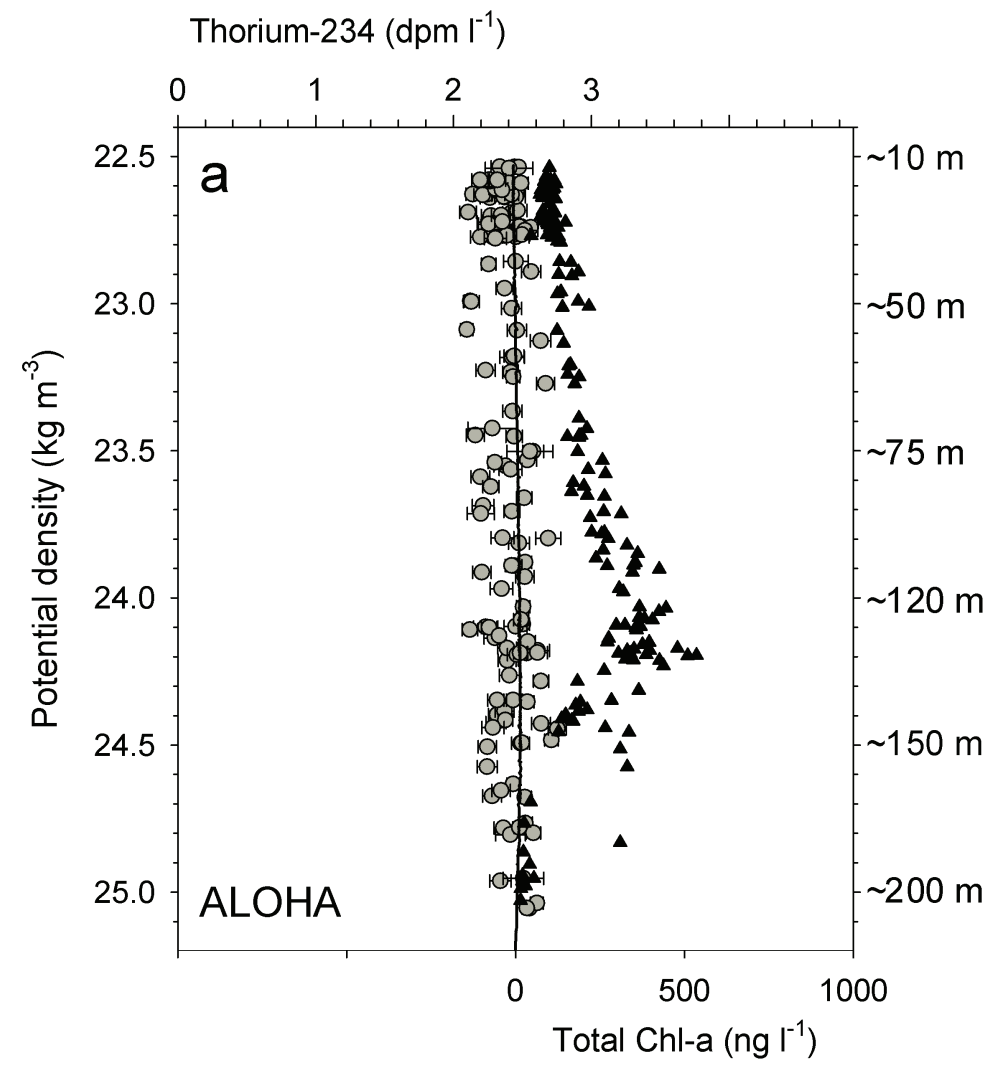


Figure 1b. Buesseler et al. DSRI 08-00230

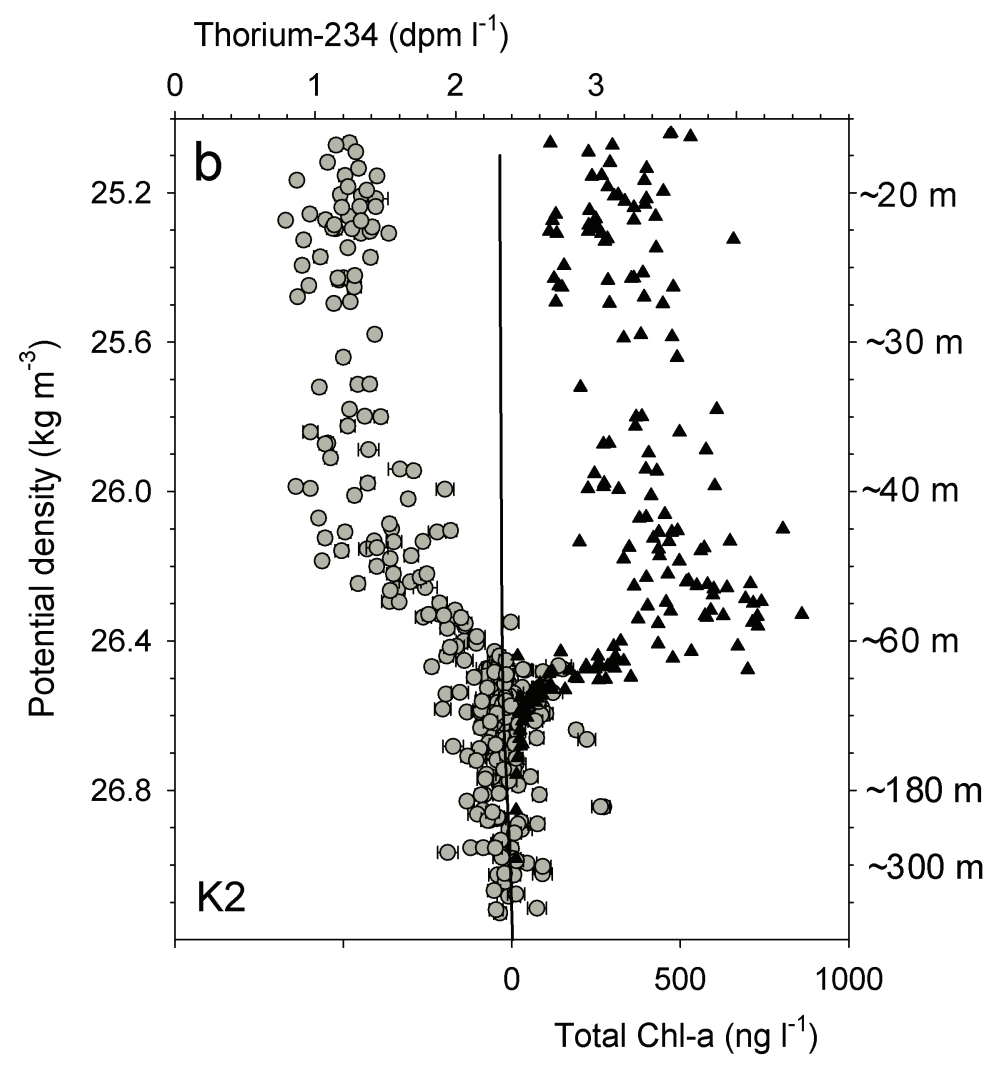


Figure 2. Buesseler et al. DSRI 08-00230
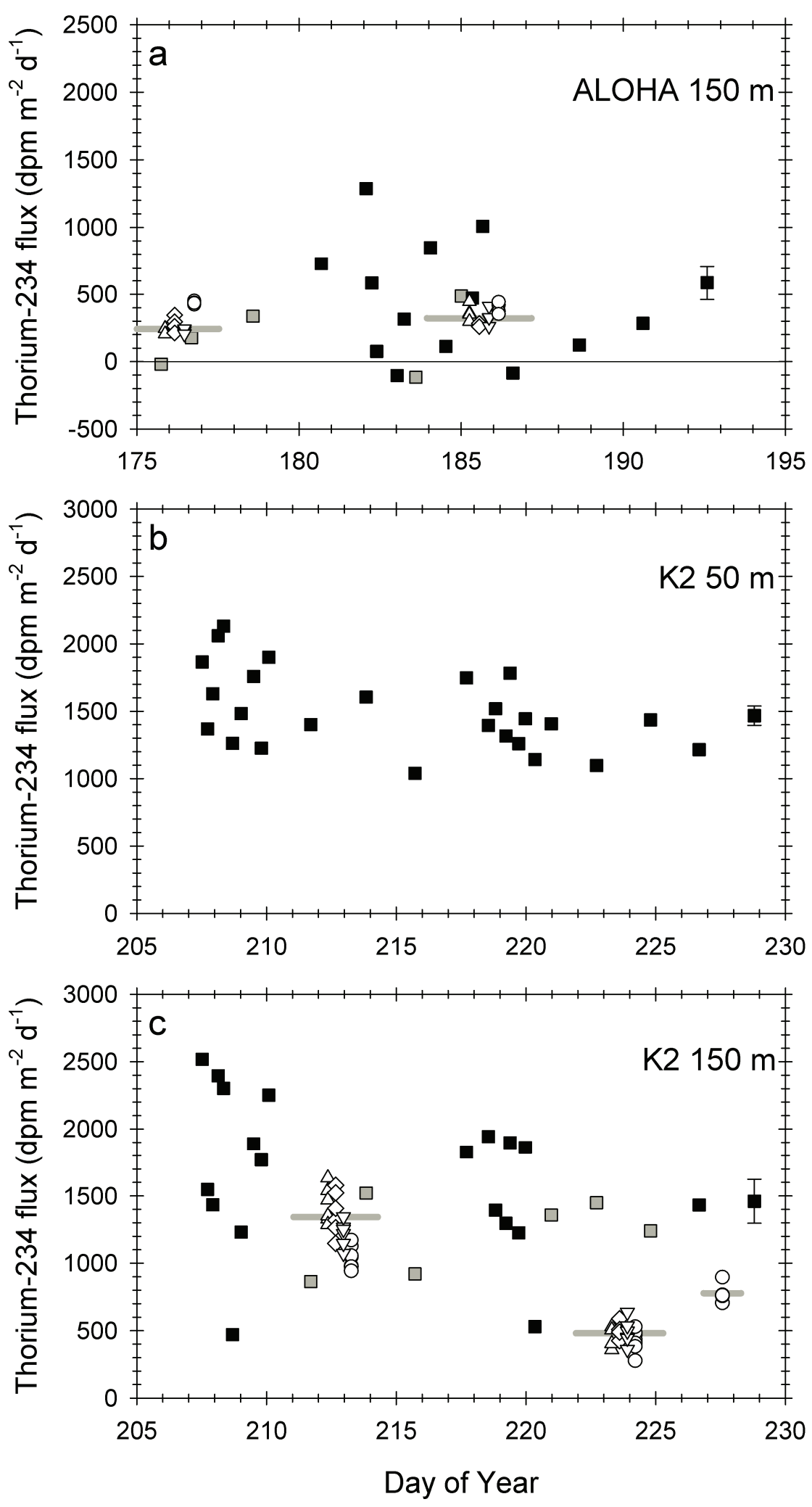
Figure 3. Buesseler et al. DSRI 08-00230
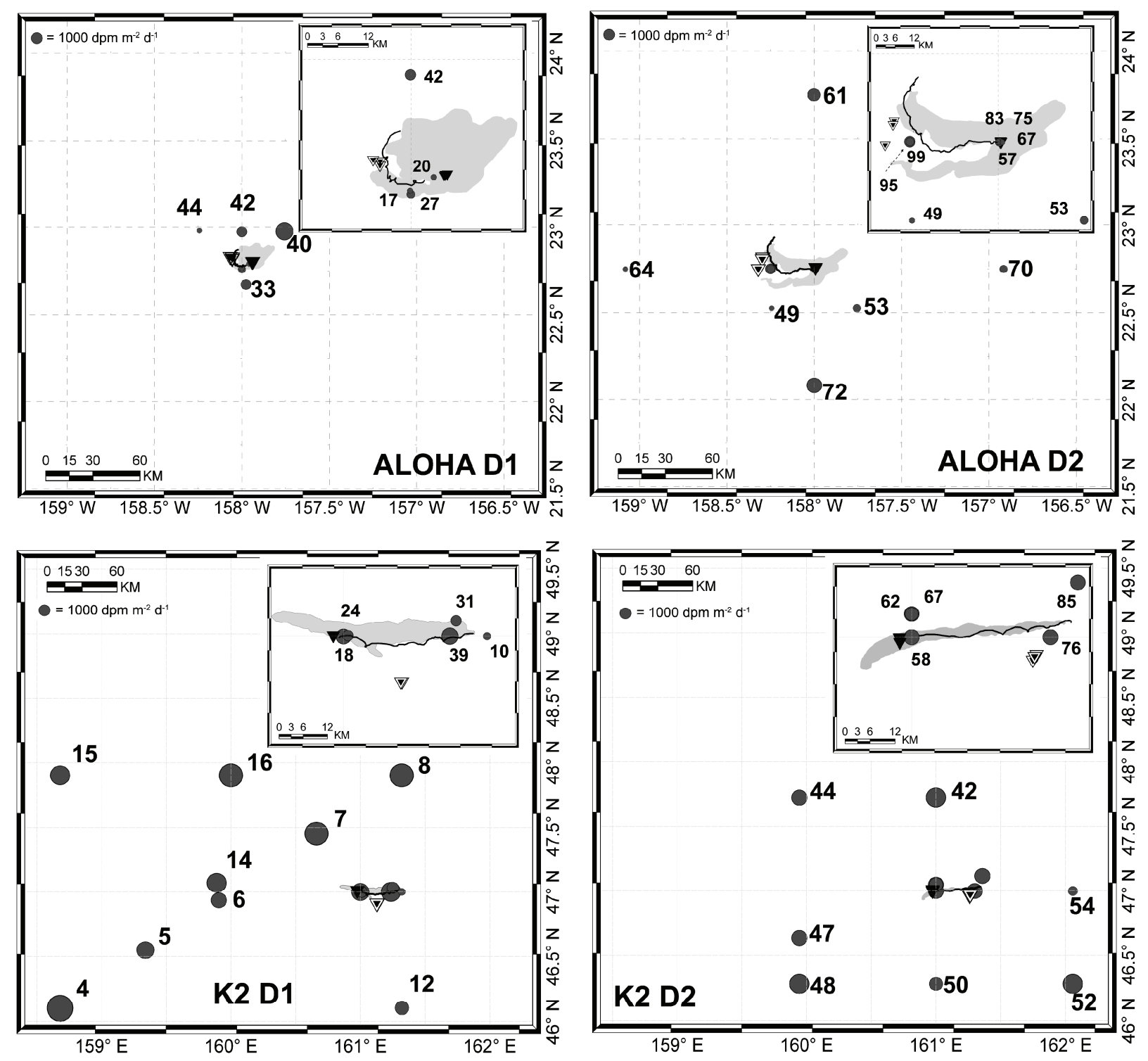
Figure 4. Buesseler et al. DSRI 08-00230
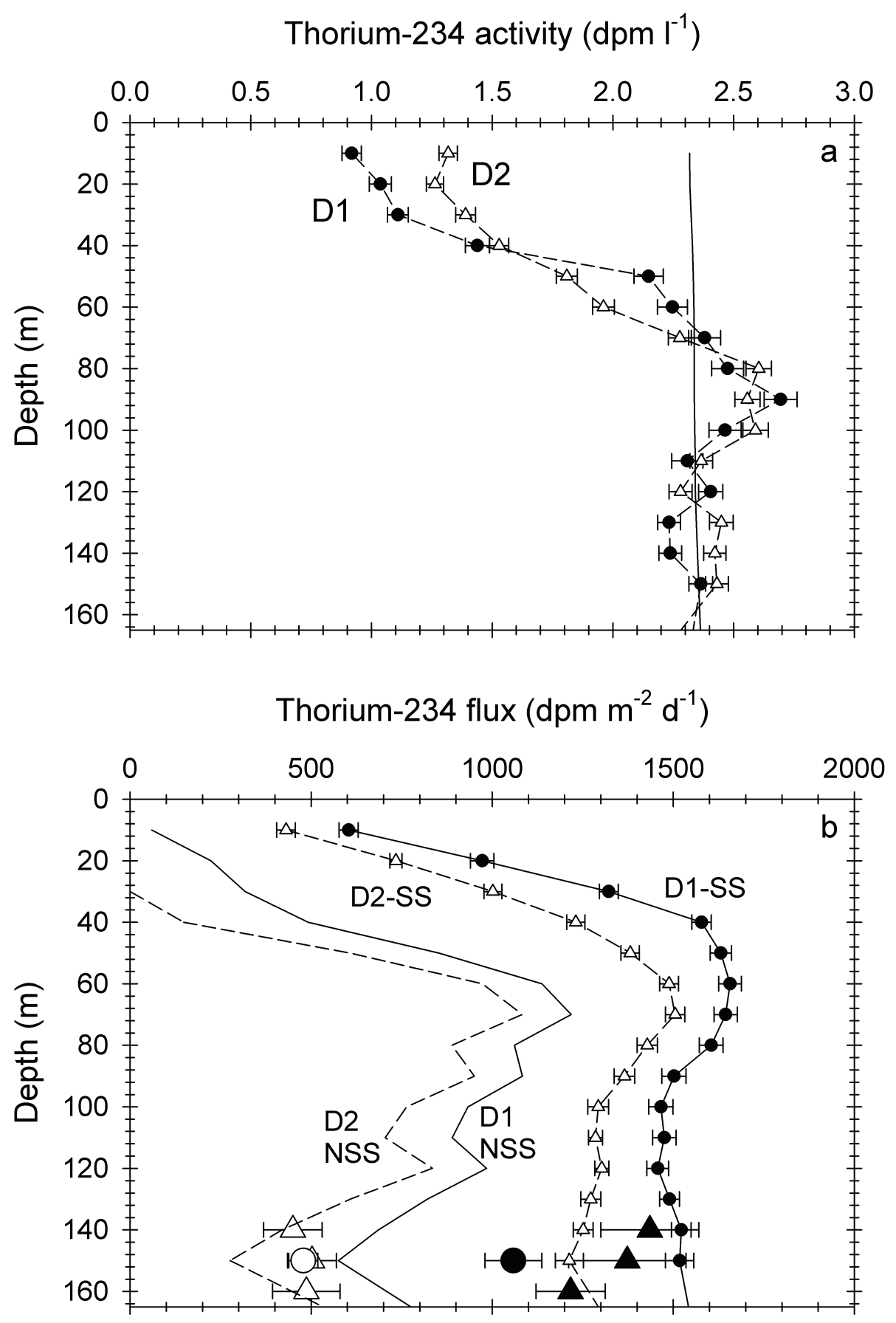
Figure 5. Buesseler et al. DSRI 08-00230

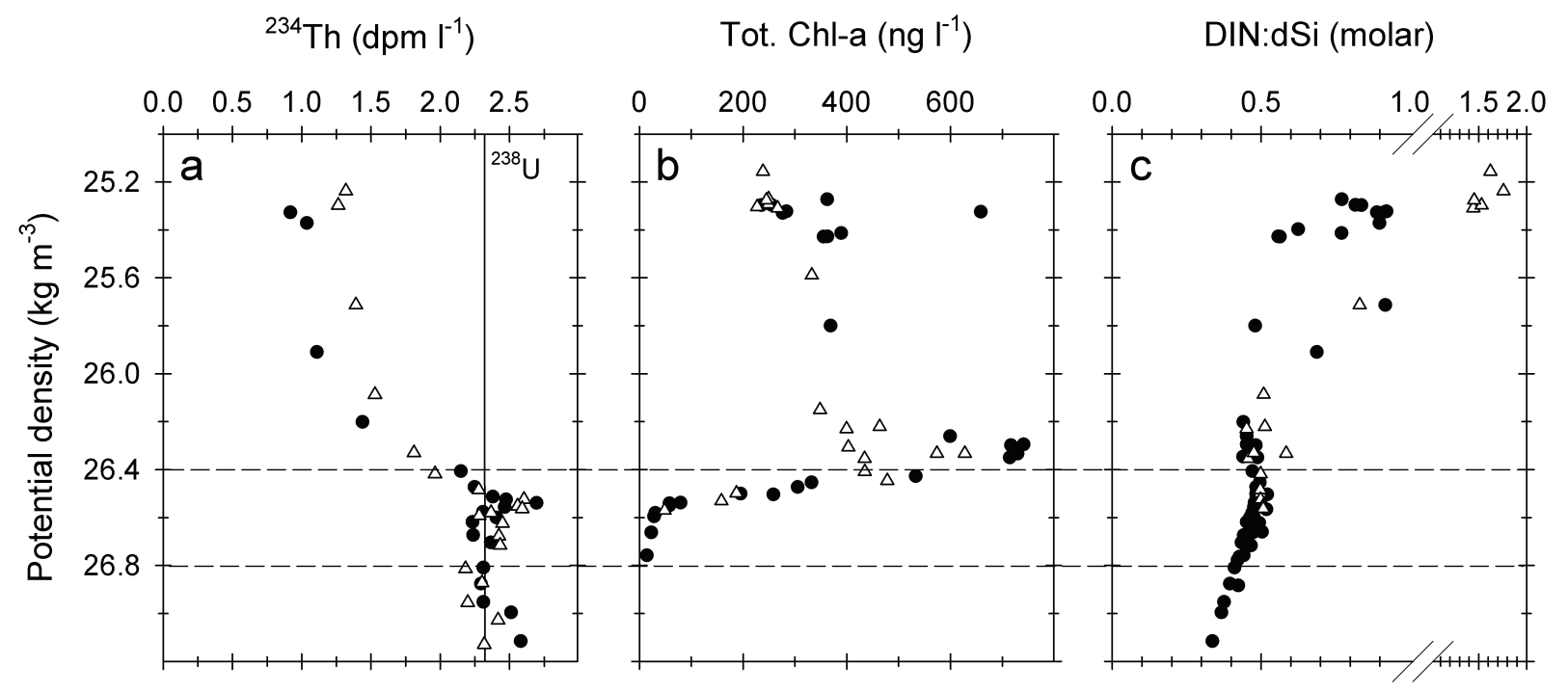


Figure 6. Buesseler et al. DSRI 08-00230

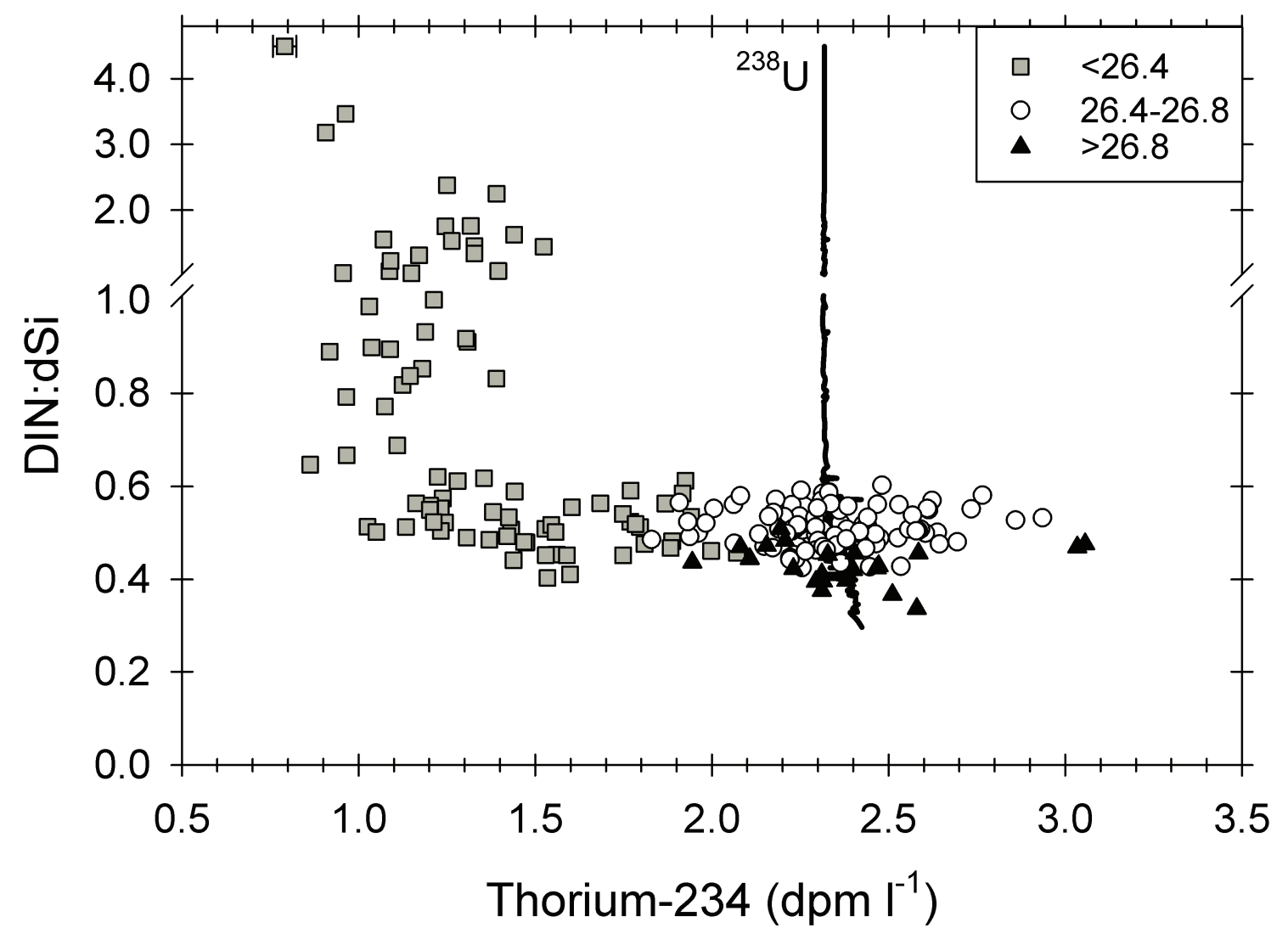


Figure 7. Buesseler et al. DSRI 08-00230

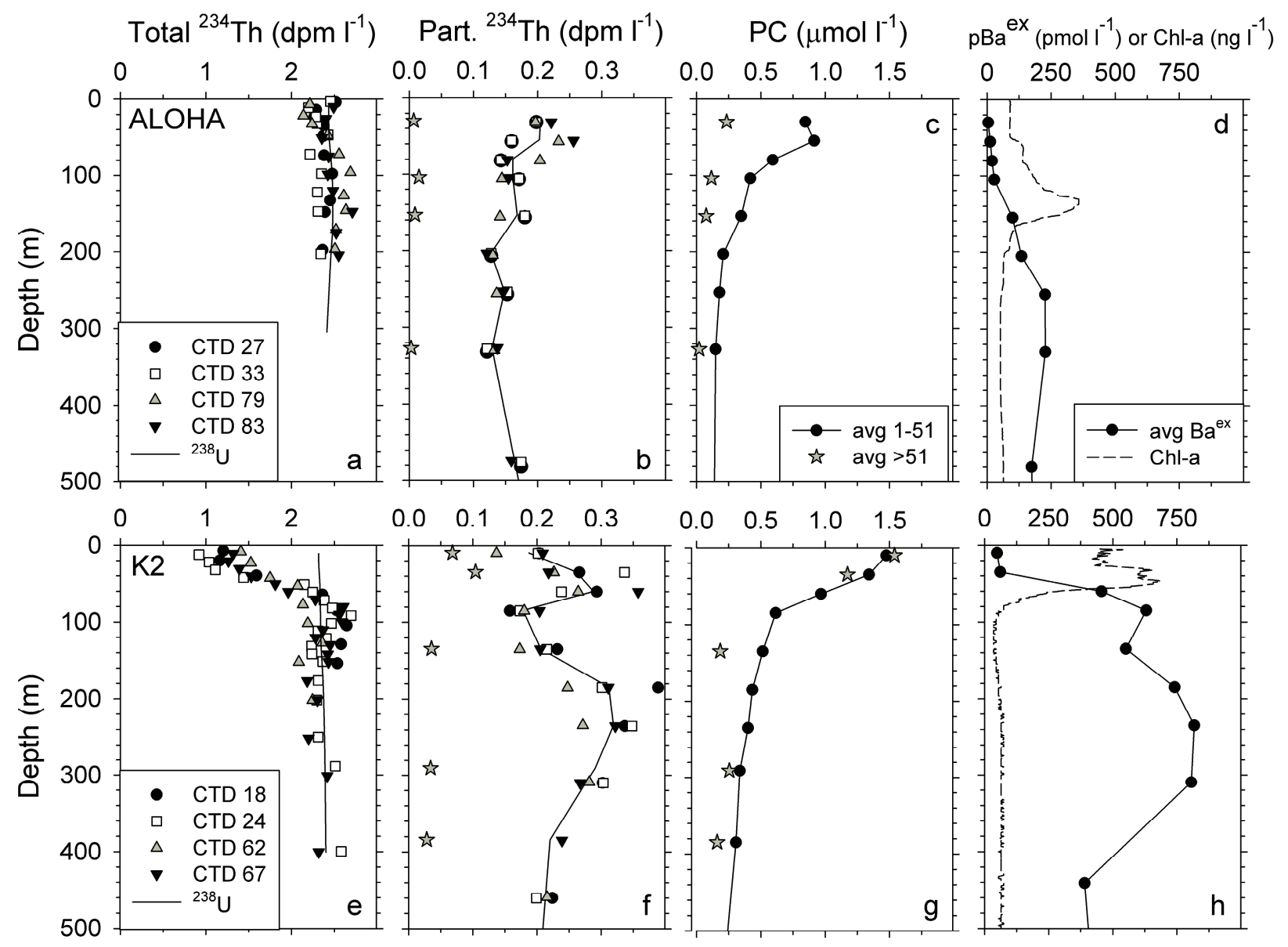




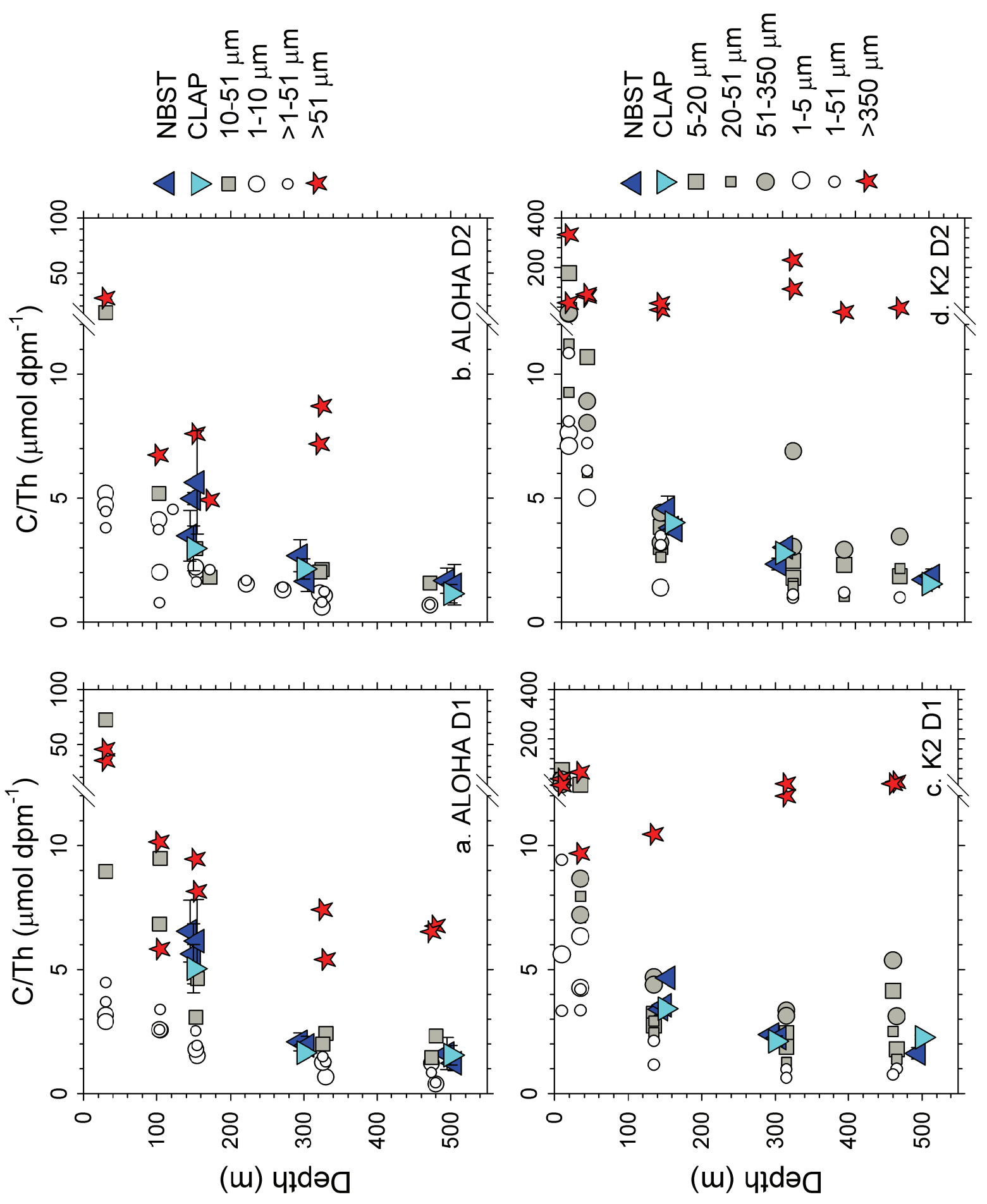


Figure 9. Buesseler et al. DSRI 08-00230

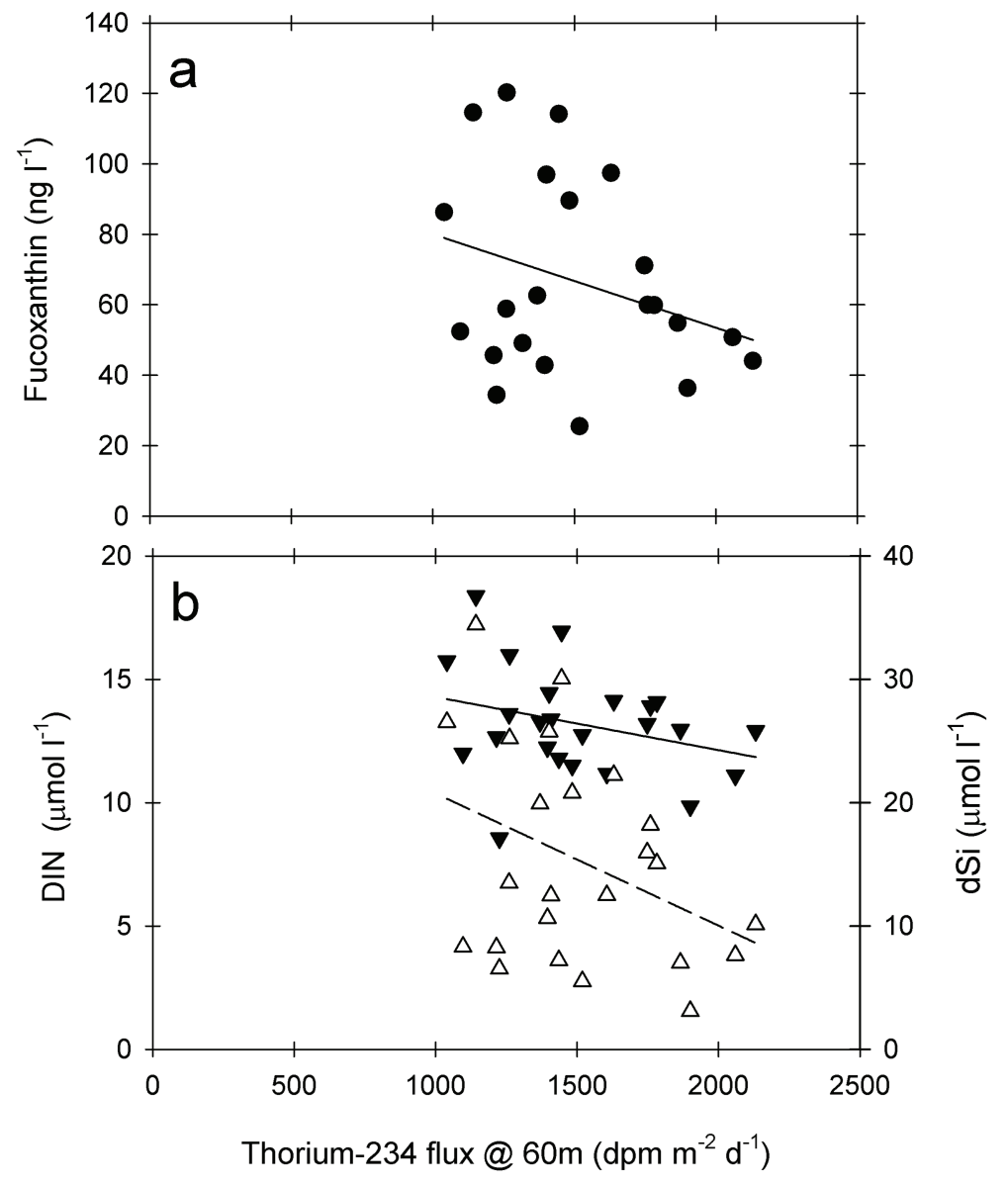


Figure 10. Buesseler et al. DSRI 08-00230

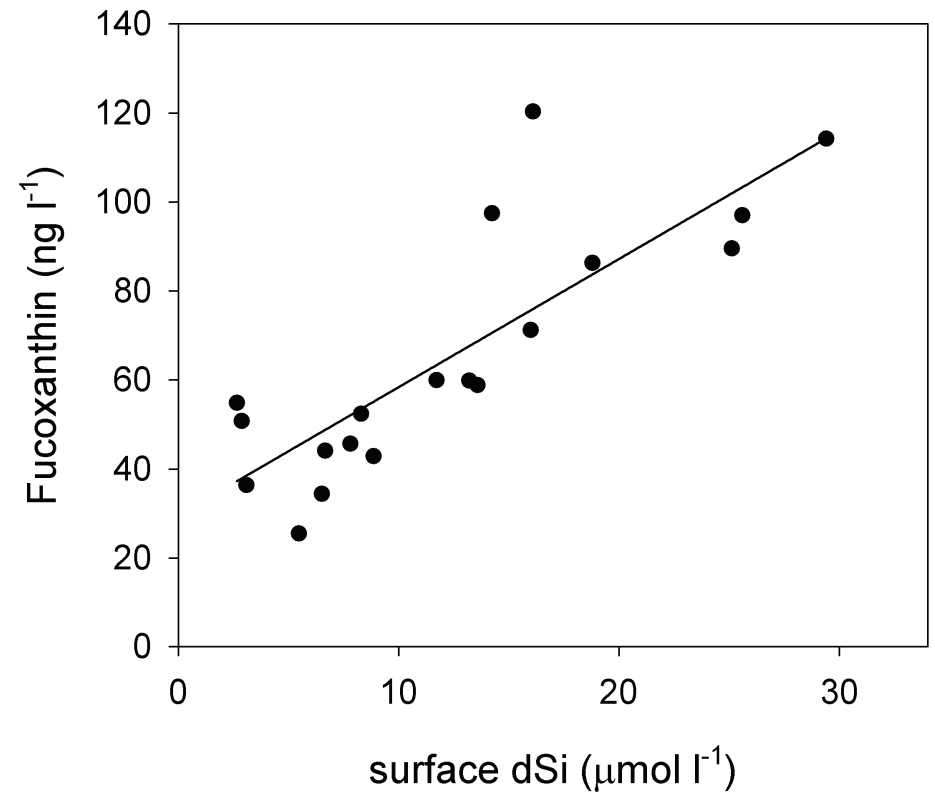


Figure 11. Buesseler et al. DSRI 08-00230

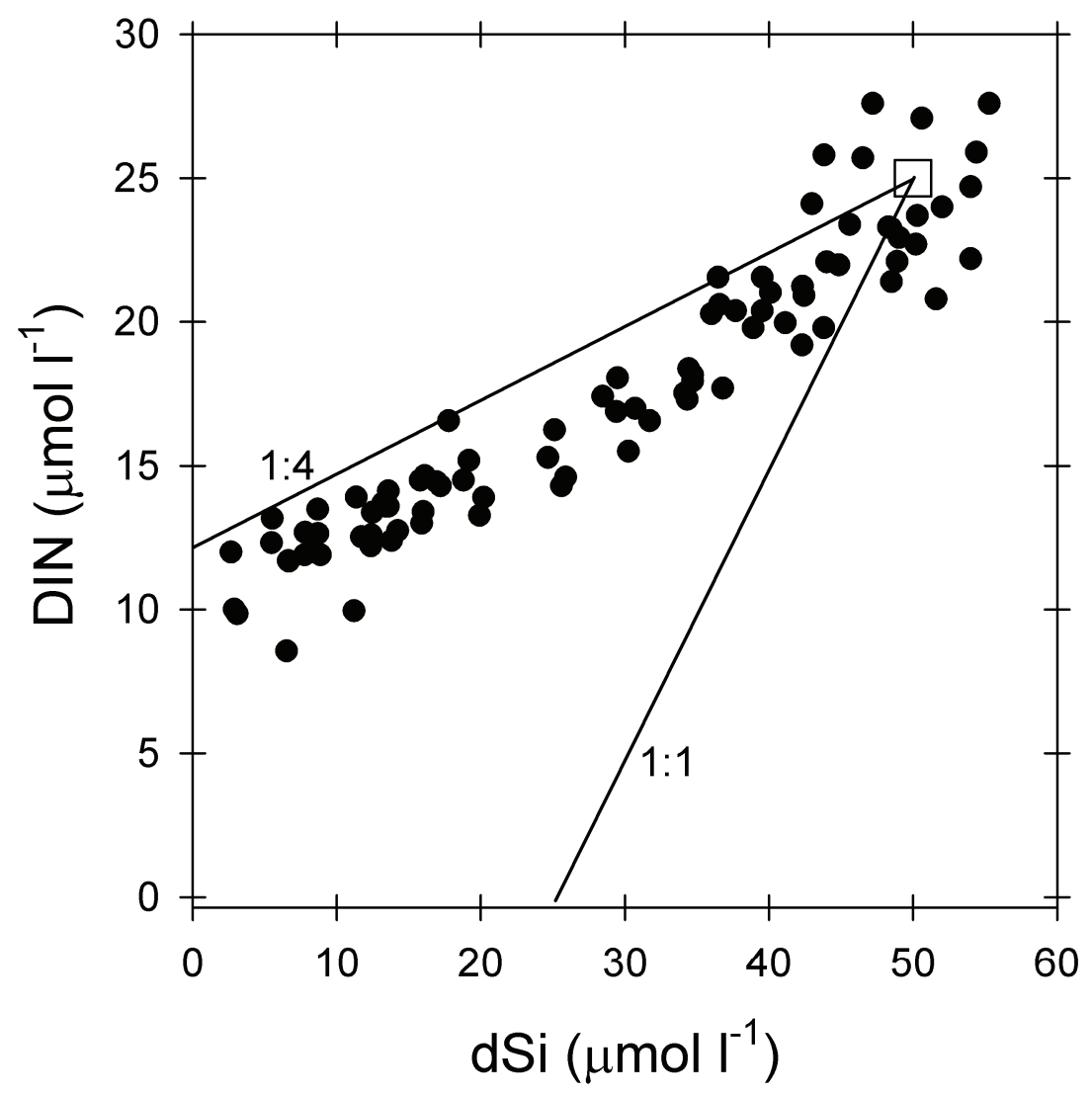


Figure 12. Buesseler et al. DSRI 08-00230
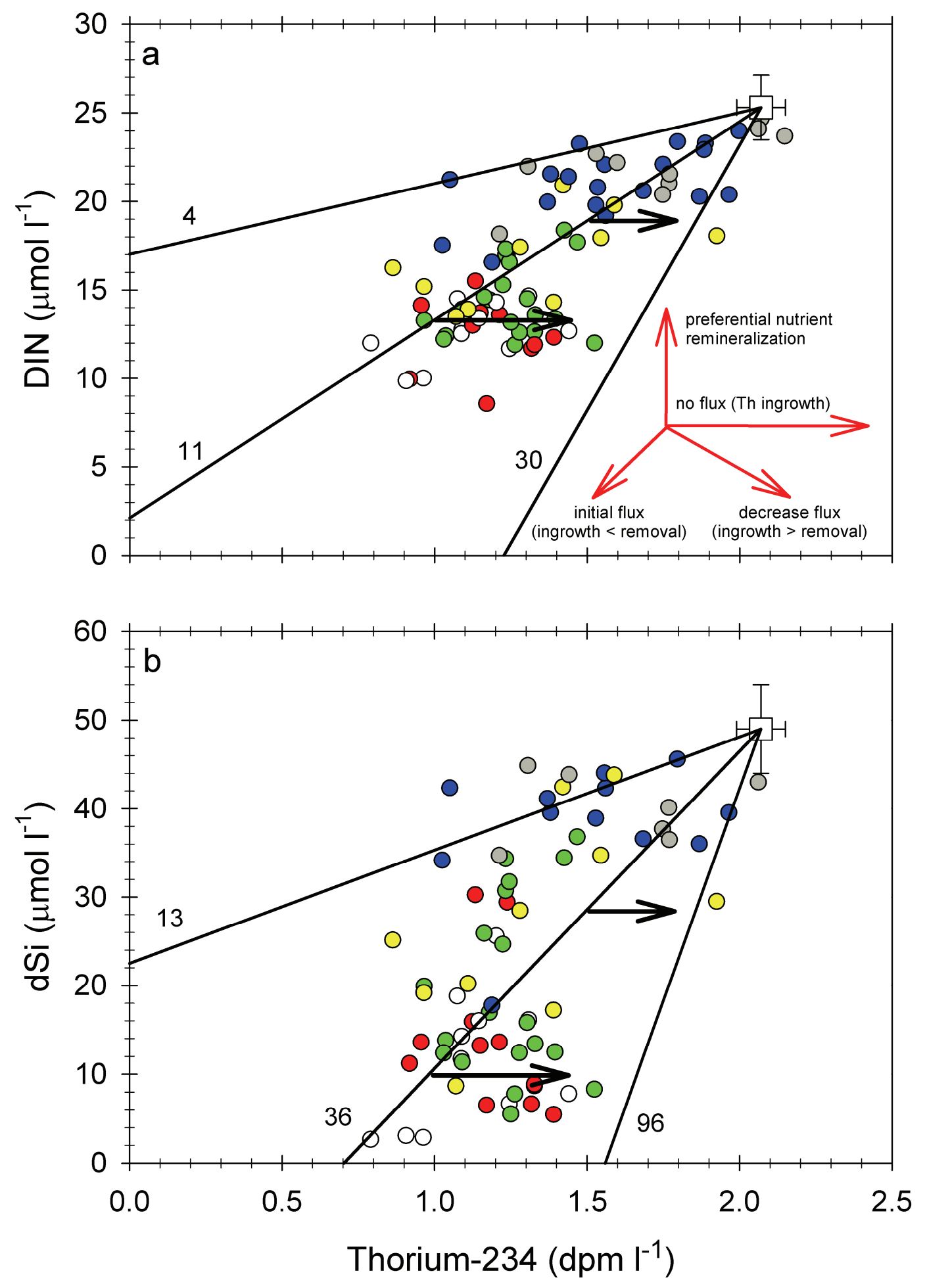
Figure 13. Buesseler et al. DSRI 08-00230

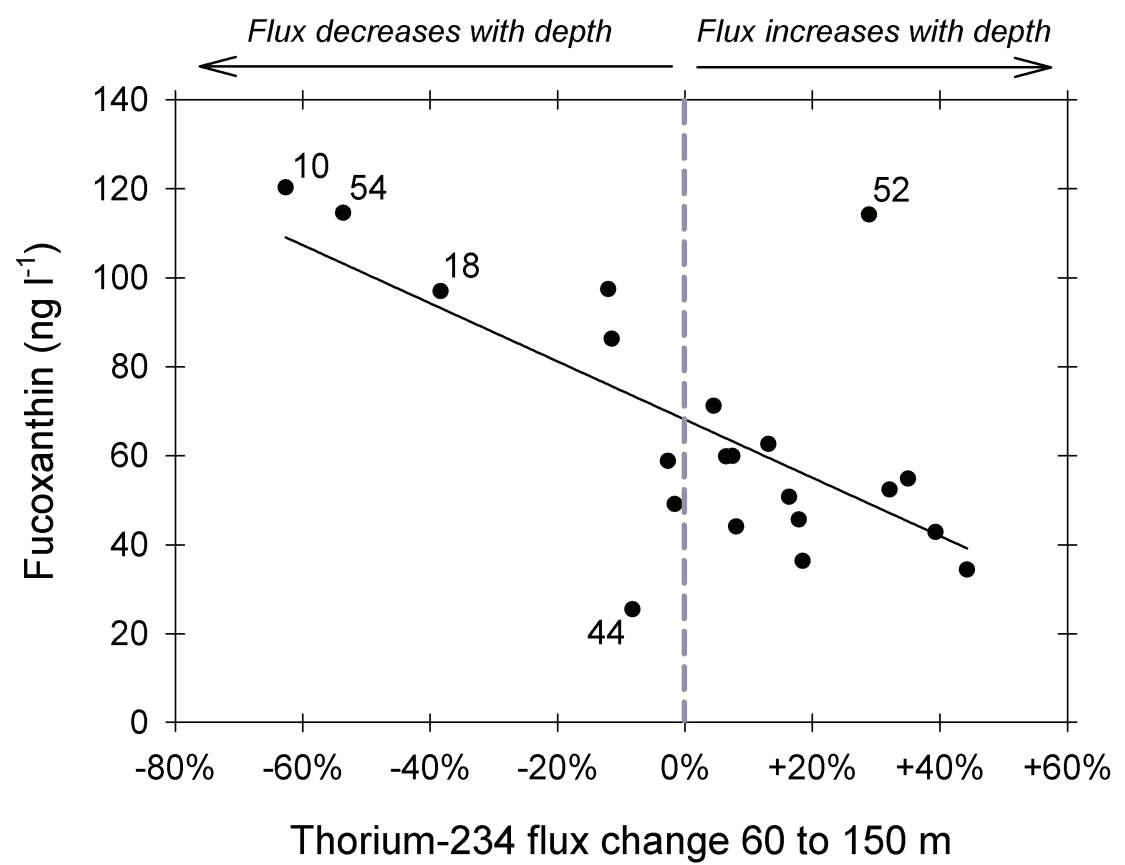

